\title{
1997 Structural Integrity Assessments for the Category C Liquid Low-Level Waste Tank Systems at Oak Ridge National Laboratory, Oak Ridge, Tennessee
}
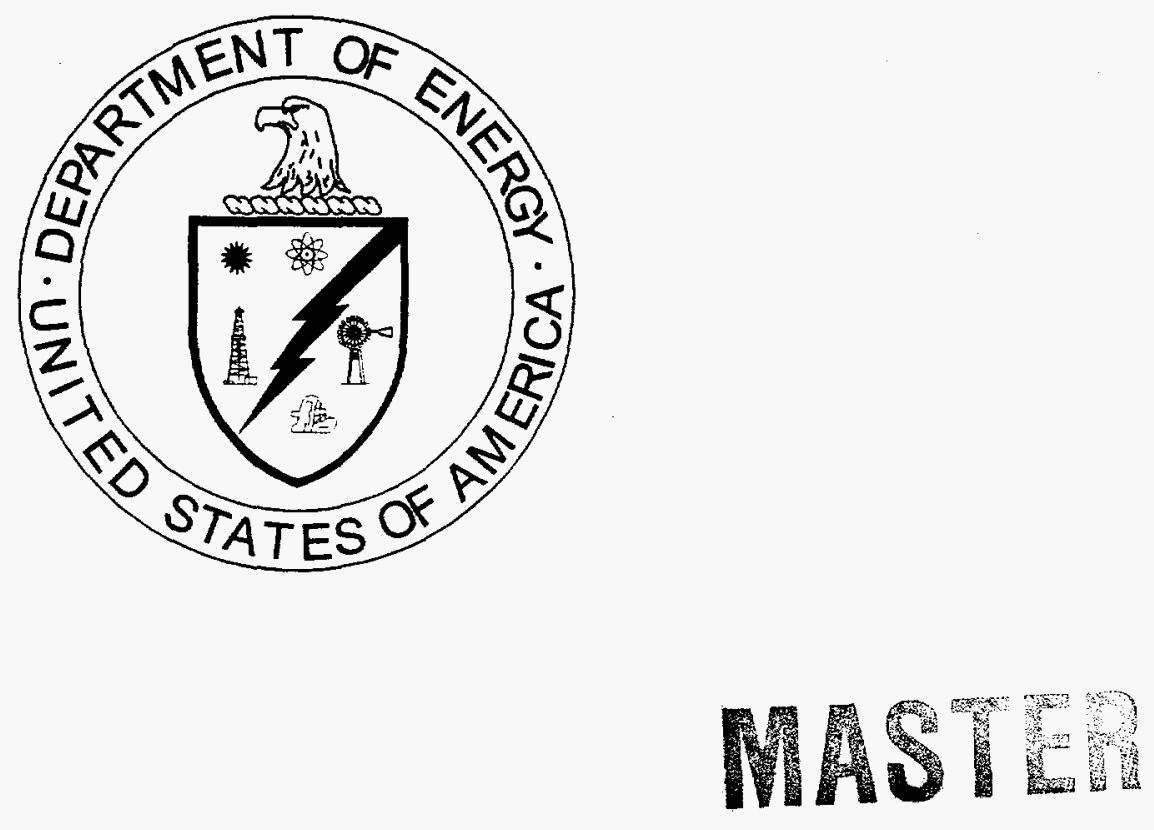

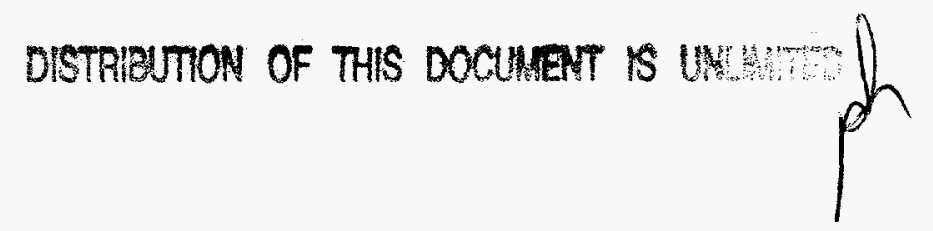

This document has been approved by the

ORNL Technical Information Office $/ 9 / 97$ 


\section{Environmental Systems Corporation and Vista Research, Incorporated,}

contributed to the preparation of this document and should not be considered eligible contractors for its review. 


\title{
1997 Structural Integrity Assessments for the Category C Liquid Low-Level Waste Tank Systems at Oak Ridge National Laboratory, Oak Ridge, Tennessee
}

Date Issued-September 1997

\author{
Prepared by \\ Environmental Systems Corporation \\ Knoxville, TN \\ under subcontract $78 \mathrm{X}$-SV914 \\ and \\ Vista Research, Incorporated \\ Mountain View, CA \\ under subcontract $78 \mathrm{X}$-SP50C \\ Prepared for the \\ U.S. Department of Energy \\ Office of Environmental Management \\ under budget and reporting code EW 20
}

Environmental Management Activities at the OAK RIDGE NATIONAL LABORATORY

Oak Ridge, Tennessee 37831 managed by

LOCKHEED MARTIN ENERGY SYSTEMS, INC.

for the

U.S. DEPARTMENT OF ENERGY

under contract DE-AC05-84OR21400 


\section{DISCLAIMER}

This report was prepared as an account of work sponsored by an agency of the United States Government. Neither the United States Government nor any agency thereof, nor any of their employees, make any warranty, express or implied, or assumes any legal liability or responsibility for the accuracy, completeness, or usefulness of any information, apparatus, product, or process disclased, or represents that its use would not infringe privately owned rights. Reference herein to any specific commercial product, process, or service by trade name, trademark, manufacturer, or otherwise does not necessarily constitute or imply its endorsement, recommendation, or favoring by the United States Government or any agency thereof. The views and opinions of authors expressed herein do not necessarily state or reflect those of the United States Government or any agency thereof. 


\section{DISCLAMMER}

Portions of this document may be illegible in electronic image products. Images are produced from the best available original document. 


\section{PREFACE}

The 1997 Structural Integrity Assessments for the Category C Liquid Low-Level Waste Tank Systems at Oak Ridge National Laboratory, Oak Ridge, Tennessee (DOE/OR/01-1634\&D1) summarizes the structural integrity certification of Category C Liquid Low Level Waste Tank Systems at Oak Ridge National Laboratory in compliance with the requirements of the Federal Facility Agreement. This report is an update to the 1996 Structural Integrity Assessments for the Category C Liquid Low-Level Waste Tank Systems at Oak Ridge National Laboratory, Oak Ridge, Tennessee (DOE/OR/01-1512\&D2). The work is being performed under Work Breakdown Structure 1.3.6.4.15.4 (Activity Data Sheet 3206, "Federal Facility Agreement Liquid Low-Level Waste Tank Compliance"). 



\section{CONTENTS}

Section

Page

PREFACE $\ldots \ldots \ldots \ldots \ldots \ldots \ldots \ldots \ldots \ldots \ldots \ldots \ldots \ldots \ldots \ldots \ldots \ldots \ldots \ldots$

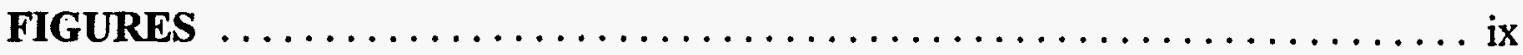

TABLES $\ldots \ldots \ldots \ldots \ldots \ldots \ldots \ldots \ldots \ldots \ldots \ldots \ldots \ldots \ldots \ldots \ldots \ldots \ldots \ldots \ldots$

ABBREVIATIONS $\ldots \ldots \ldots \ldots \ldots \ldots \ldots \ldots \ldots \ldots \ldots \ldots \ldots \ldots \ldots \ldots \ldots$

EXECUTIVE SUMMARY $\ldots \ldots \ldots \ldots \ldots \ldots \ldots \ldots \ldots \ldots \ldots \ldots$

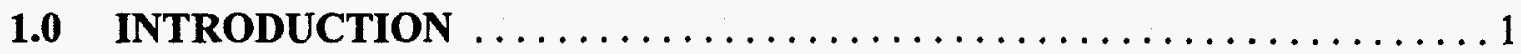

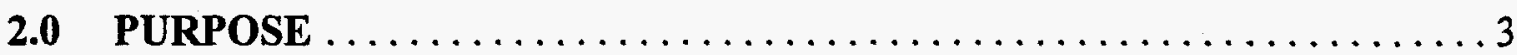

3.0 DESIGN DRAWING EVALUATION $\ldots \ldots \ldots \ldots \ldots \ldots \ldots \ldots \ldots$

4.0 GENERAL CORROSION ASSESSMENT OF THE CATEGORY C

TANK SYSTEMS $\ldots \ldots \ldots \ldots \ldots \ldots \ldots \ldots \ldots \ldots \ldots \ldots \ldots \ldots \ldots \ldots \ldots$

4.1 Corrosion by Waste Solutions $\ldots \ldots \ldots \ldots \ldots \ldots \ldots \ldots$

4.1.1 Stress Corrosion Cracking (SCC) $\ldots \ldots \ldots \ldots \ldots \ldots \ldots$

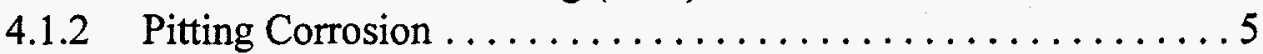

4.1.3 Crevice Corrosion ........................ 6

4.1 .4 Intergranular-Knife Line Attack . . . . . . . . . . . . 6

4.1.5 Microbiologically Influenced Corrosion (MIC) . . . . . . .6 6

4.2 Soil Side Corrosion of ORNL Waste Systems . . . . . . . . . . . . 7

5.0 INTRODUCTION TO LEAK TESTING $\ldots \ldots \ldots \ldots \ldots \ldots \ldots$

5.1 Leak Testing Methods for Tanks . . . . . . . . . . . . . . . 9

5.2 Leak Testing Methods for Pipelines $\ldots \ldots \ldots \ldots \ldots \ldots \ldots \ldots$

5.2.1 Leak Detection Method for Gravity-Fed Pipelines . . . . . . . 10

5.2.2 Leak Testing Methods for Pressurized Pipelines ......... . 11

5.3 Determination of Expected Error Values for the Untestable Pipelines . 12

5.4 Statistical Analysis and Hypothesis Testing $\ldots \ldots \ldots \ldots \ldots$

6.0 BASIS FOR TANK SYSTEM CERTIFICATION $\ldots \ldots \ldots \ldots \ldots \ldots \ldots$

7.0 TANK SYSTEM ASSESSMENTS $\ldots \ldots \ldots \ldots \ldots \ldots \ldots \ldots \ldots \ldots$ 


\section{CONTENTS (cont'd)}

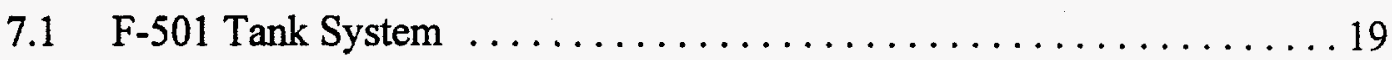

7.1.1 F-501Tank Description . . . . . . . . . . . . . . . 19

7.1.2 F-501 Pipeline Descriptions ................. 22

7.1.3 Corrosion Assessment of the F-501 Tank System . . . . . . . 23

7.1.4 Results of Leak Tests on the F-501 System . . . . . . . . 23

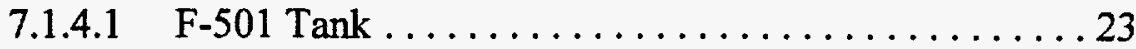

7.1.4.2 F-501 Pipelines ................... 24

7.1.4.2.1 F-501 Testable Pipelines . .......... 25

7.1.4.2.2 F-501 Untestable Pipelines ......... 25

7.1.4.3 Analysis of Leak Tank F-501 Test Data . . . . . . . . 25

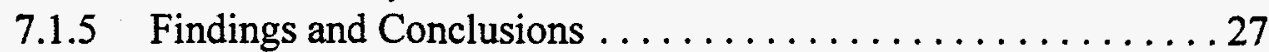

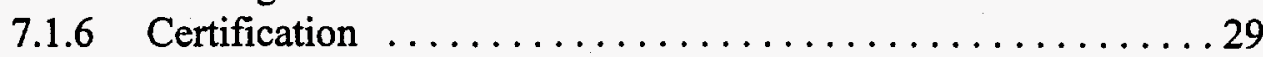

$7.2 \quad W-16$ Tank System . . . . . . . . . . . . . . . . . . . 31

7.2.1 W-16 Tank Description . . . . . . . . . . . . . . 31

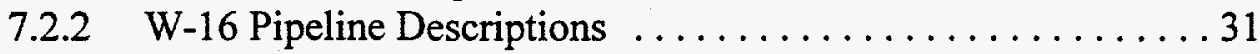

7.2.3 Corrosion Assessment of the W-16 Tank System . . . . . . . 34

7.2.4 Results of Leak Tests on the W-16 System . . . . . . . . . 35

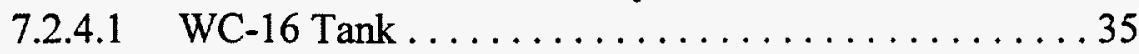

7.2.4.2 WC-16 Pipelines ....................... 36

7.2.4.2.1 WC-16 Testable Pipelines ........... 36

7.2.4.2.2 WC-16 Untestable Pipelines .......... 36

7.2.4.3 Analysis of Leak Tank WC-16 Test Data . . . . . . 37

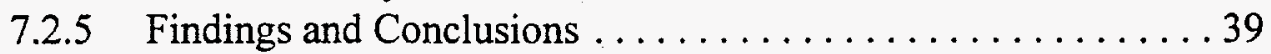

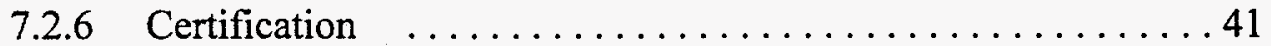

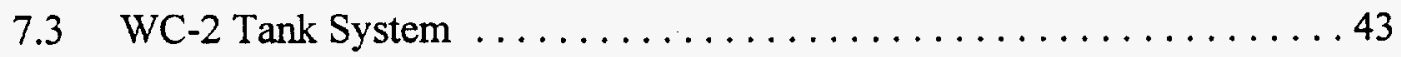

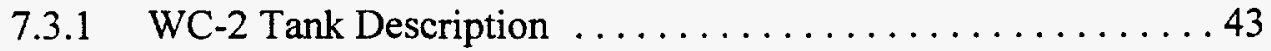

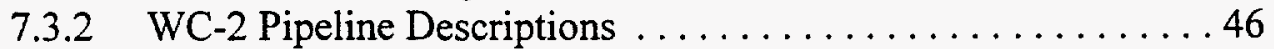

7.3.3 Corrosion Assessment of the WC-2 Tank System . . . . . . . . 47

7.3.4 Results of Leak Tests on the WC-2. System . . . . . . . . . . 48

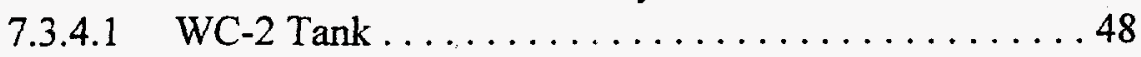

7.3.4.2 WC-2 Pipelines $\ldots \ldots \ldots \ldots \ldots \ldots \ldots \ldots \ldots \ldots$

7.3.4.2.1 WC-2 Testable Pipelines . . . . . . . . . 49

7.3.4.2.2 WC-2 Untestable Pipelines .......... 49

7.3.4.3 Analysis of Leak Tank WC-2 Test Data . . . . . . . 50

7.3 .5 Findings and Conclusions ................. 52

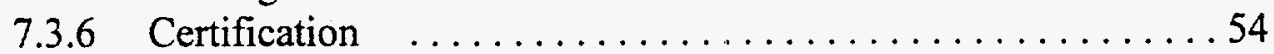




\section{CONTENTS (cont'd)}

$7.4 \quad$ WC-3 Tank System . . . . . . . . . . . . . . . . . . . . 55

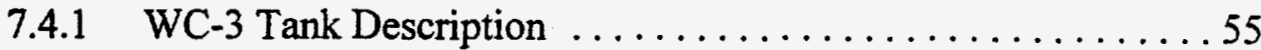

7.4.2 WC-3 Pipeline Descriptions $\ldots \ldots \ldots \ldots \ldots \ldots \ldots \ldots \ldots$

7.4.3 Corrosion Assessment of the WC-3 Tank System ... . . . . . . 59

7.4.4 Results of Leak Tests on the WC-3 System ... . . . . . . . . 59

7.4.4.1 WC-3 Tank ...................6 60

7.4.4.2 WC-3 Pipelines .................. 61

7.4.4.2.1 WC-3 Testable Pipelines ...........61

7.4.4.2.2 WC-3 Untestable Pipelines ..........61 61

7.4.4.3 Analysis of Leak Tank WC-3 Test Data . . . . . . . 62

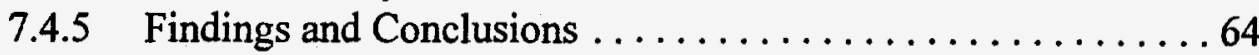

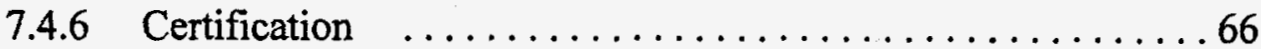

7.5 WC-9 Tank System . . . . . . . . . . . . . . . . . . . . 67

7.5.1 WC-9 Tank Description ....................67 67

7.5.2 WC-9 Pipeline Descriptions . . . . . . . . . . . . . 67

7.5.3 Corrosion Assessment of the WC-9 Tank System . . . . . . . . 71

7.5.4 Results of Leak Tests on the WC-9 System . . . . . . . . . . 71

7.5.4.1 WC-9 Tank ...................... 71

7.5.4.2 WC-9 Pipelines .................. 73

7.5.4.2.1 WC-9 Testable Pipelines .......... . 73

7.5.4.2.2 WC-9 Untestable Pipelines .......... . 73

7.5.4.3 Analysis of Leak Tank WC-9 Test Data . . . . . . . . . 74

7.5 .5 Findings and Conclusions . . . . . . . . . . . . . . 76

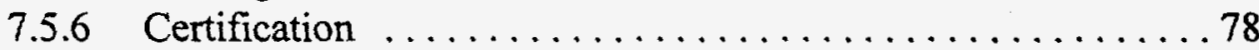

7.6 WC-10 Tank System ............................ 79

7.6.1 WC-10 Tank Description . . . . . . . . . . . . . 79

7.6.2 WC-10 Pipeline Descriptions . . . . . . . . . . . 79

7.6.3 Corrosion Assessment of WC-10 Tank System . . . . . . . . . . 84

7.6.4 Results of Leak Tests on the WC-10 System . . . . . . . . .84

7.6.4.1 WC-10 Tank .................... . . . . . . . . .

7.6.4.2 WC-10 Pipelines ............... 85

7.6.4.2.1 WC-10 Testable Pipelines ........ . 85

7.6.4.2.2 WC-10 Untestable Pipelines . . . . . . . .87

7.6.4.3 Analysis of Leak Tank WC-10 Test Data . . . . . . . . 88

7.6.5 Findings and Conclusions . . . . . . . . . . . . . . . 90

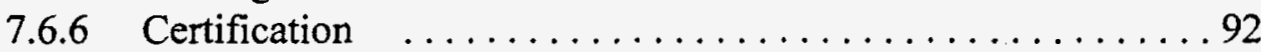





\section{FIGURES}

Figure

Page

1 Bethel Valley Category C LLLW Tank Systems ................ 2

2 1992-1995 reference set of CVRs used to test variance of 1996 CVR data . . . 14

$3 \quad$ CVR data from June 1992 through December 1996 . . . . . . . . . . . . . . . 15

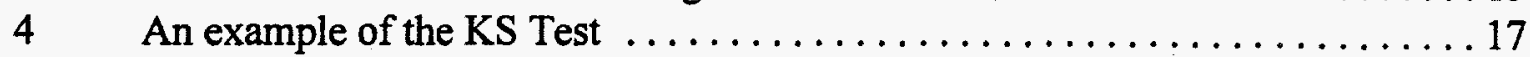

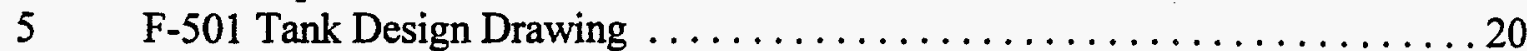

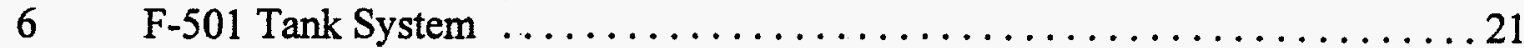

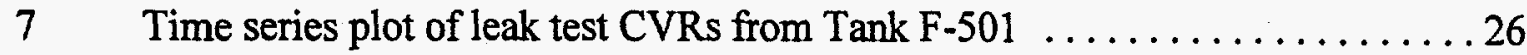

8 Cumulative frequency distributions from reference CVR data \& F-501 CY96

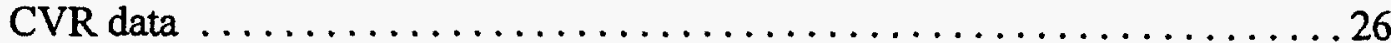

9 As-built Drawing of Tank $W-16$ Installation $\ldots \ldots \ldots \ldots \ldots \ldots \ldots \ldots \ldots \ldots \ldots \ldots$

$10 \quad W-16$ Tank System . . . . . . . . . . . . . . . . . . . . . 33

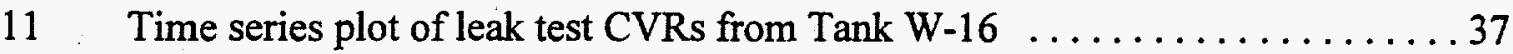

12 Cumulative frequency distribution from reference CVR data \& W-16

CY96 CVR data . . . . . . . . . . . . . . . . . . . . . 38

13 As-built Drawing of Tank WC-2 Installation $\ldots \ldots \ldots \ldots \ldots \ldots \ldots \ldots$

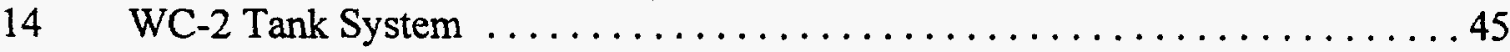

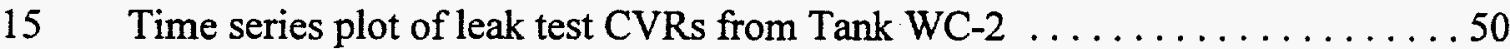

16 Cumulative frequency distribution from reference CVR data \& WC-2

CY96 CVR data . . . . . . . . . . . . . . . . . . . . 51

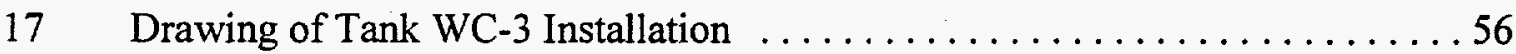

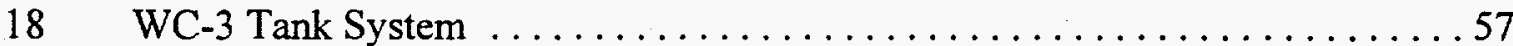

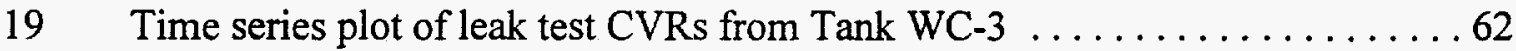

20 Cumulative frequency distribution from reference CVR data \& WC-2

CY96 CVR data . . . . . . . . . . . . . . . . . . . . . . . . . 63

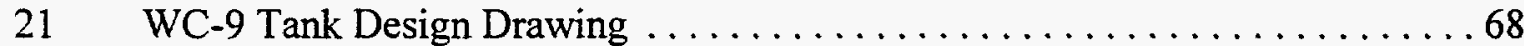

$22 \quad$ WC-9 Tank System . . . . . . . . . . . . . . . . . . . . . 69

23 Time series plot of leak test CVRs from Tank WC-9 . . . . . . . . . 74

24 Cumulative frequency distribution from reference CVR data \& WC-9

CY96 CVR data . . . . . . . . . . . . . . . . . . . . . . . . 75

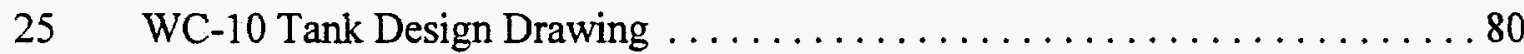

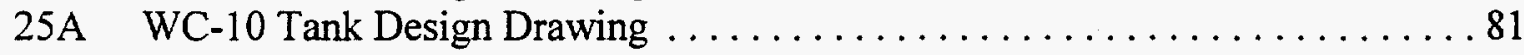

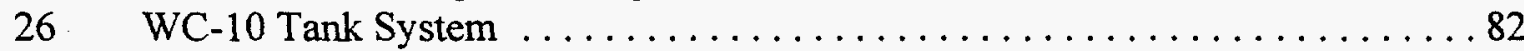

27 Time series plot of leak test CVRs from Tank WC $-10 \ldots \ldots \ldots \ldots \ldots$. . . . 89

28 Cumulative frequency distribution from reference CVR data \& WC-10

CY96 CVRdata ................................ 89 



\section{TABLES}

Table

Page

$1 \quad$ Student's $t$-distribution for a Limited Range of $N \ldots \ldots \ldots \ldots \ldots \ldots$

2 Critical Statistics for the KS "Goodness-of-Fit" Test . . . . . . . . . . . 17

3 Characteristics of Line Segments Evaluated as a Part of Tank System F-501 . . 22

$4 \quad$ Summary of Leak Tests Conducted on Tank F-501 ............... 24

5 Summary of Leak Test Results for the F-501 Testable Pipelines . . . . . . . . 25

6 Summary of Statistical Analyses of F-501 CVR Data $\ldots \ldots \ldots \ldots \ldots \ldots 27$

7 Summary of F-501 Tank System Testing and Certification ............28

8 . Characteristics of Line Segments Evaluated as a Part of Tank System W-16 . . 34

9 Summary of Leak Tests Conducted on Tank W-16 ................ 35

10 Summary of Leak Tests Results for the W-16 Testable Lines ............ 36

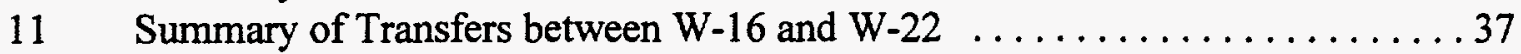

12 Summary of Statistical Analyses of W-16 CVR Data ................ 39

13 Summary of W-16 Tank System Testing and Certification .............40

14 Characteristics of Line Segments Evaluated as a Part of Tank System WC-2 . . 47

15 Summary of Leak Tests Conducted on Tank WC-2 .............. 48

16 Summary of Leak Test Results for the WC-2 Testable Lines . . . . . . . . . . 49

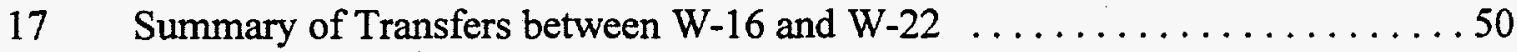

18 Summary of Statistical Analyses of WC-2 Data $\ldots \ldots \ldots \ldots \ldots \ldots \ldots \ldots \ldots$

19 Summary of WC-2 Tank System Testing and Certification ........... 53

20 Characteristics of Line Segments Evaluated as a Part of Tank System WC-3 . . 59

21 Summary of Leak Tests Conducted on Tank WC-3 ..............6 60

22 Summary of Leak Test Results for the WC-3 Testable Lines . . . . . . . . . 61

23 Summary of Transfers between WC-3 and W-22 During $1995 \ldots \ldots \ldots \ldots 61$

24 Summary of Statistical Analyses of WC-3 CVR Data .................6 63

25 Summary of Tank System Certification for Tank WC-3 ..............65

26 Characteristics of Line Segments Evaluated as a Part of Tank System WC-9 . . 70

27 Summary of Leak Tests Conducted on Tank WC-9 . . . . . . . . . . . . 72

28 Summary of Leak Test Results for the WC-9 Testable Lines . . . . . . . . . 73

29 Summary of Statistical Analyses of WC-9 CVR Data . . . . . . . . . . . 75

30 Summary of WC-9 Tank System Testing and Certification . . . . . . . . 77

31 Characteristics of Line Segments Evaluated as a Part of Tank System WC-10 . 83

32 Summary of Leak Tests Conducted on Tank WC-10 ............. 86

33 Summary of Leak Test Results for the WC-10 Testable Lines . . . . . . . . . 87

34 Summary of Transfers between WC-10 and W-22 During $1995 \ldots \ldots \ldots .87$

35 Summary of Statistical Analyses of WC-10 CVR Data .............. 90

36 Summary of Tank System Certification for Tank WC-10 ............91 



\section{ABBREVIATIONS}

$\begin{array}{ll}\text { ASME } & \text { American Society of Mechanical Engineers } \\ \text { ASTM } & \text { American Society of Testing and Materials } \\ \text { CDF } & \text { Cumulative distribution function } \\ \text { CERCLA } & \begin{array}{l}\text { Comprehensive Environmental Response, Compensation } \\ \text { and Liability Act }\end{array} \\ \text { CFR } & \text { Code of Federal Regulations } \\ \text { CVR } & \text { Compensated volume rate } \\ \text { DOE } & \text { Department of Energy } \\ \text { DP } & \text { Differential pressure } \\ \text { EPA } & \text { Environmental Protection Agency } \\ \text { EVB } & \text { Enhanced volume balancing } \\ \text { FFA } & \text { Federal Facility Agreement } \\ \text { GPD } & \text { Gas pressure decay } \\ \text { HEPA } & \text { High Efficiency Particulate Air } \\ \text { H/V } & \text { Height to volume } \\ \text { HOG } & \text { Hot off-gas } \\ \text { KS } & \text { Kolmogorov-Smirnov } \\ \text { LLLW } & \text { Liquid low level waste } \\ \text { LOC } & \text { Level of confidence } \\ \text { MDP } & \text { Modified differential pressure } \\ \text { MIC } & \text { Microbiologically influenced corrosion } \\ \text { NPS } & \text { Nominal pipe size } \\ \text { ORNL } & \text { Oak Ridge National Laboratory } \\ \text { ORR } & \text { Oak Ridge Reservation } \\ \text { PD } & \text { Probability of detection } \\ \text { PFA } & \text { Probability of false alarm } \\ \text { RTD } & \text { Resistance Thermal Detector } \\ \text { SARA } & \text { Superfund Amendment and Reauthorization Act } \\ \text { SCC } & \text { Stress corrosion cracking } \\ \text { SIA } & \text { Structural integrity assessment } \\ \text { SS } & \text { Stainless steel } \\ \text { TDEC } & \text { Tennessee Department of Environment and Conservation } \\ \text { UST } & \text { Underground Storage Tank } \\ \text { VDP } & \text { Volumetric differential pressure methods } \\ \text { WOCC } & \text { Waste Operations Control Center } \\ & \end{array}$





\section{EXECUTIVE SUMMARY}

This document provides a report of the efforts made to satisfy the Federal Facility Agreement (FFA) for the structural integrity certification of six Category C Liquid Low Level Waste (LLLW) tank systems on the Oak Ridge Reservation (ORR) in Oak Ridge, Tennessee.

This report is developed as an update to the 1995 and 1996 Structural Integrity Assessment (SIA) Reports (DOE/OR/01-1385\&D2 andDOE/OR/01-1512\&D2 respectively). The 1995 SIA (DOE/OR/01-1385\&D2) included the assessment of 14 Category C tank systems. At the end of FY96, four tank systems (2026A, F-201, WC-7 and WC-19) were removed from service and classified as Category D. Therefore, the 1996 SIA included the assessment of ten Category $\mathrm{C}$ tank systems. At the end of FY97, four additional tank systems (HFIR, T-1, T-2 and WC-20) were removed from service and classified as Category D. The remaining six Category $C$ tank systems assessed in this report include F-501, W-16, WC-2, WC-3, WC-9, and WC-10.

Within this document, each remaining Category $C$ tank system is described, including the associated pipeline segments evaluated as a part of those tank systems. Separate structural integrity assessments were conducted for the individual LLLW Tank Systems, each of which are located in Bethel Valley. The results of the 1997 structural integrity assessments are reported herein. The assessments are based on (1) a review of available tank design drawings, (2) a qualitative assessment of corrosion on the tank and pipelines, and (3) leak testing program results.

Design plans and specifications were reviewed in 1995 for a general description of the tanks and associated pipelines. Information of primary significance included tank age, material of construction, tank design, and construction specifications. Design plans were also reviewed for the layouts and materials of pipeline construction and ages of pipelines.

A generic corrosion assessment was conducted in 1995 for each tank system. Information was gathered, when available, related to the historical use of the tank and the likely contents. The corrosion assessments included a qualitative evaluation of the walls of each tank and pipelines associated with each tank, as well as the welds and joints of the systems. A general discussion of the stainless steel types encountered is included in Section 4.0 of this report. The potential for corrosion is evaluated within the sections on the individual tank systems.

The final and most important information used to certify the tank systems were the results of leak testing performed on the tank systems. Category $\mathrm{C}$ tanks were tested at least monthly between January 1996 and December 1996. Annual leak testing of pipelines was conducted between October 1996 and September 1997. The results of leak tests for each 
tank system are presented in Section 7.0 of this report. A discussion of the untestable portion of the lines is also included in this section.

This assessment determined that all of the tank systems were generally designed and constructed with materials and methods appropriate to their intended usage. It was determined that periodic additions of caustic in five of the six remaining Category $C$ tank systems has significantly reduced the potential of corrosion. Each of the six Category $\mathrm{C}$ tanks was leak tested in 1996. Five of the six tanks frequently passed leak testing and have been certified. None of the tanks have shown indications of an outflow or leak. Most of the testable pipelines that require leak testing have been tested and certified.

Certification results for each specific tank system are presented in the tank-specific subsections of Section 7.0. Certification for each specific tank system is provided at the end of each tank section. 


\subsection{INTRODUCTION}

The Superfund Amendment and Reauthorization Act (SARA) of the Comprehensive Environmental Response, Compensation, and Liability Act (CERCLA) required the Department of Energy (DOE) to execute a Federal Facility Agreement (FFA) with the Environmental Protection Agency (EPA) and the Tennessee Department of Environment and Conservation (TDEC) for the ORR.

The FFA distinguishes four categories of tank and pipeline systems:

- New systems with secondary containment (Category A),

- Existing systems with secondary containment (Category B),

- Existing systems without secondary containment (Category C), and

- Inactive systems (Category D).

Section IX.F of the FFA specifically requires structural integrity assessments of the Category C LLLW systems. Results of the structural integrity assessments are to be submitted to the EPA Region IV and the TDEC to enable the continued use of the Category $C$ tank systems until the next annual reassessment or removal from service, in accordance with FFA requirements.

The active Category C portion of the Oak Ridge National Laboratory (ORNL) LLLW system is now located solely in the Bethel Valley area of the ORR. The active, singly contained portion of the LLLW system consists of six tanks ranging in size from 400 to 2300 gallons. Tank locations are shown in Figure 1. The tanks are used to collect and store liquid wastes.

The initial "Structural Integrity Assessments for the Category C LLLW Tank Systems" [DOE/OR/01-1385\&D2] was submitted to EPA and TDEC in September 1995. The results of the structural integrity assessments for 14 tank systems classified as Category $C$ were presented.

The "1996 Structural Integrity Assessment for the Category C LLLW Tank Systems" [DOE/OR/01-1512\&D2], was submitted in September 1996. Prior to this submittal, four tank systems, including Tanks F-201, 2026A, WC-7, and WC-19 were removed from service and Category $\mathrm{C}$ classification. Four additional tank systems, consisting of HFIR, T-1, T-2, and WC-20 were removed from service and Category C classification in 1997. Included herein is the 1997 annual assessment of the structural integrity for the six tank systems that remain classified as Category $\mathrm{C}$. 


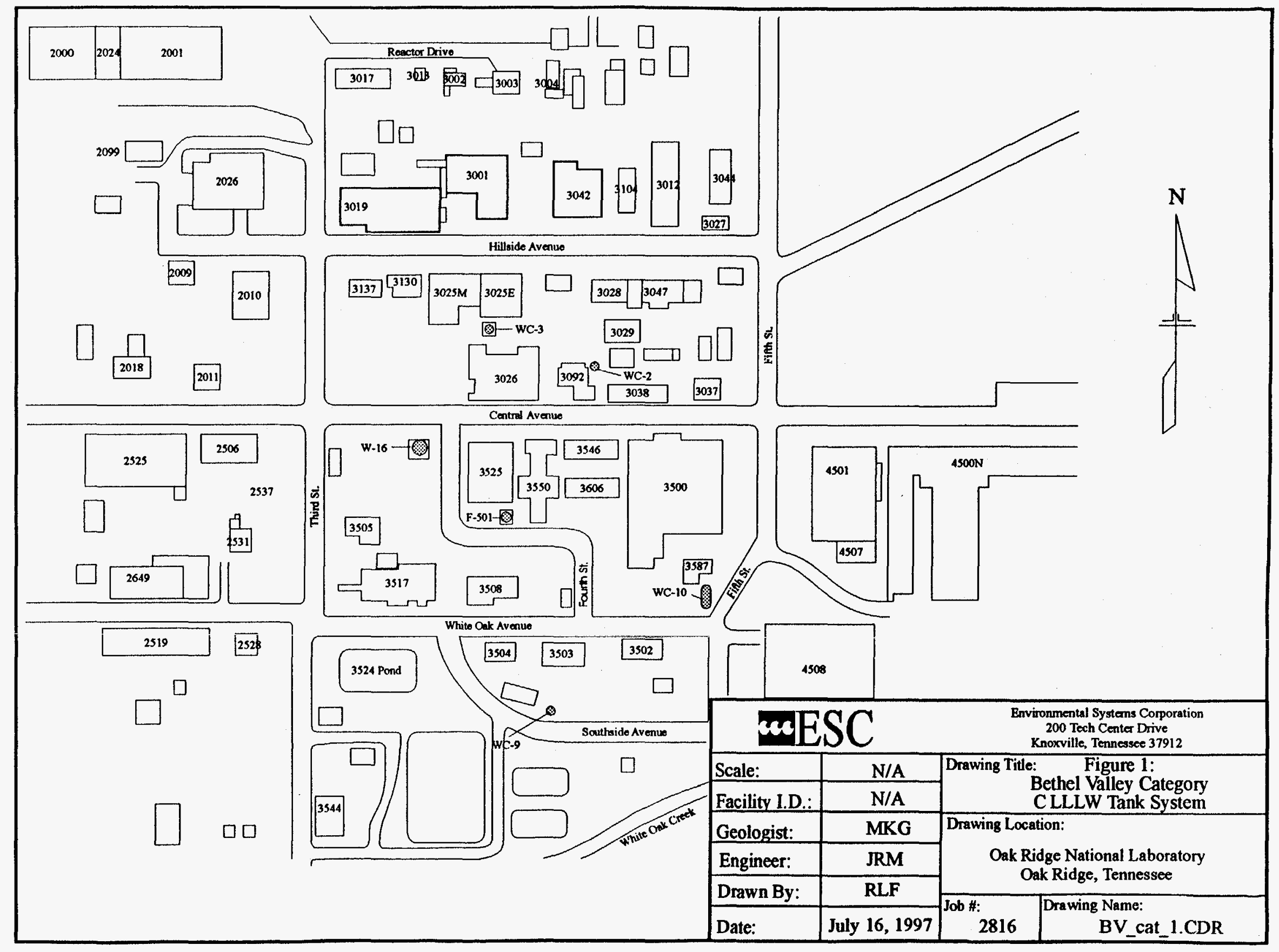




\subsection{PURPOSE}

This report presents the results of a series of evaluations to determine if the individual Category $\mathrm{C}$ tank systems retain sufficient structural integrity to continue being used for liquid storage. The approach used to reach the final certification/conclusion consisted of three phases, including:

- Review of the original engineering design drawings and construction materials to determine whether the tank and line systems were capable of containing liquids without leaking (and also to check that the construction materials were compatible with liquids that might have been placed in these systems). While drawings in this report may be of poor quality, they are copies of the best available originals.

- A qualitative corrosion assessment conducted in 1995 that further evaluated both the potential internal corrosion effects of materials in the tank and in the potential external corrosion effects of the backfill and native soil at the Oak Ridge National Laboratory (ORNL). The ability to accurately measure or predict the amount of corrosion present on both the internal and external walls of the tanks and pipelines is extremely limited. However, when available, data were used to assess the historical tank contents and usage and the probable corrosive effects on the tank system materials of construction.

- Performance of monthly leak tests were completed on the tanks and annual leak tests were completed on associated testable pipelines. This task was judged to be the most important criteria for determining structural integrity due to the proven performance of the technology and processes involved.

\subsection{DESIGN DRAWING EVALUATION}

Design drawings were reviewed for each of the six Category $C$ tanks. In the case of Tank WC-2 and W-16, drawings which were updated to show as-built conditions were also reviewed.

The drawings were reviewed for materials of construction, specifications, and any codes that were met by the tanks at the time of installation. Types of welds and the presence or absence of any extra flanges or ports were also noted. The information gained from review of the available drawings was used during the certification process for determining whether the tanks were suitable to contain LLLW at the time of installation, and to note any circumstances which may have contributed to deterioration of a tank's structural integrity. 


\subsection{GENERAL CORROSION ASSESSMENT OF THE CATEGORY C TANK SYSTEMS}

A qualitative corrosion assessment was completed based on available data pertaining to material of construction, historical tank system usage and the corrosive effects of native soils. Although the corrosion assessment is limited in nature, the data provided is considered a vital part of the structural integrity assessment.

Most of the waste tanks and associated piping at ORNL are constructed of types 347 and 304L stainless steel. Both of these stainless steel alloys nominally contain $18 \%$ chromium and $8 \%$ nickel and exhibit good corrosion resistance in many environments, particularly oxidizing ones. The corrosion resistance of 347 stainless steel is similar to that of $304 \mathrm{~L}$ stainless steel. The carbon content in 347 stainless steel can be as high as $0.08 \%$, whereas in $304 \mathrm{~L}$ it is a maximum of $0.03 \%$. Both have an austenitic crystal structure and are easy to weld. Type 347 stainless steel is welded with 347 weld rod, and type $304 \mathrm{~L}$ stainless steel is welded with $308 \mathrm{~L}$ rod. The compositions of both weld rods are essentially the same as the base metal except that the chromium content is somewhat greater to compensate for chromium vaporization during welding. Generally, the corrosion resistance of the cast weld structure closely matches that of the base metal.

The stainless steels owe their stainless character to the presence of chromium. Depending on the environment, a minimum chromium content of 12 to $14 \%$ is required to produce a stainless alloy. In the temperature range of 480 to $870^{\circ} \mathrm{C}\left(900\right.$ to $\left.1600^{\circ} \mathrm{F}\right)$, the carbon in stainless steels that is in excess of $0.03 \%$ diffuses to grain boundaries, where it is precipitated as chromium carbide. Since the solid state diffusion rate of chromium is much less than carbon, the chromium content in a very thin layer at the edges of the grains is reduced to below the 12 to $14 \%$ level, and the metal in that thin layer is no longer a stainless steel. Stainless steel in such a condition is said to be sensitized, and in such conditions corrosion manifests itself by attacking along grain boundaries (intergranular corrosion) in some environments. If the alloy contains sufficient niobium (ten times the carbon content), as in 347 stainless steel, niobium carbide forms in preference to chromium carbide. The edges of the grains retain their chromium and the alloy is not subject to intergranular attack. Because of the niobium addition, 347 stainless steel is said to be stabilized; however, 304L stainless steel is stabilized by virtue of its low carbon content.

\subsection{Corrosion by Waste Solutions}

The ORNL waste solutions have varied compositions, and under some conditions may' be highly corrosive to stainless steels. The corrosiveness of these solutions can be greatly reduced by adding caustic to make the solutions alkaline. This is the current and past practice for most of the ORNL tanks, but there were unspecified periods when caustic was not added.

Corrosion failures seldom occur because of uniform attack (general wall thinning) but are much more likely to result from some form of localized attack. Several localized 
failure modes are briefly discussed below. None of these forms of attack are likely to occur if the solution $\mathrm{pH}$ is high; however, during periods when caustic was not added in the past or if the tank solutions are allowed to become only slightly alkaline or acidic in the future, localized attack may result. For the storage tanks, it is assumed that the temperature of the contents has never exceeded $25^{\circ} \mathrm{C}\left(77^{\circ} \mathrm{F}\right)$ (due to the tanks being located below grade), that the concentration of radiolysis products in solution is insufficient to influence corrosion reactions, and that the solution composition is uniform throughout the tank.

\subsubsection{Stress Corrosion Cracking (SCC)}

Austenitic stainless steels under tensile stress are susceptible to stress corrosion cracking (SCC) in the presence of chloride ions, but the minimum temperature required for cracking to occur is 50 to $60^{\circ} \mathrm{C}\left(122\right.$ to $\left.140^{\circ} \mathrm{F}\right)$, well above the assumed normal temperature of the waste systems. Other agents can also produce SCC in stainless steel (e.g., caustic solutions, fluoride ions, and polythionic acids) but these require either higher temperature or fully sensitized microstructures which do not exist in the ORNL waste systems. Consequently, SCC does not represent a potential failure mode for these systems.

\subsubsection{Pitting Corrosion}

The austenitic stainless steels are subject to pitting in the presence of chloride ions. Under some conditions, chloride ions can initiate very localized corrosion on passive surfaces and at these sites pits may form. Once formed, a pit may continue to grow or spontaneously passivate. For a pit to form and continue to grow, the electrochemical potential of the metal must be above some minimum value which becomes lower as the chloride concentration and temperature increase. In addition, the presence of the other anions in a solution inhibits the pitting process [Lechkie 1966]. As an example, the minimum hydroxide ion concentration to prevent pitting of stainless steel in a solution with a given chloride concentration at $25^{\circ} \mathrm{C}\left(77^{\circ} \mathrm{F}\right)$ is given by the following equation:

$$
\log \left[\mathrm{Cl}^{-}\right]=1.62 \log \left[\mathrm{OH}^{-}\right]+1.84
$$

Similar relationships are given for other anions.

When a pit develops, the base of the pit is the anode and the surrounding area is the cathode of the corrosion cell. The solution within the pit is significantly different from the bulk solution and has a lower $\mathrm{pH}$ than the bulk solution. An active pit usually deepens at an appreciable rate, leading to relatively rapid penetration of vessel walls.

The alkaline solutions that presently exist in most ORNL waste tanks and the expected low chloride concentrations make growth of existing pits or formation of new ones very unlikely. However, if the $\mathrm{pH}$ of the solutions is allowed to become only slightly alkaline or acidic, pitting could lead to failure. 


\subsubsection{Crevice Corrosion}

Crevice corrosion may occur under deposits, between metal flanges, and in other confined regions where the small volume of solution cannot readily mix with the bulk solution. Crevice corrosion often starts as a differential aeration cell, where corrosion processes consume the dissolved oxygen in the solution within the crevice and the potential of the metal in that region becomes more active than the surfaces outside of the crevice. Thus, an electrochemical cell is formed with the metal in the crevice region serving as a node. Once initiated, pitting and crevice corrosion proceeds by the same mechanism.

Crevice corrosion is very improbable in solutions with highly alkaline $\mathrm{pH}$ values, but in only slightly alkaline or acidic solutions it represents a potential failure mode. A properly constructed system, however, without significant solids in the bottom, should provide few locations for crevice corrosion to begin.

\subsubsection{Intergranular-Knife Line Attack}

Since neither 347 nor $304 \mathrm{~L}$ stainless steels are subject to chromium carbide grain boundary precipitation, conventional intergranular attack is not to be expected. However, the niobium stabilization of 347 stainless steel produces one detrimental effect during welding that sometimes leads to "knife-line attack" [Shreir 1994, 3:56]. The metal immediately adjoining the fusion zone is subject to very high temperatures during welding, causing precipitated niobium carbide to go into solution. On reheating, as in multipass welding, carbide, possibly containing some chromium, may form. Thus, a very narrow band adjacent to the weld may be susceptible to intergranular attack in some environments. In contrast to knife-line attack, "weld decay" or "heat affected zone" corrosion that results from welding unstabilized stainless steel occurs a slight distance $(\sim 2 \mathrm{~mm})$ from the weld.

\subsubsection{Microbiologically Influenced Corrosion (MIC)}

It has only been in the last 10 to 20 years that the influence of microorganisms on corrosion processes has been recognized and understood by most corrosion engineers. There are many different microorganisms that can influence corrosion. Some operate under anaerobic conditions while others thrive in aerated environments. Under favorable conditions, doubling times of 60 to 120 minutes are possible, so a small number of microorganisms originally present can form large colonies in relatively short times [Sherier 1994, 2:87-97]. Before MIC can begin, the microorganisms must colonize on a metal surface. Colonization is not possible when the solution flows rapidly past a metal surface; however, metals exposed to slow-moving or stagnant solutions are prime candidates for MIC.

While there is presently no evidence that MIC has been involved in corrosion of either the interior or exterior surfaces of the LLLW waste system, MIC appears possible and needs to be considered a possible failure mechanism in slightly acidic, neutral, or slightly alkaline solutions; however, in highly alkaline solutions, MIC is highly improbable. 


\subsection{Soil Side Corrosion of ORNL Waste Systems}

Many of the ORNL waste tanks and essentially all associated piping are buried directly in soil. These tanks and pipes were not coated, nor has cathodic protection been applied on any of the tanks or much of the singly contained piping. Consequently, there is concern about the condition of the stainless steel after more than 40 years in the soil. There are two reports of testing programs and experience at the Savannah River Plant that suggest damage is probably not severe at ORNL.

The most extensive study of stainless steel corrosion by soils was conducted by Romanoff of the National Bureau of Standards [Romanoff]. Pipe sections of 304 stainless steel $(0.05 \%$ and $0.08 \%$ carbon) were buried for up to 14 years in different soils across the United States. Chloride, sulfate, and $\mathrm{pH}$ values ranged from zero to $10,000 \mathrm{ppm}, 12$ to $10,500 \mathrm{ppm}$, and 4.8 to 9.4 respectively. In all cases, uniform attack was negligible. In soils containing low concentrations of chloride and sulfate, such as at ORNL, maximum pit depths were 0.006 inches in 14 years. In a subsequent study, many 304 stainless steel specimens $(0.05 \%$ and $0.06 \% \mathrm{C})$ were exposed in different soils for up to eight years. Only a few very shallow (unmeasured) pits were reported [Gerhold 1981].

Many underground stainless steel pipelines at the Savannah River Plant are neither coated nor cathodically protected. These lines were installed in the early 1950 s, and as of about five years ago, not a single failure had been observed [Ondrejcin 1991]. On the other hand, underground stainless steel lines at the Hanford Reservation, installed during World War II, began leaking in 1947. Penetrations were caused by localized pitting which was probably initiated by MIC [Bucholz 1960]. Installation of cathodic protection on all buried lines stopped the failures. One major difference between the soils at Hanford and Savannah River (and ORNL) is the porosity. Hanford has an alluvial soil with about $30 \%$ porosity, whereas the porosity at Savannah River and ORNL is much less.

In spite of the Hanford experience, the data obtained by Romanoff and the observation at Savannah River, combined with the apparent lack of failure in the ORNL waste system after more than 40 years, implied that stainless steel corrosion by ORNL soils is minimal and is unlikely to contribute significantly to any possible future failures. Evidence to support this theory was found when a section of stainless steel piping installed as a part of the W-16 Tank System in 1951 was purposely unearthed in May 1995. The section had sustained very little external corrosion or damage and appeared to be structurally sound. 


\subsection{INTRODUCTION TO LEAK TESTING}

The LLLW tank systems are comprised of several components, including the tanks and several different types of pipelines. Different types of components, or similar components with significantly different volume capacities or other characteristics, can require different leak testing methods. This is a consequence of the existing instrumentation or performance requirements, actual configuration of the system, environmental effects, operational constraints, or a combination of these factors. Tanks, pressurized pipelines, and gravity-fed pipelines each present distinctly different technical problems for leak testing, and thus require different methods.

The pipelines at ORNL were divided into two classifications based on the way liquids are moved in the lines-by gravity or by pressure. The method for testing gravity lines adds minimal volumes of water at a controlled rate to the line being tested. If the rate received is comparable to the rate sent, then the line passes the test. The pressurized pipelines are tested by the gas pressure decay (GPD) method (followed by a tracer technique when required). This method measures the rate of change of pressure in the line and quantifies the change in terms of liquid leak rate.

The LLLW tanks are tested using another volumetric method. While the protocol for using this method is slightly different depending upon the size of the tank, for the six tanks included in this structural integrity assessment update, this method precisely measures the change in liquid volume over a 24-hour period using a differential-pressure sensor that is installed in the tank.

The LLLW tanks are tested monthly, while the pipelines are tested annually. The performance of all of the leak testing methods employed at ORNL has been evaluated, and all meet the basic performance requirements described in the underground storage tank (UST) regulations. The tank methods have been shown to be capable of detecting a leak of $0.2 \mathrm{gal} / \mathrm{hr}$ with a probability of detection (PD) of at least $95 \%$, and with a probability of false alarm (PFA) of no more than $5 \%$. The pipeline methods have a performance sufficient to detect leaks that are full-use equivalent to $0.1 \mathrm{gal} / \mathrm{hr}$, with a PD of at least $95 \%$ and a PFA of no more than $5 \%$.

As part of the certification process, the leak test methods, protocol, and evaluation procedures and documents were examined for accuracy and applicability to ORNL's LLLW system. These efforts showed that the methods used were consistent with the LLLW components tested, that the methods used were consistent with the evaluation approach, and that the leak testing at ORNL was conducted in accordance with the test procedures and protocols appropriate to the method used.

Each leak test results in one of several test decisions. A PAss decision indicates that the absolute value of the measured volume rate of the component tested was less than a specified test threshold value. A FAIL decision indicates a negative volume rate that exceeded the threshold, suggesting a leak in the system. An INCONCLUSIVE result indicates 
that the data quality was too poor to make a decision, or that there were known factors rendering the test unreliable. For the LLLW tanks, two other test decisions are possible: EMPTY and INFLOW. An EMPTY result indicates that the liquid level is at or below the bottom of the dip leg of the level sensor, and therefore the liquid level cannot be recorded. An INFLOW result occurs when the measured rate of volume change is positive and greater than expected-suggesting that liquid is flowing into the tank from external sources. Because the vault sumps in some of the tank pits collect runoff during rainfall events, data collected during rain events occurring during leak tests were analyzed to determine whether rainfall affected the test. Suspected inflows due to rain can cause an INCONCLUSIVE or INFLOW test result.

\subsection{Leak Testing Methods for Tanks}

The tanks were tested by a method based upon differential pressure (DP) measurement of the liquid level in the tank, using an instrument called a DP cell. The DP cell measures liquid level by sensing the head pressure produced by the liquid, with respect to the pressure in the vapor space of the tank. As the liquid depth increases, the pressure increases. The output of the DP cell is proportional to the measured pressure. The liquid level can be determined from a measurement of the output with a calibrated sensor.

As configured at ORNL, the DP cell infers the tank liquid level by measuring the mass of the liquid in a vertical column above the outlet of a bubbler tube that is placed into the tank. In a container with constant cross-sectional area, and where the bubbler tube extends to the bottom of the container, the output of the DP cell is independent of level (volume) changes that result from thermally induced expansion and contraction of the liquid. That is, the DP cell is self-compensating for thermally produced volume changes in the liquid, and eliminates the need to compensate for the liquid volume changes due to temperature fluctuations.

The testing protocol begins with a 12-hour waiting period. This is done to minimize external factors that can affect the test results. During wait and test periods, the operators/owners using the tank are asked to suspend additions to and transfers from the tank. In addition, outside activities such as air sparging to clear the level gauge air lines, are also suspended. The waiting period gives the tank and its contents an opportunity to stabilize, thereby maximizing the quality of the leak test data.

After the waiting period, a data collection period is initiated. The tanks discussed in this report were tested for one or two consecutive trial periods of 24 hours each. The second trial is conducted only if a result other than PASS is achieved in the first trial. If the decision is INCONCLUSIVE or indicates that the tank is empty or experiencing an inflow or outflow, a second trial is scheduled as soon as possible. If there are two sequential outflow decisions, the outcome of the test is FAIL. 


\subsection{Leak Testing Methods for Pipelines}

The gravity-fed pipelines generally transport only small volumes of waste (i.e., fractions of a gallon to a few tens of gallons) at any given time, carrying the liquid from a hot cell or other facility to a collection tank. The gravity-fed lines typically contain no liquid, except during infrequent transfers of waste or when liquids remain in low spots at the bottom of a horizontally oriented pipe following these transfers. Since none of these lines could be isolated from the tank for a pressure test, they were tested using a variation of the volume balancing method. The pressurized pipelines generally carry a larger volume than do gravity-fed lines. Some of the pressurized lines could be isolated from their respective tanks by valves and were therefore pressure tested. The remainder of the pressurized lines could not be isolated due to lack of isolation valves or injection points. Thus they could not be pressure-tested. Some, however, can be assessed by comparing volumes sent through the pipelines to volumes received at the collecting tank.

\subsubsection{Leak Detection Method for Gravity-Fed Pipelines}

Gravity-fed pipelines were tested using a variation of the volume balancing method. Traditional volume balancing methods are not used to test gravity lines at ORNL because the lines are used infrequently and tend to dry out between uses (and are likely to be dry before a test). With dry pipes, an unknown portion of an added volume is lost due to "wetting" of the walls of the pipe, and some additional unknown portion can "pool" or accumulate in low spots in the line. Thus, the volume added to the line and the volume received by the tank would generally never balance. In this case, it wouldn't be known if the volume loss was due to wetting and pooling or to a leak in the line. A further difficulty with traditional volume balancing is that, in the case of a small leak, it requires that a large volume of liquid be added at the inlet end of the line so that the observed volume difference will be large enough to be measured. This creates additional waste liquids that must be processed; this is not encouraged.

These problems were addressed at ORNL by means of a variation on the traditional volume balancing method, in which the rate of flow of liquid added at the inlet end of the line is compared to the rate of flow of liquid collected in the tank. This is referred to as an "enhanced volume balancing" method, or EVB. Once a steady rate of flow has been established at the inlet and another steady rate of flow is observed in the collection tank, the line has been wetted and low spots have been filled. The difference between the flow rate at which liquid is being added to the line and the flow rate being recorded in the tank is a direct measure of the leak rate of the pipeline (after known environmental effects have been compensated for, and within the uncertainties of the method).

Successful use of the EVB method requires: (1) that the collection tank is nonleaking (so any measured volume rate can be attributed to the pipeline), (2) that the precision of the pump used to add water at the inlet be at least an order of magnitude better than the leak rate to be detected, and (3) that the height-to-volume (H/V) ratio of the collection tank is known precisely. These requirements are met by (1) ensuring that the collection tank is tight prior 
to leak testing the pipeline, (2) using a precise and calibrated metering pump, together with a closed loop pump speed controller, and (3) measuring the $\mathrm{H} / \mathrm{V}$ correction factor as part of the EVB test protocol.

\subsubsection{Leak Testing Methods for Pressurized Pipelines}

The LLLW pressurized pipelines were tested using a gas pressure decay (GPD) method, followed by a helium tracer technique if necessary.

In the GPD test, the pipeline is first drained or purged of liquid and then pressurized with nitrogen (or air). The line is then isolated from the pressure source while the line pressure is monitored and recorded for 24-hours. After a short waiting period to allow adiabatic effects to subside, the recorded data are processed so that the rate of change of pressure in the line is converted into an equivalent liquid-loss rate. The data are then compared to a detection threshold. Within the allowable noise of the method, a pressure drop in the line can be attributed to losses in the line caused by either: (1) a "hole" in the line, or (2) poorly fitted valves that allow the gas to pass through the valve seat into the downstream piping. If a GPD test results in a PASS decision, the line is tight. If the GPD test results in a FAIL decision, a helium tracer technique is employed so that the failure can either be verified (and the leak located or localized) or the GPD result can be declared a false alarm due to poorly seated valves.

When the helium tracer technique is employed following a GPD test, a helium purge is first used to ensure a $100 \%$ helium atmosphere in the pipeline. Following the helium purge, the line is pressurized with helium and continuous pressure is maintained for the duration of the measurement period. After a short waiting period (which allows helium to begin to suffuse upward from the buried line, if a hole in the line exists), a helium detector is walked along the surface of the ground directly above and parallel to the surveyed location of the pipeline. Gas samples are collected at frequent intervals along the line, from small accumulator locations that have been "punched" into the soil (or drilled into the roadway); these data are then recorded. The process is repeated so that the helium has sufficient time to reach the surface, even in soils with low permeability.

Successful helium tracing of the pressurized line requires that: (1) the isolation valves can be closed sufficiently to enable pressure buildup, (2) the location of the line is well known, (3) frequent sample intervals are used to maximize the chance of detecting any helium that might be escaping from a hole in the line, and (4) escaping helium remains confined within a few feet laterally of the pipeline. At ORNL, these requirements are met by: (1) replacing faulty valves, (2) surveying the location of the line from the as-built drawings, backed up with "line locator" measurements, (3) punching or drilling helium accumulator pockets at eight to ten foot intervals along the surveyed location. The fourth requirement should be met because of the expectation that leaking helium will remain within the confines of the pipeline trench. 


\subsection{Determination of Expected Error Values for the Untestable Pipelines}

Although some pipelines in the LLLW system cannot be tested for leaks, a rough assessment of their integrity can be inferred if liquid transfers are made through these lines during the assessment period, and if the volumes "sent" from the sending tank and the volumes "received" by the receiving tank are recorded for each transfer. This assessment can be made by subjecting the difference between the two volumes to an error analysis, based upon the errors expected to be observed given the measuring instruments and other factors. The sources of error included in this analysis are: (1) the precision of the level sensor and (2) the accuracy of the measurement, which depends on strapping table error, signal conditioning accuracy, level sensor accuracy, and the influence of temperature changes in the liquid that are not compensated for. The foregoing sources of error are quantified either through estimates provided in the manufacturer's specifications or through analysis of the data. The resulting numbers are then combined statistically to obtain a numerical value for the expected error. The discrepancy between the input and output volumes is considered significant if its absolute value is greater than the expected error. Sources likely to contribute to this error, and the assessment approach are presented below.

Precision of the level sensor. The first step is to determine the precision of the level sensor, $P_{R}$, for each tank. $P_{R}$ is based on the noise observed in the data. The process can be expressed by:

$$
P_{R}=\sqrt{\left(2^{*} \sigma^{2}\right)},
$$

where $\sigma$ is the standard deviation. This was determined from the noise observed in the level data from the sending and receiving tanks. It is assumed that $\sigma$ before transfer $\cong \sigma$ after transfer.

Accuracy of the measurement. The accuracy of the measurement, $\mathrm{P}_{\mathrm{A}}$, is then determined for each tank. There are four components to $P_{A}$ :

- S (strapping table error). $S=0.5 \%$ of full scale, based upon an engineering estimate made from manufacturer specifications.

- G (ActionPak accuracy). $\mathrm{S}=0.1 \%$ of full scale, based on manufacturer specifications. (The ActionPak is a signal conditioning amplifier used in the DP cell-to-computer level measurement scheme.)

- A (sensor accuracy). $\mathrm{A}=0.2 \%$ of full scale, based upon manufacturer specifications for the Foxboro 823DP cell.

- $\mathbf{U}$ (uncompensated temperature influence). $U=0.1 \%$ of full scale, as determined from the level data from the sending and receiving tanks.

The values of S, G, A and U, once calculated, are converted to volume (in gallons) based on the height-to-volume ratios at the before-and-after levels in the tanks. In the horizontal 
tanks, $\mathrm{P}_{\mathrm{A}}$ may vary between transfers because the tank's $\mathrm{H} / \mathrm{V}$ ratio can vary according to the level of liquid. The numbers are then combined statistically, according to:

$$
P_{A}=(1 / 3) \sqrt{S_{\text {level } 1}^{2}+G_{\text {level } 1}^{2}+A_{\text {level } 1}^{2}+U_{\text {level } 1}^{2}+S_{\text {level } 2}^{2}+G_{\text {level } 2}^{2}+A_{\text {level } 2}^{2}+U_{\text {level } 2}^{2}}
$$

(These are all $3 \sigma$ numbers, so the $1 / 3$ factor converts each to a $1 \sigma$ number.)

When the errors from all of the above sources have been considered, the error for an individual tank, $\mathrm{P}$ (a $1 \sigma$ number), can be determined. Since the $\mathrm{P}_{\mathrm{A}}$ values are all given as a percent of full scale, they are dependent on the volume transferred:

$$
P=\sqrt{2 *\left(P_{R}\right)^{2}+\left(\frac{V_{T}}{V_{F S}}\right)^{2} *\left(P_{A}^{2}-P_{R}^{2}\right)},
$$

where $V_{T}$ is the volume transferred and $V_{F S}$ is the total volume capacity of the tank. In this scenario, as one approaches zero volume transferred,

$$
\mathrm{P} \rightarrow \sqrt{2^{*} P_{R}^{2}},
$$

and as one approaches full volume transferred,

$$
\mathrm{P} \rightarrow \sqrt{P_{R}^{2}+P_{A}^{2}}
$$

Based on the equation

$$
\text { Expected Error }=3 * \sqrt{P_{\text {tank } 1}^{2}+P_{\text {tank } 2}^{2}} \text {, }
$$

the (maximum) expected error (a $3 \sigma$ number) can now be calculated for a specific transfer between two tanks. The analysis included in this report compares the recorded volume transfer differences to the maximum expected error, and flags significant differences.

\subsection{Statistical Analysis and Hypothesis Testing}

A key element of the analysis performed to support the structural integrity assessments for the Category C LLLW systems is statistical analysis and hypothesis testing, using the compensated volume rate (CVR) data collected in each reporting year. In the analysis, a null hypothesis test is used to test the mean of the data, and another null hypothesis test is used to test the variance of the data. As described in the "analysis" sections of the first SIA document [DOE/OR/01-1385\&D2], the purpose of the analysis is to determine whether the data "...was consistent with data expected from a non-leaking tank, with the evaluated performance of a calibrated leak testing method used as the comparator." 
In performing the analysis for earlier SIA reports, it was shown that the CVR populations were non-gaussian, which is an implied requirement for many statistical tests. This is expected in large populations of real data, such as the body of data that has been, and continues to be, accumulated at ORNL. Based upon the non-gaussian findings, it was determined that a Student's-t test could be used to test the mean of the CVR data (compared to $0 \mathrm{gal} / \mathrm{hr}$ ), and a Kolmogorov-Smirnov test (KS) could be used to test the variance of the CVR data (compared to a "reference" population).

Figure 2 shows a three-and-one-half-year history of all ${ }^{1}$ of the conclusive compensated volume rate data collected from six LLLW tanks-F-501, W-16, WC-2, WC-3, WC-9, and 2026A-that have been repeatedly shown to be "tight" and non-leaking. The data in this plot, starting at the very beginning of ORNL's leak testing program in June 1992 and ending on December 31, 1995, were used as the "reference" set for the KS test in this report.

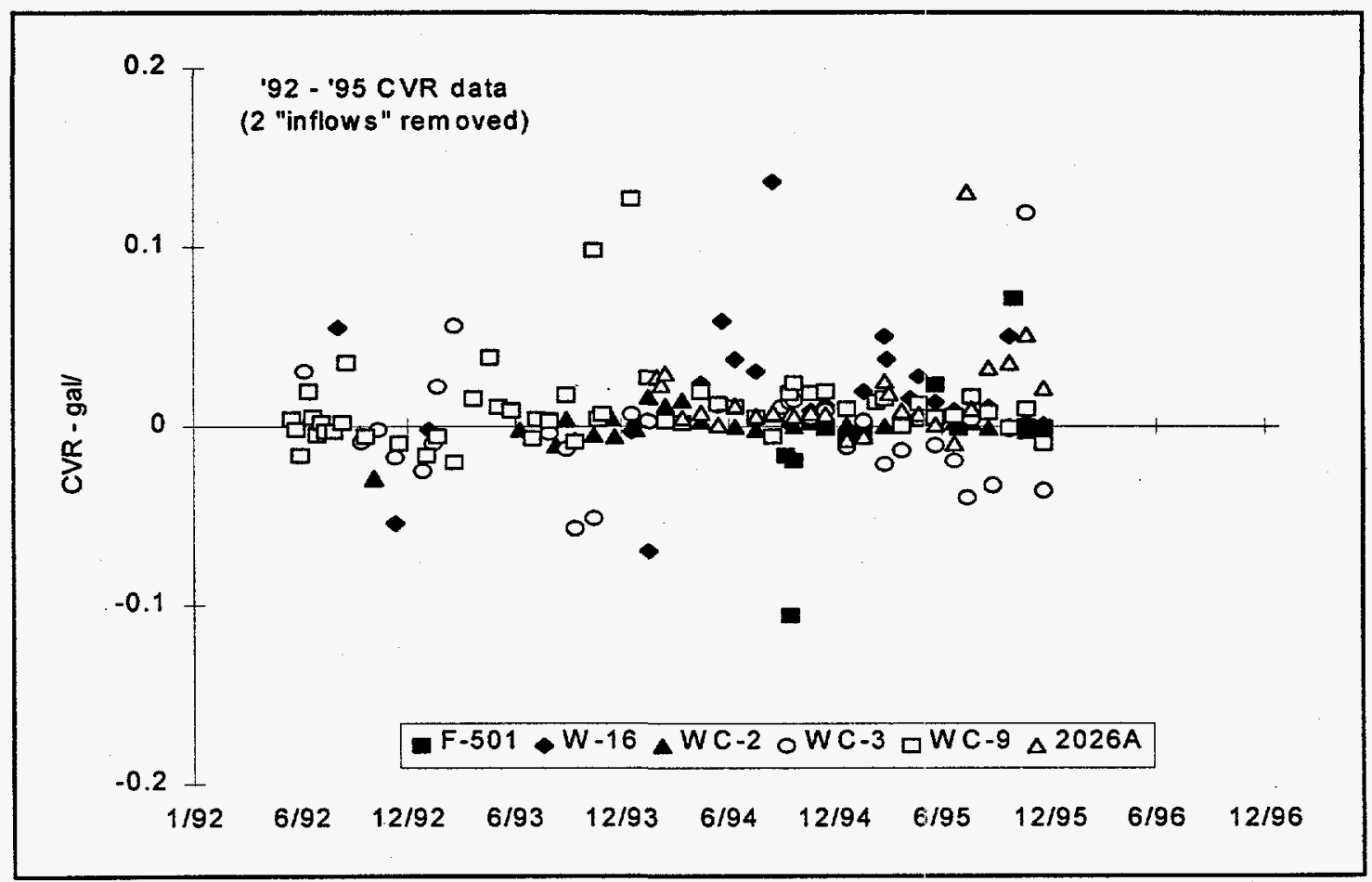

Fig. 2. 1992 - 1995 "reference" set of CVRs used to test variance of 1996 CVR data.

Figure 3 repeats the data in Figure 2 and adds the CVR data from CY96. It is this CY96 data that is being quantitatively tested in the sections below. Qualitatively, the figure shows that there has been little or no change in the nature of the data over the past year.

\footnotetext{
1 Two inflow results recorded for WC-3 in September 1994 were removed from this data set.
} 


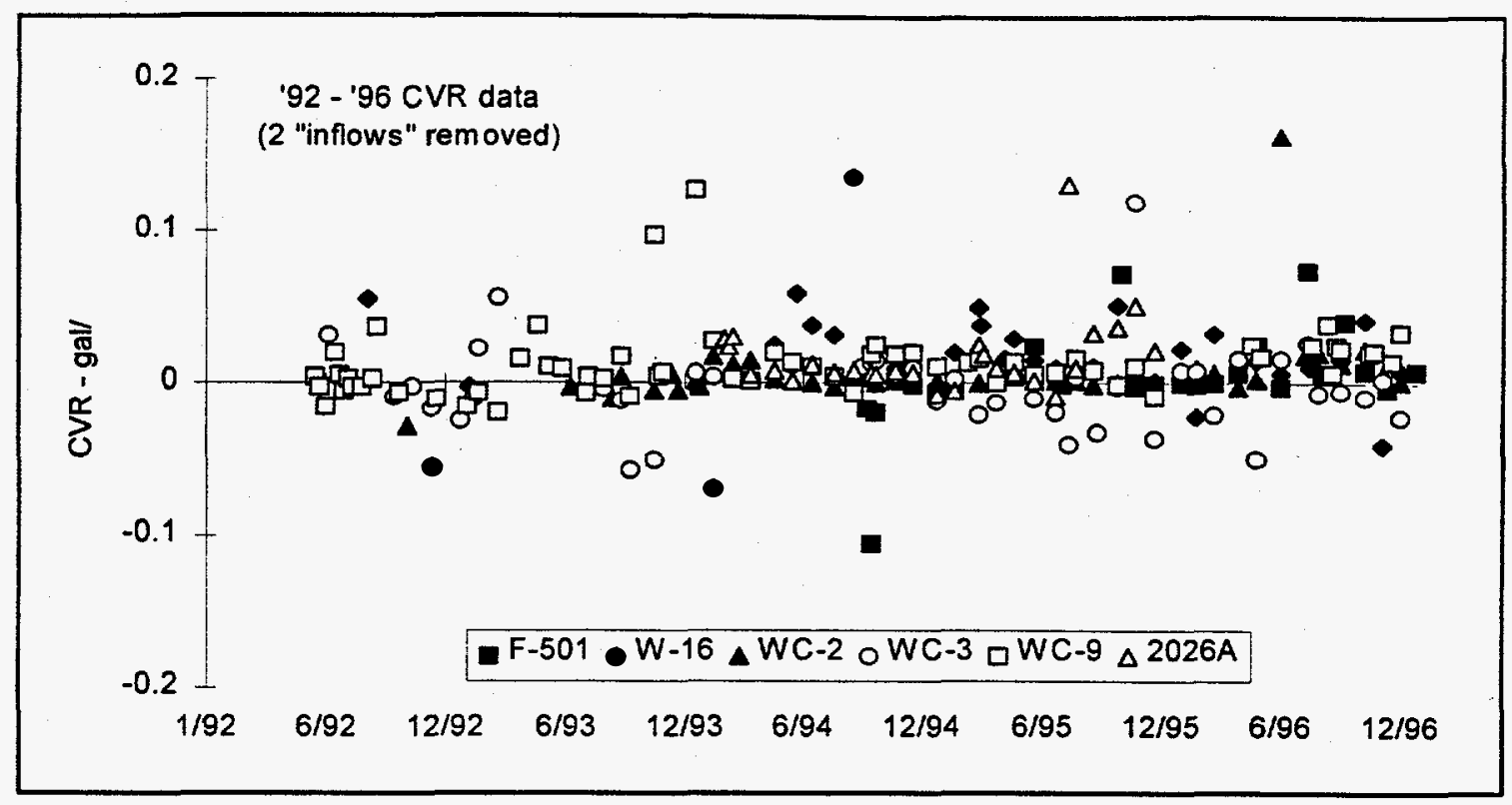

Fig. 3. CVR data from June 1992 through December 1996.

The hypothesis testing utilized a Student's-t test to test the means of the CVR data, and an Kolmogorov-Smirnov test to test the variance of the CVRs. Each of these tests calculates a test statistic that is compared to a critical value, for a specified level of confidence (LOC). If the test statistic is greater than the critical value, then the null hypothesis is rejected. The LOC chosen for this analysis is $99 \%$ in order to minimize the chances of incorrectly rejecting the null hypothesis-that is, declaring the mean or variance of a set of CVRs to be "different than expected from a non-leaking tank," when in fact it was not different. Table 1 shows the critical values used in the Student's $t$-test for a LOC of $99 \%$, as a function of the number of degrees of freedom, df, in the data set. Here, $\mathrm{df}$ is $(\mathrm{N}-1)$, where $\mathrm{N}$ is the number of CVR values in the data set to be tested.

Table 1. Student's-t Distribution for a Limited Range of $\mathbf{N}(\mathrm{df}=\mathrm{N}-1)$

\begin{tabular}{rccc}
\hline \hline df & $\mathbf{T}_{\text {critical (99\%) }}$ & df & $\mathbf{T}_{\text {critical (99\%) }}$ \\
\hline 5 & 4.032 & 11 & 3.106 \\
6 & 3.707 & 12 & 3.055 \\
7 & 3.499 & 13 & 3.012 \\
8 & 3.355 & 14 & 2.977 \\
9 & 3.250 & 15 & 2.947 \\
10 & 3.169 & 16 & 2.921 \\
\hline \multicolumn{4}{c}{}
\end{tabular}


The t-statistic is calculated as:

$$
t_{\text {stat }}=\sqrt{N} \frac{m}{s}
$$

where $\mathrm{N}$ is the number of points in the (CVR) data set, $\mathrm{m}$ is the mean of the $\mathrm{N}$-points of data, and $s$ is the standard deviation of the data.

Although there are several tests that could be used to test the variance of CVR data, the Kolmogorov-Smirnov (KS) "goodness-of-fit" test not only meets the requirement for handling non-gaussian data but is also very simple and direct. ${ }^{2}$ The KS test examines the deviations between a hypothesized cumulative distribution function (CDF), $\mathrm{F}_{\mathrm{X}}(\mathrm{x})$, and the observed cumulative histogram, $\mathrm{F}^{*}\left(\mathrm{X}^{(\mathrm{I})}\right)=\mathrm{I} / \mathrm{n}$, in which $\mathrm{X}^{(\mathrm{)})}$ is the $i$ th largest observed value in the random sample of size $N$. (In this case, $F_{X}(x)$ would be represented as the cumulative distribution of a set of reference CVRs, and $\mathrm{F}^{*}\left(\mathrm{X}^{(\mathrm{l})}\right)$ would be represented by the cumulative distribution of the CVR from a particular tank that is being "tested.") The KS test statistic is expressed algebraically as:

$$
K S_{\text {stat }}=\max _{i=1}^{N}\left[\left|F^{*}\left(X^{(i)}\right)-F x\left(X^{(i)}\right)\right|\right]
$$

$\mathrm{KS}_{\text {stat }}$ is the largest of the absolute values of the $\mathrm{N}$ differences between the reference CDF and the CDF of the data under test.

Procedurally, the KS test is performed in this analysis by first calculating a reference $\operatorname{set}^{3}$ of CVRs that is scaled to the appropriate height-to-volume $(\mathrm{H} / \mathrm{V})$ of the test tank. The mean of the scaled CVRs is then subtracted and the CDF is calculated to obtain the "reference" distribution, $\mathrm{F}_{\mathrm{X}}(\mathrm{x})$. The test set is obtained by subtracting the mean of the data being tested, and the CDF of the test data, $\mathrm{F}^{*}\left(\mathrm{X}^{(\mathrm{I})}\right)$ is calculated. The test statistic is then calculated as the largest ordinal (i.e., vertical) difference between the two CDFs. The critical statistic is determined from a table of values for the KS test. Table 2 shows the KS critical values for a $\mathrm{LOC}$ of $99 \%$, for a range of $\mathrm{N}$ that spans the data considered here. (When the means are subtracted from the data, the number of degrees of freedom is reduced by one; accordingly, the "sample size" used must be reduced by one. For example, if a tank has 11 conclusive CVR values over the 12 -month period being considered, the $\mathrm{KS}$ critical value is 0.49 ). Just as for the $t$-test, if the KS test statistic is less than the KS critical value, the null

\footnotetext{
${ }^{2}$ The KS test could be used to test both the mean and variance of the CVR populations. In this analysis, the mean was tested with the Student's t-test and the variance was tested using the KS test.

3 In this analysis the reference is the set of CVR values obtained from the ORNL tests for the six tanks described above, from the beginning of the leak testing program up to, but not including, the data in the current analysis period. As more leak test data is obtained, it is expected that future KS tests will utilize same-tank data as the reference. Once 40 to $50 \mathrm{CVRs}$ for a particular tank have been obtained from earlier tests, that data will be as the reference for that tank. This eliminates the need for height-to-volume scaling and provides a direct comparison of the data sets.
} 
hypothesis is accepted. If the test statistic is greater than the critical value, the null hypothesis is rejected.

Table 2. Critical Statistic for the KS "Goodness-of-Fit" Test

\begin{tabular}{cc}
\hline Sample size & KS $_{\text {critical (99\%) }}$ \\
\hline 5 & 0.67 \\
10 & 0.49 \\
15 & 0.40 \\
20 & 0.35 \\
25 & 0.32 \\
30 & 0.29 \\
40 & 0.25 \\
Large N & $1.63 /(\mathrm{N})^{1 / 2}$ \\
\hline (Abstracted from [Benjamin and Cornell, 1970])
\end{tabular}

Figure 4 illustrates the KS test, using the WC-3 data reported later in this document. After removing the means from both the data to be tested and the scaled reference set of data, the cumulative distribution functions of both sets are calculated and plotted. The bold solid line in the figure shows the CDF calculated from the set of (12) CVR values to be tested, while the light dashed line shows the CDF calculated from the reference set of CVRs. The two distributions are differenced over the range of the data and the maximum difference is obtained; here, the maximum difference, $\mathrm{KS}_{\text {stat }}$, is 0.25 and occurs at a $\mathrm{CVR} \cong+0.01 \mathrm{gal} / \mathrm{h}$. The set of CVRs being tested had 12 values in the set. Since the mean was removed, reducing the number of degrees of freedom by one, a "sample size" of $(12-1)=11$ was used to look up the $\mathrm{KS}$ critical value in Table 2 ; here, $\mathrm{KS}_{\text {crit }}$ has an interpolated value $=0.47$. Since $\mathrm{KS}_{\text {stat }}$ is smaller than $\mathrm{KS}_{\text {crit }}$, we fail to reject the null hypothesis that "...there is no statistical difference between the two populations." Thus, the two populations are deemed equivalent.

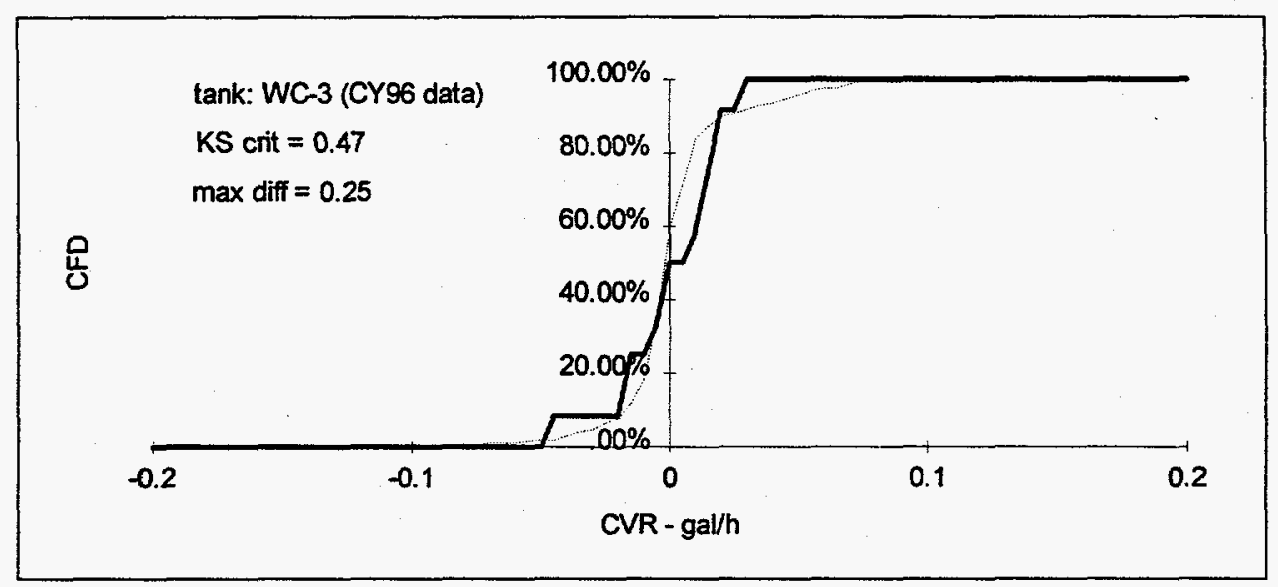

Fig. 4. An example of the KS test. 


\subsection{BASIS FOR TANK SYSTEM CERTIFICATION}

Tank certification in this effort was based on three specific areas where data were available. Design drawings for each tank system were available for review. A corrosion evaluation of each system provided limited, but useful, information concerning remaining structural integrity. The major data set upon which the structural integrity assessment was based was the leak test information. For example, a leak test with a pass result is sufficient to determine that the remaining structural integrity of the tank is adequate to hold the liquid, at the time of the test.

Line tests provide a similar method by which the remaining integrity of the line can be assessed and a determination made concerning the ability of the line to contain fluid. However, for gravity lines, this certification is valid only up to the flow rate under which the EVB was conducted and for the date and time of testing. GPD testing provides sufficient information to certify the entire pressurized line segment at full capacity for the date and time of testing.

With such a significant reliance on leak detection methods to certify the tank and its ability to successfully retain liquids, it is important that the testing results meet the agreed upon requirements, which have their foundation in 40 CFR Part 280. Included are the requirements of greater than $95 \% \mathrm{PD}$ of detecting a leak of $0.2 \mathrm{gal} / \mathrm{hr}$ and less than $5 \%$ PFA. Results which successfully demonstrate that they meet or exceed these requirements are accepted as a PASS and used as a basis for certification of the tank. Certification applies only to that portion of the tank which was wetted during the leak test. This limiting value can be stated either as a depth of liquid in the tank or as a percent of total tank capacity. In many cases each tank has been tested on multiple occasions. The successful test with the greatest depth or percent of total capacity is accepted as the certification limit. If a future leak test is conducted with a greater volume in the tank and the result is pass, certification may be extended to the greater volume upon reevaluation.

A review of the design drawings for each of the tank systems must demonstrate and validate that the tank systems were properly designed to retain the liquid wastes placed in them. Each tank and its associated lines were evaluated. The resultant certification, based on available data, should not be construed as a guarantee that leaks have not occurred in the tank or lines in the past, nor that they will not leak in the future. 


\subsection{TANK SYSTEM ASSESSMENTS}

This section of the report details the actual leak testing performed, and the corresponding certification results, for each of the six Category C LLLW tank systems. Throughout this section, individual pipelines are referred to using a unique "line segment number" and "index number." These line segment and index numbers are in accordance with previous numbering in "Detailed Leak Detection Test Plan and Schedule for the Oak Ridge National Laboratory Liquid Low-Level Waste Active Pipelines" [DOE/OR/01-1167\&D2]. While each pipeline has a line segment number, only testable lines were assigned index numbers.

\subsection{F-501 Tank System}

The F-501 Tank System is located south of Building 3525, as shown in Figure 1. The system collects LLLW from Building 3525 . The waste is transferred by truck from F-501 to the Evaporator Complex. The tank system consists of Tank F-501 and three pipelines connected to the system. Because the lines and tank do not meet the requirements for secondary containment, the tank system is classified as Category $\mathrm{C}$.

\subsubsection{F-501 Tank Description}

Tank F-501 is a 400-gallon tank located in an unlined, reinforced concrete vault. Installed in 1962, Tank F-501 is mounted vertically on four 3" $\times 3$ " x 5/16" L legs anchored to the floor of the vault. The tank is constructed of 304L stainless steel and has a wall thickness of 1/4" with ASME standard 304L stainless steel flanged and dished heads. The outside diameter of the tank is 48 " with an overall length of 46". The working volume of the tank is stated as 192 gallons. The drawing for Tank F-501 is provided as Figure 5.

The tank is equipped with four 1" diameter nozzles, two 2 " diameter nozzles, and one 3 "diameter flanged on nozzle top of the tank. Six of these nozzles are located around an 18" radius from the center of the tank. The flanged nozzle is located 12" from the center of the tank with a 1" offset from the tank centerline. One 4" diameter nozzle is located on the side of the tank, 4-1/2" below the weld of the top flanged dished head. Another $3^{\prime \prime}$ diameter nozzle is located 6-1/5" below the weld of the top flanged dished head on the opposite side of the tank of the 4" diameter nozzle. All nozzles are 304L stainless steel. Two lifting lugs are positioned on opposite edges of the top flanged dish head.

The unlined reinforced concrete vault has interior dimensions of 7'-6" $\times 6^{\prime}-6^{\prime \prime}$ and walls 12 " thick. The top of the vault is constructed to receive inwardly stepped plugs used to allow inspection and maintenance. The floor of the vault is sloped to a $1^{\prime}-0^{\prime \prime} \times 1^{\prime}-0^{\prime \prime} \times 1^{\prime}-0$ " sump. The outside of the vault has a waterproofing membrane and by a $1 / 2$ " fiber board to within $4^{\prime}-0$ " of the top of the vault.

Tank F-501 is capable of receiving material from two sources. The sources originate in Building 3525 and Tank F-201. Tank F-201 is no longer in service. The liquids generated in Building 3525 are gravity-fed into Tank F-501. A schematic of the tank system with numbered line segments is shown in Figure 6. 


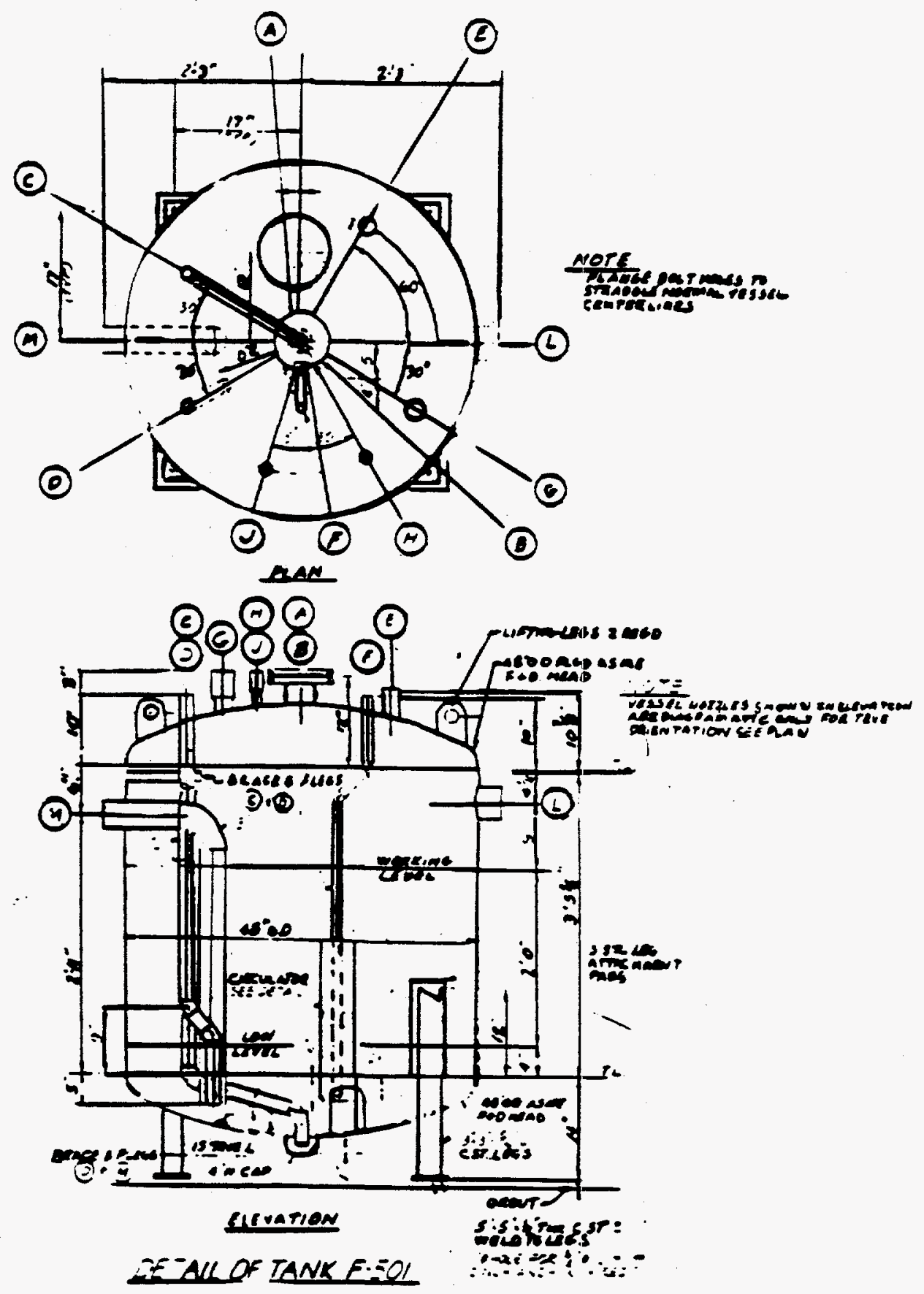

FIGURE 5 F-501 Tank Design Drawing 


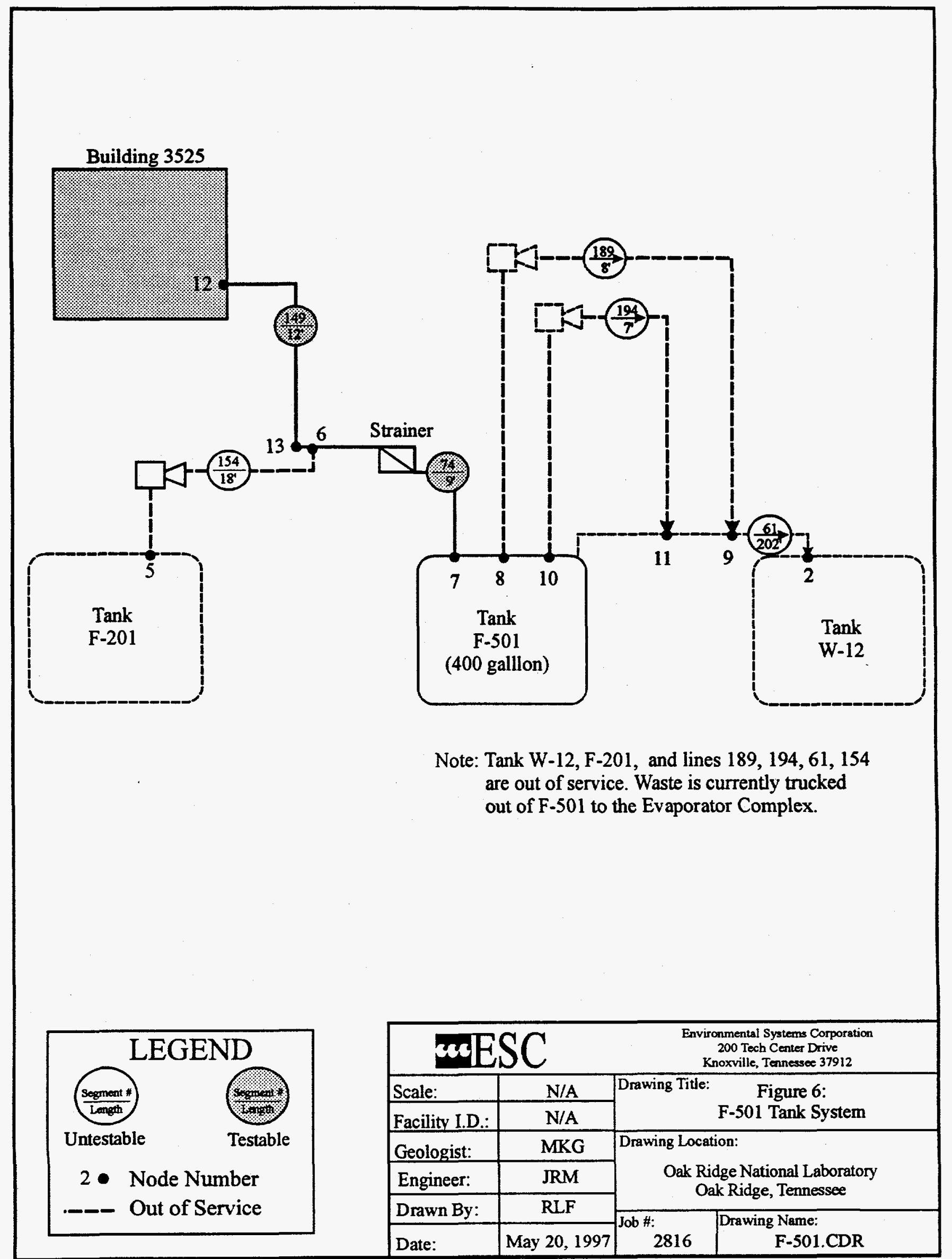




\subsubsection{F-501 Pipeline Descriptions}

The F-501 system has three pipelines, each of which consists of multiple line segments. The first pipeline, identified as Index No. G30 (node 12 to node 7 in Figure 6), has 2" and 4" diameter segments, and is constructed of 304L stainless steel. This line, made up of two line segments, is a gravity-fed line connecting a cell header in Building 3525 with Tank F-501. The first segment, Line Segment 149, is a 12' long segment that leaves the cell header in Building 3525 as a 2" diameter line constructed of 304L stainless steel (node 12 to node 6). The second segment, Line Segment 74, is a 4" diameter line, and is 9' long (node 6 to node 7 ).

The second pipeline is a portion of the transfer line connecting Tank F-201 to Tank F-501. This segment, Line Segment 154, is $18^{\prime}$ long, with a 1-1/2" diameter, and is constructed of 304L SS. This segment extends from Tank F-201 to the 4" diameter segment described above as Line Segment 74 (node 6 to node 7). Tank F-201 and Line Segment 154 are no longer in service.

The third element of the F-501 Tank System is the matrix of discharge transfer lines leading from Tank F-501 to Tank W-12. Even though described here, these discharge lines are no longer in service. Waste is trucked from Tank F-501 to the Evaporator Complex. These transfer lines are comprised of three line segments, all constructed of $304 \mathrm{~L}$ stainless steel. The first, Line Segment 189 (node 8 to node 9), is 8 ' long and has a 1" diameter. Line Segment 189 transfers liquid from Tank F-501, via steam jet to Line Segment 61 which leads to Tank W-12. Line Segment 194 (node 10 to node 11), is $7^{\prime}$ long and has a 1" diameter. Line Segment 194 previously transferred liquids from Tank F-501, via steam jet to Line Segment 61 . The third, Line Segment 61 (node 9 to node 2), is 202' long, with a 3" diameter. Table 3 contains a summary of the F-501 Tank System pipeline characteristics.

Table 3. Characteristics of Line Segments Evaluated as a Part of Tank System F-501

\begin{tabular}{|c|c|c|c|c|c|c|c|}
\hline \multicolumn{2}{|c|}{ Line Segment } & $61^{*}$ & 74 & 149 & $154^{*}$ & $189^{\star}$ & $194^{*}$ \\
\hline \multicolumn{2}{|c|}{ Node Numbers } & 9 to 2 & 6 to 7 & 12 to 6 & 5 to 6 & 8 to 9 & 10 to 11 \\
\hline \multicolumn{2}{|c|}{ Index Number } & & G30 & G30 & & & \\
\hline \multicolumn{2}{|c|}{ Diameter (in) } & 3 & 4 & 2 & 1.5 & 1 & 1 \\
\hline \multicolumn{2}{|c|}{ Material } & 304L SS & $304 \mathrm{~L}$ SS & 304L SS & $304 \mathrm{~L} \mathrm{SS}$ & 304L SS & 304L SS \\
\hline \multicolumn{2}{|c|}{ Length ( $\mathrm{ft}$ ) } & 202 & 9 & 12 & 18 & 8 & 7 \\
\hline \multicolumn{2}{|c|}{ Volume (gal) } & 78 & 6 & 2 & 2 & $<1$ & $<1$ \\
\hline \multicolumn{2}{|c|}{ Transfer Method } & SJ & G & G & $\begin{array}{c}\text { SJ \& } \\
\text { SJ Suct. }\end{array}$ & $\begin{array}{c}\text { SJ \& } \\
\text { SJ Suct. }\end{array}$ & $\begin{array}{c}\text { SJ \& } \\
\text { SJ Suct. }\end{array}$ \\
\hline \multicolumn{2}{|c|}{ Install Date } & 1962 & 1962 & 1962 & 1962 & 1962 & 1962 \\
\hline \multicolumn{8}{|c|}{$\begin{array}{ll}* & \text { Out of service } \\
\text { G } & \text { Gravity } \\
\text { SJ } & \text { Steam jet pump } \\
\text { SS } & \text { Stainless steel } \\
\text { Suct. } & \text { Suction } \\
\end{array}$} \\
\hline
\end{tabular}




\subsubsection{Corrosion Assessment of the F-501 Tank System}

Tank F-501 is an active tank used to collect liquid waste from Building 3525. Solutions collected in the tank include acids (including $\mathrm{HCl}$ and $\mathrm{HF}$ ), bases, salts, and detergent solutions used for decontamination. No effort is made to maintain the tank solution at a high $\mathrm{pH}$, and the solution may have a high or low $\mathrm{pH}$ depending on what was most recently added to the tank.

Because of the unknown and variable composition of the tank solution, pitting and crevice corrosion as well as a high general corrosion rate must be considered possible. It is not possible to estimate the present condition of the tank.

Since the tank is situated in a concrete vault, external corrosion is not a concern. Some of the stainless steel piping is buried and is subject to corrosion by soil. However, based on information cited in Section 4.0, corrosion of stainless steel by ORNL soil is not believed to be severe.

\subsubsection{Results of Leak Tests on the F-501 System}

This section summarizes the results of the leak detection tests conducted on Tank System F-501. Each test was completed with a method appropriate for that element. Each method used has been demonstrated to detect a specified leak rate $(0.2 \mathrm{gal} / \mathrm{hr}$ for tank methods; $0.1 \mathrm{gal} / \mathrm{hr}$ for pipeline methods) with a PD no less than $95 \%$ and a PFa no greater than $5 \%$. The test method used for each component of the system is shown in Section 7.1.5.

\subsubsection{F-501 Tank}

Leak testing of Tank F-501 began in January 1996 and continued at frequent intervals through December 1996, with a total of 18 leak test attempts on the tank during this reporting period. The results of these tests are summarized in Table 4, which shows the date of each test, the volume of LLLW in the tank at the time of the test, the percent of Tank F-501's total volume the test represented, ${ }^{4}$ the test result, and comments pertinent to particular tests. The table shows that Tank F-501 recorded PASS results for twelve of the 18 leak tests conducted during this reporting period, with INCONCLUSIVE results comprising the remainder of the tests. However, there was a PASS result obtained for each of the 12 months in CY96. The reason for the inconclusive results was high measurement noise due to elevated temperatures in the instrumentation cabinet, which caused the temperature sensor to malfunction. The maximum volume for which the tank passed the leak testing during this reporting period was

${ }^{4}$ Although the LLLW tank documentation and drawings show that F-501 has a 400-gal capacity, an overflow drain limits the actual capacity to $192 \mathrm{gal}$. The look-up table used by the tank liquid level monitoring system uses a $100 \%$ capacity of 192 gal for Tank F-501. Since the leak tests are based upon data from the level monitoring system, the percent of capacity here is based on a 192-gal capacity; these values are rounded to the nearest percent. 
170 gal, or $89 \%$ of the total capacity. This is greater than the previously certified level of $139 \mathrm{gal}(72 \%)$ for this tank, which was observed during a leak test on January 6, 1995.

Table 4. Summary of Leak Tests Conducted on Tank F-501

\begin{tabular}{|c|c|c|c|c|}
\hline W & Hor Gallons & \% Capacity & Test Result & Comment \\
\hline $12 \operatorname{Jan} 96$ & 143 & 74 & PASS & \\
\hline 2 Feb 96 & 170 & 89 & PASS & New high level \\
\hline 1 Mar 96 & 66 & 34 & PASS & \\
\hline 5 Apr 96 & 37 & 19 & PASS & \\
\hline 3 May 96 & 67 & 35 & PASS & \\
\hline 7 Jun 96 & 83 & 43 & PASS & \\
\hline $19 \mathrm{Jul} 96$ & 103 & 54 & PASS & \\
\hline 2 Aug 96 & 116 & $\mathrm{n} / \mathrm{a}$ & INCONCLUSIVE & High noise \\
\hline 9 Aug 96 & 101 & 53 & PASS & \\
\hline $6 \operatorname{Sep} 96$ & 117 & $\mathrm{n} / \mathrm{a}$ & INCONCLUSIVE & High noise \\
\hline $13 \operatorname{Sep} 96$ & 115 & 60 & PASS & \\
\hline 11 Oct 96 & 126 & 66 & PASS & \\
\hline 8 Nov 96 & 35 & $\mathrm{n} / \mathrm{a}$ & INCONCLUSIVE & High noise \\
\hline 15 Nov 96 & 43 & 22 & PASS & \\
\hline 6 Dec 96 & 43 & $\mathrm{n} / \mathrm{a}$ & INCONCLUSIVE & High noise \\
\hline $13 \operatorname{Dec} 96$ & 74 & $\mathrm{n} / \mathrm{a}$ & INCONCLUSIVE & High noise \\
\hline $20 \mathrm{Dec} 96$ & 64 & $\mathrm{n} / \mathrm{a}$ & INCONCLUSIVE & High noise \\
\hline $27 \operatorname{Dec} 96$ & 53 & 28 & PASS & \\
\hline
\end{tabular}

The 12 usable compensated volume rate (CVR) values from the leak tests shown above were analyzed (1) to verify that the test method was performing properly in this application, and (2) to confirm that during this assessment period the use and performance of the leak testing method had not deteriorated. This analysis included a statistical examination of the CVR data, as well as a comparison of this year's assessment data with prior data. The analysis and the results are described in Section 7.3.4.3.

\subsubsection{F-501 Pipelines}

The results of the leak detection tests on the testable portion of the F-501 pipeline are summarized in Section 7.1.4.2.1. As described in Section 7.1.4.2.2, all of the remaining portions of the F-501 piping system have been taken out of service and thus no longer require leak testing. 


\subsection{F-501 Testable Pipelines}

The testable portion of the F-501 pipeline system is comprised of a single gravity-fed inlet line leading from Building 3525 to Tank F-501 (see Figure 6). This line was tested in October 1996 and achieved a PASS result. Table 5 summarizes this test.

Table 5. Summary of Leak Test Results for the F-501 Testable Pipelines

\begin{tabular}{|c|c|c|c|c|}
\hline Tind Ex Number & Line Seginent & Test Date & Test Resuit & Comment \\
\hline \hline G30 & $\mathbf{7 4 , 1 4 9}$ & Oct 96 & PASS & \\
\hline
\end{tabular}

\subsection{F-501 Untestable Pipelines}

The untestable portion of the F-501 system included a portion of a no-longer-used line leading from Tank F-201 to Tank F-501, and the discharge line leading from Tank F-501 to Tank W-12. Tank W-12 was taken out of service on October 15, 1995. Since LLLW is being trucked from F-501, instead of transported through the transfer piping, there are no longer any parts of the F-501 discharge piping that require leak testing.

\subsubsection{Analysis of Tank F-501 Leak Test Data}

During this assessment period, a total of 18 leak tests were attempted on Tank F-501; of these, twelve tests resulted in conclusive decisions. Figure 7 shows a time series plot of the CVR data obtained from each of the useable test results. It can be seen from the plot that all 12 of the CVR values are within the inflow decision and outflow decision thresholds, and are thus consistent with a PASS result.

A comparative analysis of the data shown in Figure 7 was performed. The analysis included using the Student's t-test [Mendenhall, 1992] and the Kolmogorov-Smirnov test (KS) [Benjamin and Cornell, 1970]. The Student's t-test is used to determine the significance of the mean of the CVR data. The KS analysis is used to determine if the population of CVR values from F-501 is significantly different from a reference set of CVRs. These statistical tests are fully described in Section 5.4.

Applying the $t$-test to the twelve data values shown above results in a $t$-statistic, $t_{\text {stat, }}$ of 1.99 , while the critical value, $t_{\text {crit }}$, with a $99 \%$ level of confidence is 3.11 . Based upon these numbers, we conclude that the mean of the 1996 CVR data from Tank F-501 is essentially the same as $0 \mathrm{gal} / \mathrm{h}$.

Figure 8 graphically illustrates the KS test applied to the F-501 data. The bold line in the figure shows the cumulative distribution function (CDF) obtained from the CVR data shown in Figure 7, after the mean has been removed from the data. This CDF shows that the total "spread" about the mean in the CVR data is very small. The light line in the figure shows the CDF obtained from the reference set of CVR values (see Section 5.4). The similarity of the data sets defined by the two lines illustrated in Figure 11 is "tested" with the 
KS "goodness-of-fit" test. Here, the test statistic, $\mathrm{KS}_{\text {stat }}$ is 0.32 , while the critical value, $\mathrm{KS}_{\text {crit }}$, is 0.45 . Since $\mathrm{KS}_{\text {stat }}$, the maximum ordinal difference between the CDF and the test $\mathrm{CDF}$, is less than $\mathrm{KS}_{\text {crit, }}$ the two populations are deemed to be equivalent. Thus, it is concluded from the KS analysis that the CY96 population of Tank F-501 CVR values is not different from the reference population of CVR values.

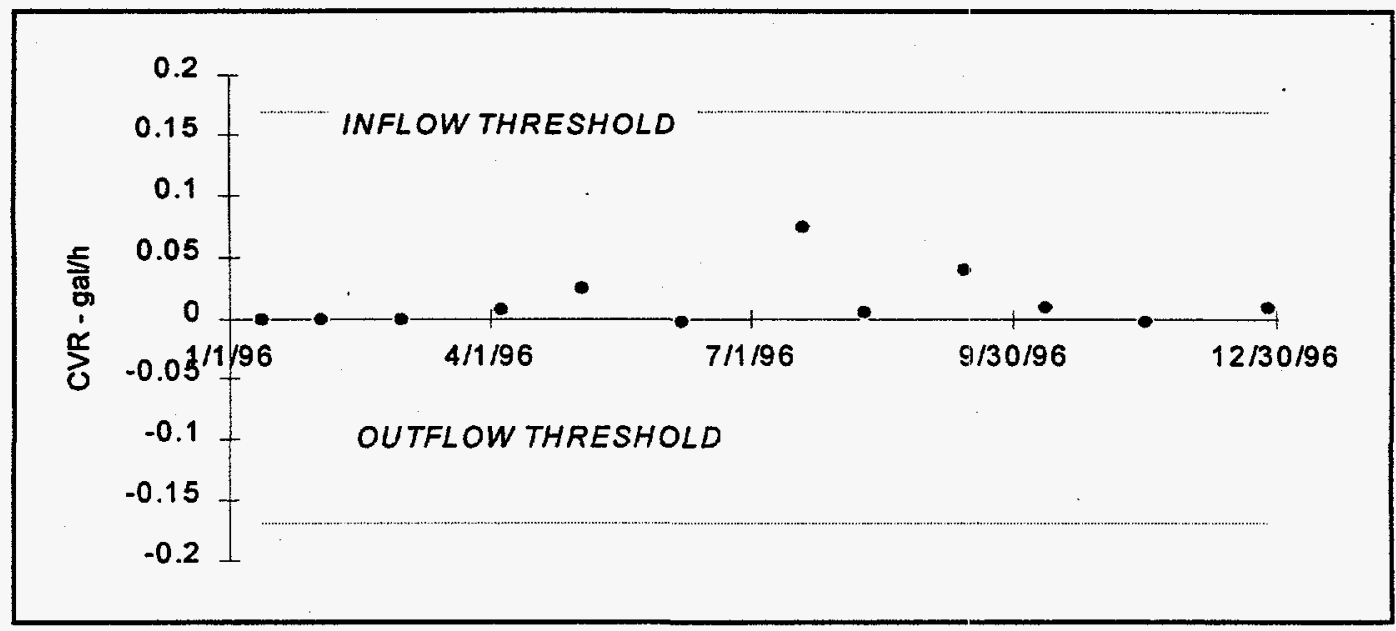

Fig. 7. Time series plot of leak test CVRs from 'Tank F-501.

Table 6 summarizes the statistical analyses of the Tank F-501 CVR data. The table shows that the mean of the CY96 test data is equivalent to zero gallons per hour, and that the population of the CY96 CVR values is not different from the population of CVR values in the reference (or comparison), data set.

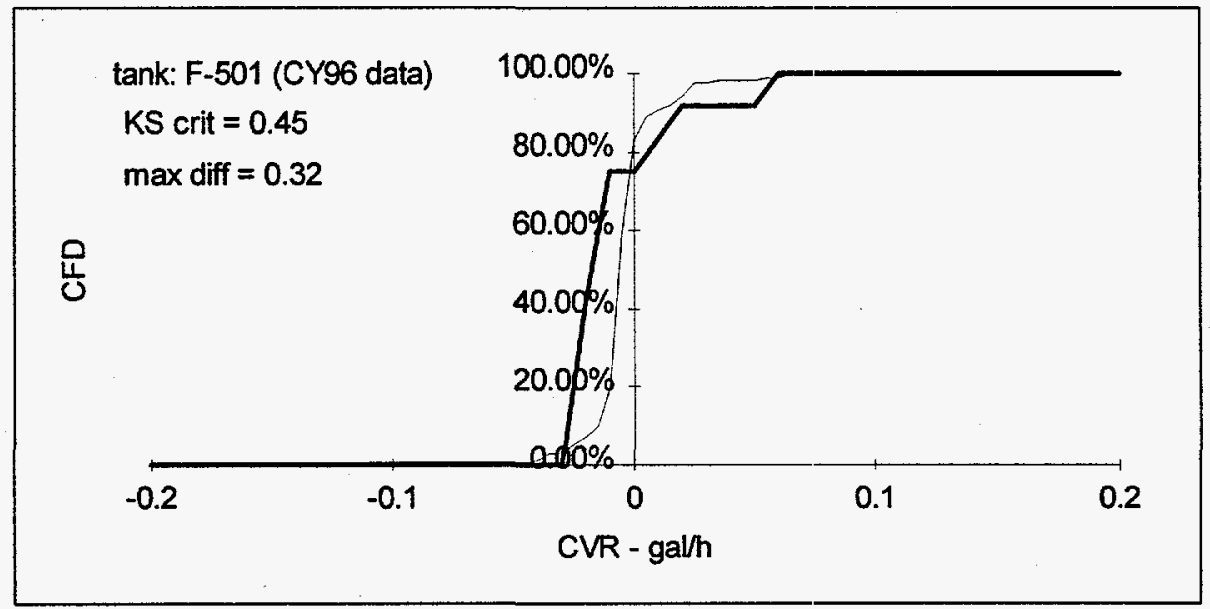

Fig. 8. Cumulative frequency distributions from the reference CVR data (light line) and F-501 CY96 CVR data (bold line). 
Table 6. Summary of Statistical Analyses of F-501 CVR Data $(\mathrm{H} / \mathrm{V}=7.77 \mathrm{gal} / \mathrm{in}$.

\begin{tabular}{|c|c|c|}
\hline & Reference CVR Data & 96 CVR Data \\
\hline $\mathrm{N}$ & 171 & 12 \\
\hline Mean (gal/h) & 0.003 & 0.0013 \\
\hline Variance (gal/h) & 0.016 & 0.123 \\
\hline t-statistic & 1.99 \\
\hline t-critical (1\%) & \\
\hline t-test Inference & \\
\hline KS-statistic & \\
\hline KS-critical (1\%) & \\
\hline Ks-test Inference & \\
\hline
\end{tabular}

\subsubsection{Findings and Conclusions}

The findings of this report are based on (1) a review of available tank design drawings, (2) a qualitative assessment of corrosion on the tank and pipelines, and (3) leak testing results from the tank and testable pipelines.

Review of the design drawings indicated that the tank was designed in accordance with acceptable practices defined by ASTM and ASME. The design drawings revealed a sound design of the F-501 Tank.

The corrosion assessment determined that with the present and past uses of the tank system, all forms of corrosion on the interior walls of the tank and associated piping may be considered possible.

Leak testing of Tank F-501 was successfully completed by the DP method in 12 tests. The tank passed each of the 12 tests. Six tests resulted in inconclusive results.

One testable pipeline exists for this tank system (G30). This line passed the EVB approved test method.

All untestable lines associated with Tank F-501 have been removed from service and do not require certification.

All of these factors were considered in determining certification of the F-501 Tank System components. Table 7 summarizes the elements of the tank system which were certified and the conditional limits on their certifications. 
Table 7. Summary of F-501 Tank System Testing and Certification

\begin{tabular}{|c|c|c|c|c|c|c|c|}
\hline \multicolumn{2}{|c|}{$\begin{array}{l}\text { System } \\
\text { Component }\end{array}$} & $\begin{array}{c}\text { Length } \\
\text { (ft) } \\
\end{array}$ & $\begin{array}{r}\text { Tested } \\
\text { (Yes } / \text { No) } \\
\end{array}$ & $\begin{array}{l}\text { Leak Test } \\
\text { Method } \\
\end{array}$ & $\begin{array}{r}\text { Test } \\
\text { Result } \\
\end{array}$ & Certification & $\begin{array}{c}\begin{array}{c}\text { Certification } \\
\text { Level }\end{array} \\
\end{array}$ \\
\hline \multicolumn{2}{|c|}{ Tank F-501 } & & Yes & DP & PASS & Yes & $89 \%$ \\
\hline \multicolumn{2}{|c|}{ LS-61* } & 202 & No & NT & NT & No & NA \\
\hline \multicolumn{2}{|l|}{ LS-74 } & 9 & Yes & EVB & PASS & Yes & $32 \mathrm{gph}$ \\
\hline \multicolumn{2}{|c|}{ LS-149 } & 12 & Yes & EVB & PASS & Yes & $32 \mathrm{gph}$ \\
\hline \multicolumn{2}{|c|}{ LS-189* } & 8 & No & NT & NT & No & NA \\
\hline \multicolumn{2}{|c|}{ LS-194* } & 7 & No & NT & NT & No & NA \\
\hline \multicolumn{2}{|c|}{ LS-154* } & 18 & No & NT & NT & No & $\mathrm{NA}$ \\
\hline $\begin{array}{l}* \\
\text { DP } \\
\text { EVB } \\
\text { gph } \\
\text { LS } \\
\text { NT } \\
\text { NA } \\
\end{array}$ & \multicolumn{7}{|c|}{$\begin{array}{l}\text { Out of Service } \\
\text { Differential Pressure } \\
\text { Enhanced volume balancing } \\
\text { Gallons per hour } \\
\text { Line segment } \\
\text { Not tested } \\
\text { Not applicable }\end{array}$} \\
\hline
\end{tabular}




\subsubsection{Certification}

Based on the results of the design drawings review, the qualitative corrosion assessment, and the results of the leak testing program, it is my professional opinion that Tank F-501 retains sufficient structural integrity to contain liquids at operating levels up to the maximum level which achieved a PASS during the testing program. Also, based upon the results of the pipeline tests, it is my professional opinion that Line Segments 74 and 149 retain sufficient integrity to contain liquids up to a flow rate of $32 \mathrm{gph}$. Table 7 provides a summary description of the certifications for the F-501 Tank System. If future testing is conducted at larger pipeline flows and greater tank levels, then certification levels may also increase.

It is recommended that leak detection and line testing be continued, using EPA and TDEC approved methods to support annual certification until this system has been removed from operation or replaced.

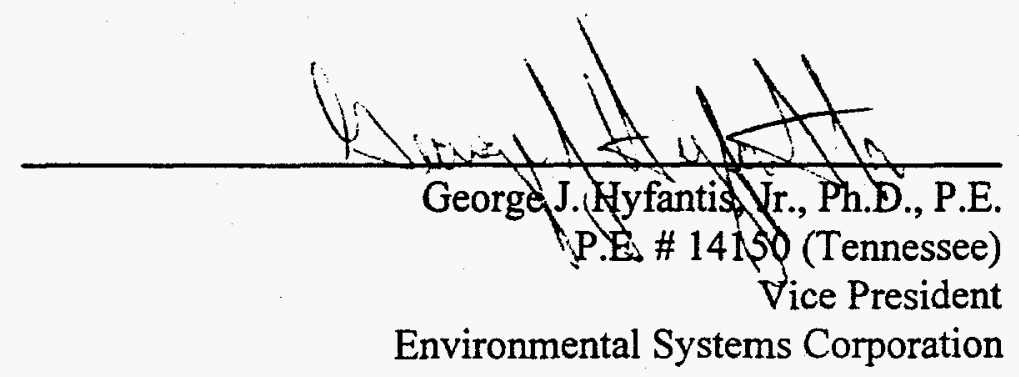





\subsection{W-16 Tank System}

The W-16 Tank System is located near the South Tank Farm, as shown in Figure 1. The tank system previously collected LLLW waste from Building 3026 and discharged these liquids by steam jet to Valve Box 1 at the Central Waste Collection Header. The system consists of Tank W-16 and nine line segments connected to the tank system. Because the lines and tank are all singly contained, the tank system has been classified as Category C.

\subsubsection{W-16 Tank Description}

Tank W-16 is a 1,000 gallon, buried, singly contained tank on a concrete pad. Installed in 1951, Tank W-16 is mounted vertically on 3/8" thick stainless steel angle legs welded to the side of the tank near the base and bolted to an 8 " thick concrete pad. The tank is constructed of 347 stainless steel and has a wall thickness of $1 / 4 "$. The outside diameter of the tank is 66", with a length of 88". The working volume of the tank is 700 gallons. The drawing for Tank W-16 is provided as Figure 9.

The tank is equipped with ten nozzles and one float gauge on the top of the tank. All the nozzles are located around an unknown radius of the tank center, and the float gauge is located in the center of the tank. Four lifting lugs are positioned symmetrically around the edges near the top of the tank. The excavation pit was backfilled with crushed stone to the top of the tank. A schematic of the tank system with numbered line segments is provided as Figure 10.

\subsubsection{W-16 Pipeline Descriptions}

Nine line segments make up the portion of the LLLW pipeline system belonging to Tank W-16. Characteristics of the nine lines are listed in Table 8, and the line segments are shown in Figure 13. All pipelines associated with the W-16 Tank System are constructed of 347 stainless steel and were installed in 1951.

As shown in Figure 13, W-16 has one inlet and one discharge pipeline. The remaining eight line segments are not directly connected to Tank W-16.

Line Segment 145 is the pipeline that transports waste into Tank W-16. Line Segment 145 is a gravity-fed, 200', 3" diameter stainless steel line that connects Building 3026D to Tank W-16. This line has been removed from service. The remaining eight pipelines are all components of the tank discharge pipeline system. Line Segment 163 is a $14^{\prime}$ long section of 1" diameter suction line leading from the tank to a steam jet. Line Segments 181, 181 A, 181B, and $181 \mathrm{C}$ are each $4^{\prime}$ long sections of $2^{\prime \prime}$ diameter line that make up a manifold system for the discharge of Tanks W-16, W-17 and W-18 (nodes 4 to 11,11 to 13,12 to 13 and 14 to 13 , respectively). The line leaving the discharge manifold, Line Segment 24, is a 55' section of 2" diameter line. Each of these lines is pressurized by steam jet, which is used to transfer the liquids. 


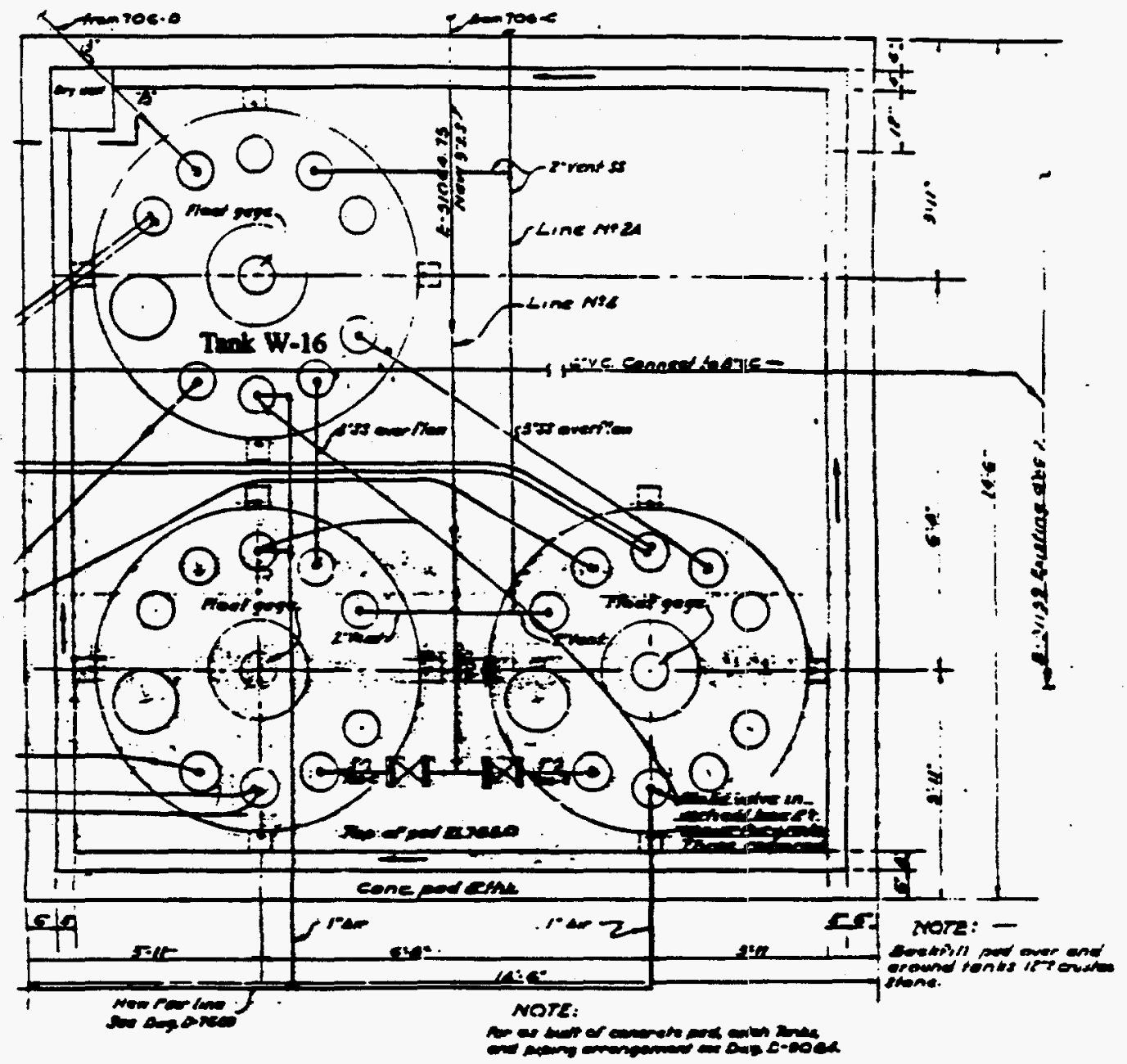

FIGURE 9 As-built Drawing of Tank W-16 Installation 


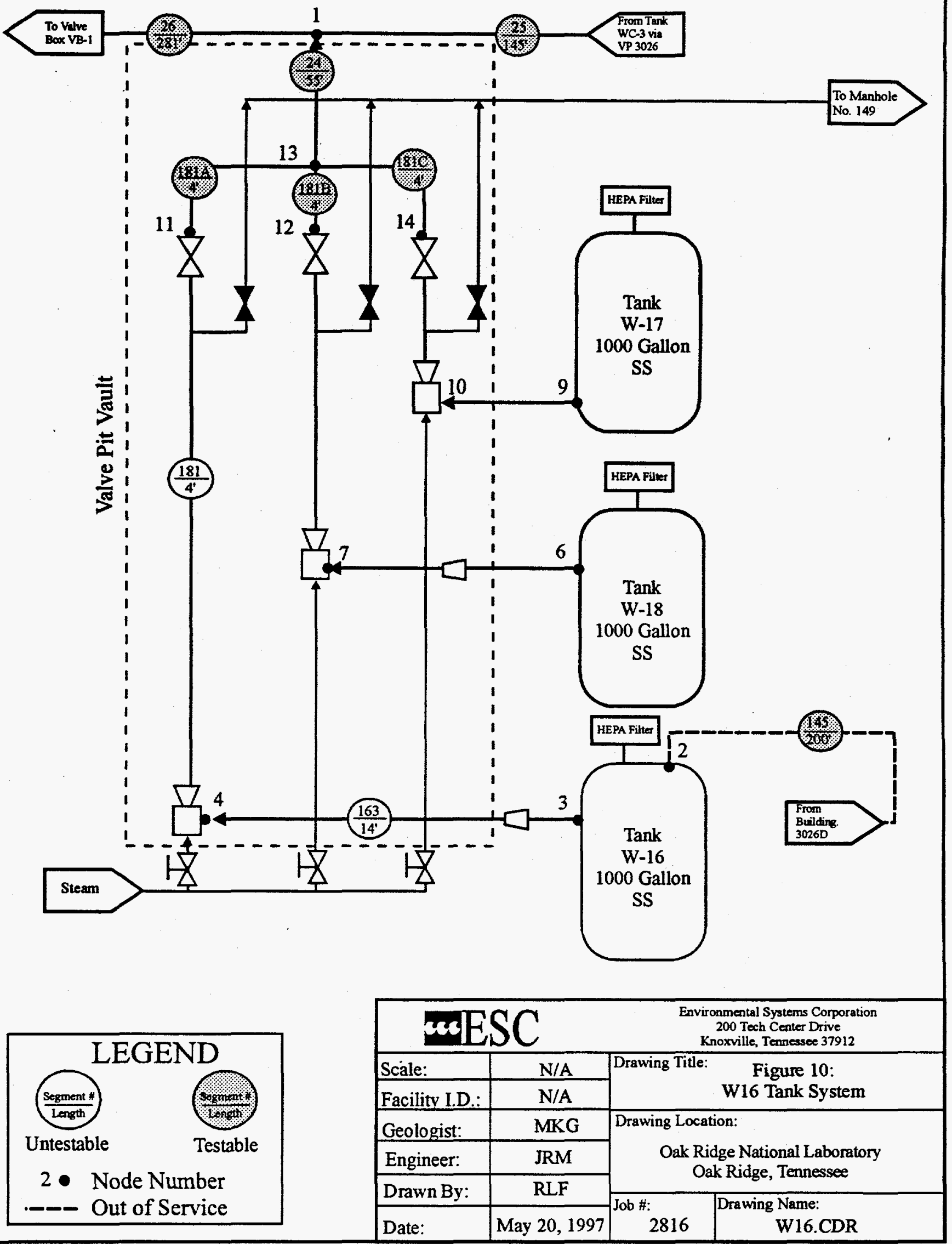


Line Segment 24 connects to a pipeline leading from the discharge of Tanks WC-3. and WC-19 and continues to Valve Box No. 1 (VB-1). Two segments of 2" diameter line make up this pipeline. Line Segment 25 is a 145' long, pressurized line that runs from Tank WC-3 and WC-19 discharge connection to the connection with Line Segment 24. Line Segment 26 is a $281^{\prime}$ long pressurized line that runs from the Segment 24 connection to VB-1.

Line Segments 24, 25, 26, 181 A, 181B and $181 \mathrm{C}$ are all designated as Tank W-16 lines. These lines are not isolated from Tank WC-3 and Tank WC-19 discharge piping, all of which are denoted as P37. Therefore, these six lines were leak tested with the WC-3 Tank System. The line segments which are part of P37 but defined as part of the W-16 Tank System are shown in Table 8. Leak test results are included in Section 7.2.4.

Table 8. Characteristics of Line Segments Evaluated as a Part of Tank System W-16

\begin{tabular}{|c|c|c|c|c|c|c|c|c|c|c|}
\hline \multicolumn{2}{|c|}{ Line Segment } & 24 & 25 & 26 & $145^{\star}$ & 163 & 181 & 181A & $181 \mathrm{~B}$ & $181 \mathrm{C}$ \\
\hline \multicolumn{2}{|c|}{ Node Numbers } & 13 to 1 & $\begin{array}{c}\text { VP } 3026 \\
\text { to } 1\end{array}$ & 1 to VB-1 & 3026 to 2 & 3 to 4 & 4 to 11 & 11 to 13 & 12 to 13 & i4 to 13 \\
\hline \multicolumn{2}{|c|}{ Index Number } & P37 & P37 & P37 & G17 & & & P37 & P37 & P37 \\
\hline \multicolumn{2}{|l|}{ Diameter (in) } & 2 & 2 & 2 & 3 & 1 & 2 & 2 & 2 & 2 \\
\hline \multicolumn{2}{|l|}{ Material } & $347 \mathrm{SS}$ & $347 \mathrm{SS}$ & $347 \mathrm{SS}$ & $347 \mathrm{SS}$ & $347 \mathrm{SS}$ & $347 \mathrm{SS}$ & $347 \mathrm{SS}$ & & 347 SS \\
\hline \multicolumn{2}{|l|}{ Length $(\mathrm{ft})$} & 55 & 145 & 281 & 200 & 14 & 4 & 4 & 4 & 4 \\
\hline \multicolumn{2}{|l|}{ Volume (gal) } & 10 & 25 & 49 & 77 & 2 & 1 & 1 & 1 & 1 \\
\hline \multicolumn{2}{|l|}{$\begin{array}{l}\text { Transfer } \\
\text { Method }\end{array}$} & SJ & SJ & SJ & $\mathrm{G}$ & SJ Suct. & SJ & SJ & SJ & SJ \\
\hline \multicolumn{2}{|l|}{ Install Date } & 1951 & 1951 & 1951 & 1951 & 1951 & 1951 & 1951 & 1951 & 1951 \\
\hline \multicolumn{11}{|c|}{$\begin{array}{ll}\text { G } & \text { Gravity } \\
\text { SJ } & \text { Steam jet pump } \\
\text { Suct. } & \text { Suction } \\
\text { SS } & \text { Stainless Steel } \\
* & \text { Out of service } \\
\end{array}$} \\
\hline
\end{tabular}

\subsubsection{Corrosion Assessment of the W-16 Tank System}

Tank W-16 formerly collected waste from Building, 3026D, but the tank has not been used for that purpose since 1990 . The $\mathrm{pH}$ of the tank solution is maintained at highly alkaline levels, and corrosion damage since 1990 should have been very slight. Corrosion damage that may have occurred when the system was used for its intended purpose (radioisotope production and decontamination) cannot be assessed.

Some of the stainless steel piping is buried and is subject to corrosion by soil. However, based on information cited in Section 4.0, corrosion of stainless steel by ORNL soil is not believed to be severe. 


\subsubsection{Results of Leak Tests on the W-16 System}

This section summarizes the results of the leak detection tests conducted on Tank System W-16 (the tank and its associated pipelines). Each test was completed with a method appropriate for that element. Each method used has been demonstrated to detect a specified leak rate $(0.2 \mathrm{gal} / \mathrm{hr}$ for tank methods; $0.1 \mathrm{gal} / \mathrm{hr}$ for pipeline methods) with a PD no less than 95\% and a PfA no greater than 5\%. The test method used for each element is shown in Section 7.5.5.

\subsubsection{W-16 Tank}

Leak testing of Tank W-16 began in January 1996 and continued at monthly intervals through December 1996, with a total of 12 leak test attempts on the tank during this reporting period. The results of these tests are summarized in Table 9, which shows the date of each test, the volume of LLLW in the tank at the time of the test, the percent of Tank W-16's total volume the test represented, ${ }^{5}$ the test result, and comments pertinent to particular tests. The table shows that Tank W-16 recorded PASS results for all 12 of the monthly leak tests. The maximum volume for which the tank passed the leak testing during this reporting period was $180 \mathrm{gal}$, or $16 \%$ of the total capacity. This is less than the previously certified level of 382 gal (33\%) for this tank, which was achieved during a leak test on August 5, 1994.

Table 9. Summary of Leak Tests Conducted on Tank W-16

\begin{tabular}{|c|c|c|c|c|}
\hline Date & \# of Gallons & \% Capacity & Test Result & Comment \\
\hline \hline 12 Jan 96 & 180 & 16 & PASS & \\
\hline 2 Feb 96 & 176 & 15 & PASS & \\
\hline 1 Mar 96 & 177 & 15 & PASS & \\
\hline 5 Apr 96 & 166 & 14 & PASS & \\
\hline 3 May 96 & 166 & 14 & PASS & \\
\hline 7 Jun 96 & 167 & 15 & PASS & \\
\hline 22 Jul 96 & 170 & 15 & PASS & \\
\hline 2 Aug 96 & 171 & 15 & PASS & \\
\hline 6 Sep 96 & 124 & 11 & PASS & \\
\hline 11 Oct 96 & 126 & 11 & PASS & \\
\hline 8 Nov 96 & 141 & 12 & PASS & \\
\hline 6 Dec 96 & 118 & 10 & PASS & \\
\hline
\end{tabular}

${ }^{5}$ WOCC look-up tables show $100 \%$ capacity for W-16 as 1,148 gal. The percent capacity shown in the table is based on this number. 
The 12 usable compensated volume rate (CVR) data values from these leak tests were analyzed (1) to verify that the test method was performing properly in this application and (2) to confirm that during this assessment period the use and performance of the leak testing method had not deteriorated. This analysis included a statistical examination of the CVR data, as well as a comparison of this year's assessment data with prior data. The analysis and the results are described in Section 7.2.4.3

\subsubsection{W-16 Pipelines}

The results of the leak detection test on the testable W-16 pipelines are summarized in Section 7.2.4.2.1. An assessment of the integrity of these lines based upon transfer records is summarized in Section 7.2.4.2.2.

\subsection{W-16 Testable Pipelines}

There are two testable pipelines associated with the W-16 tank system. One is a gravity-fed line leading from Building 3026D to Tank W-16. This line is out of service and will not be leak tested.

The second testable pipeline in the W-16 system is a discharge line that joins W-16. to the WC-3 discharge line and cannot be isolated from that system. P37 is comprised of six separate segments; it was tested on August 8, 1997 and achieved a PASS results. Table 10 summarizes the test.

Table 10. Summary of Leak Test Results for the WC-16 Testable Lines

\begin{tabular}{|c|c|c|c|c|}
\hline $\begin{array}{c}\text { Index } \\
\text { Number }\end{array}$ & Line Segment & Test Date & Test Result & Comment \\
\hline P37 & $24,25,26,181 \mathrm{~A}, 181 \mathrm{~B}, 181 \mathrm{C}$ & 8 Aug 97 & PASS & \\
\hline
\end{tabular}

\subsection{W-16 Untestable Pipelines}

The untestable portion of the W-16 system (line segments 181 and 163) carries transfers from Tank W-16 through VB-1 to Tank W-22. WOCC transfer records show that during the period from January 1996 through December 1996, there was one transfer made from W-16 to W-22. Table 11 summarizes this transfer, for which the expected error was 141 gal. The recorded transfer showed a difference in input/output volume that was less than the maximum expected error; therefore, it is concluded that there were no significant differences during this assessment period. 
Table 11. Summary of Transfers between W-16 and W-22 from January through December 1996

\begin{tabular}{|c|c|c|c|c|c|c|}
\hline 3. & 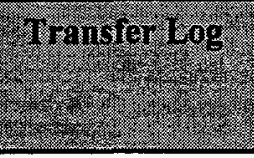 & 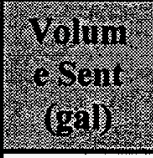 & 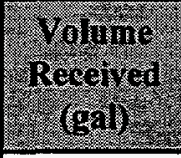 & 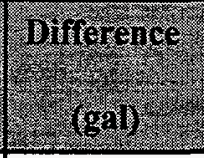 & 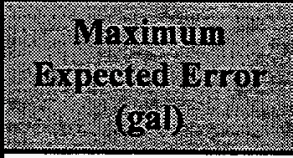 & 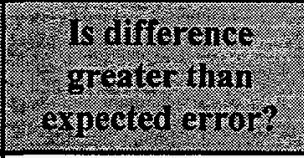 \\
\hline 5 Sep 96 & $W-16$ to $W-22$ & 68 & 68 & 0 & 141 & No \\
\hline
\end{tabular}

\subsubsection{Analysis of Tank W-16 Leak Test Data}

During this assessment period, a total of 12 leak tests were attempted on Tank W-16, all of which resulted in conclusive decisions. Figure 11 shows a time series plot of the CVR data obtained from each of the usable test results. It can be seen from the plot that all 12 of the CVR values are within the inflow decision and outflow decision thresholds, and are thus consistent with a PASS result.

A comparative analysis of the data shown in Figure 11 was performed. The analysis included using the Student's t-test [Mendenhall, 1992] and the Kolmogorov-Smirnov test (KS) [Benjamin and Cornell, 1970]. The Student's t-test is used to determine the significance of the mean of the CVR data. The KS analysis is used to determine if the population of CVR values from W-16 is significantly different from a reference set of CVRs. These statistical tests are fully described in Section 5.4. Applying the t-test to the 12 data values shown above results in a $t$-statistic, $t_{\text {stat }}$, of 1.34 , while the critical value, $t_{\text {crit, }}$ with a $99 \%$ level of confidence is 3.11 . Based upon these numbers, we conclude that the mean of the 1996 CVR data from Tank W-16 is equivalent to $0 \mathrm{gal} / \mathrm{h}$.

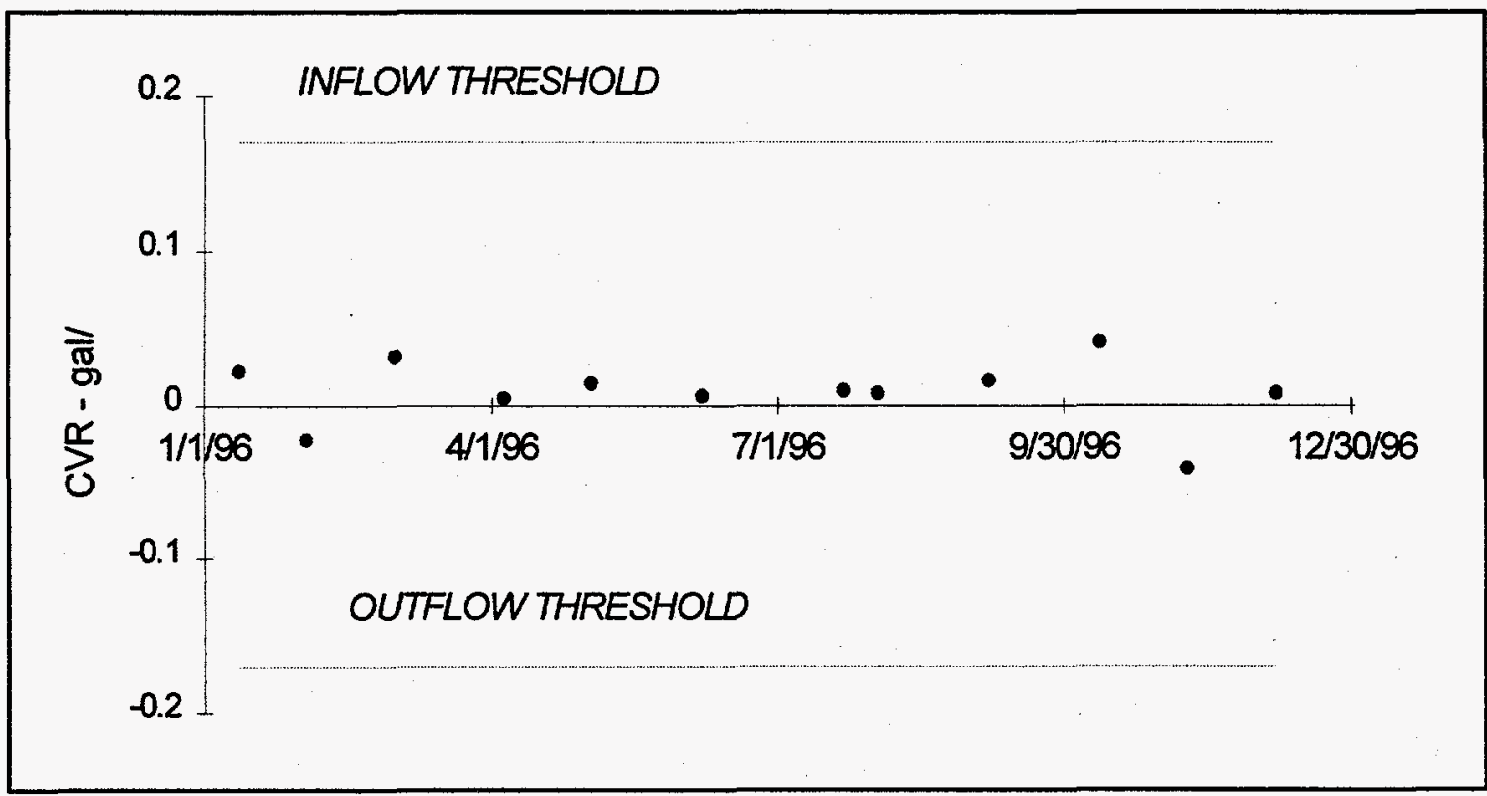

Fig. 11. Time series plot of leak test CVRs from Tank W-16. 
Figure 12 graphically illustrates the Kolmogorov-Smirnov test applied to the W-16 data. The bold line in the figure shows the cumulative distribution function (CDF) obtained from the CVR data in Figure 11, after the mean has been removed from the data. This CDF shows that the total "spread" about the mean in the CVR data ranges from about $-0.05 \mathrm{gal} / \mathrm{h}$ to about $+0.03 \mathrm{gal} / \mathrm{h}$. The light line in the figure shows the CDF obtained from the reference set of CVR values (see Section 5.4). The similarity of the data sets, defined by the two lines illustrated in Figure 11 is "tested" with the KS "goodness-of-fit" test. Here, the test statistic, $\mathrm{KS}_{\text {stat }}$, is 0.15 , while the critical value, $\mathrm{KS}_{\text {crit }}$, is 0.47 . Since $\mathrm{KS}_{\text {stat }}$, the maximum ordinal difference between the $\mathrm{CDF}$ and the test $\mathrm{CDF}$, is less than $\mathrm{KS}_{\text {crit }}$, the two populations are deemed to be equivalent. Thus, it is concluded from the KS analysis that the CY96 population of Tank W-16 CVR values is not different from the reference population of CVR values.

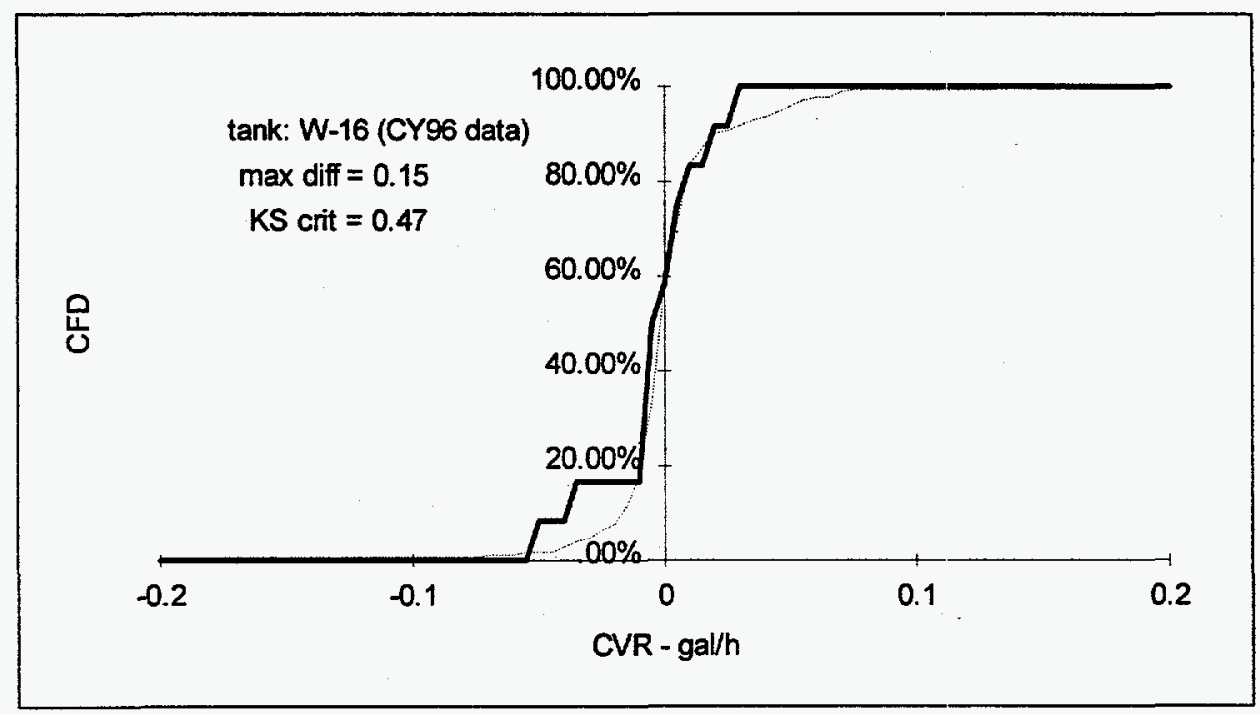

Figure 12. Cumulative frequency distributions from reference CVR data (light line) and W16 CY96 CVR data (bold line).

Table 12 summarizes the statistical analyses of the Tank W-16 CVR data. The table shows that the mean of the CY96 test data is equivalent to $0 \mathrm{gal} / \mathrm{h}$, and that the population of the CY96 CVR values is not different from the population of CVR values in the reference (or comparison) data set. 
Table 12. Summary of Statistical Analyses of W-16 CVR Data (HTV = 14.72 gal/in.)

\begin{tabular}{|l|c|c|}
\hline & Reference CVR Data & 96 CVR Data \\
\hline $\mathrm{N}$ & 171 & 12 \\
\hline Mean (gal/h) & 0.005 & 0.009 \\
\hline Variance (gal/h) & & 0.022 \\
\hline t-statistic & 0.027 & 1.34 \\
\hline t-critical (1\%) & \\
\hline t-test Inference & \\
\hline KS-statistic & \\
\hline KS-critical (1\%) & \\
\hline KS-test Inference & \\
\hline
\end{tabular}

\subsubsection{Findings and Conclusions}

The findings of this report are based on (1) a review of available tank design drawings, (2) a qualitative assessment of corrosion on the tank and pipelines, and (3) leak testing results from the tank and testable pipelines. Review of the design drawings revealed an abundance of nozzles into the tank that were not connected to pipelines. However, because the unused nozzles are located on the top of the tank, there is no concern that leakage could occur at those locations as long as the tank is operating at less than full capacity. The design drawings revealed a sound design of the W-16 Tank.

During the corrosion assessment, it was determined that with the recent use of the tank system, all forms of corrosion on the interior walls of the tank and associated piping should be nonexistent. Corrosion damage that may have occurred when the tank was used in past environments cannot be assessed. Furthermore, an analysis of the general aspects of corrosion at ORNL revealed that corrosion of stainless steel by ORNL soil is not believed to be severe.

Leak testing of Tank W-16 was completed by the DP method in 12 tests. The tank passed all of the 12 tests.

Seven of the eight testable line segments passed leak testing by methods discussed previously. The eighth testable line segment is not used and was not leak tested.

Transfer logs were used to qualitatively assess the pipelines which are not testable by currently approved methods. Transfer logs reveal that one transfer was made in September 1996 between W-16 and W-22. The difference in the volume sent and the volume received did not exceed the expected error. The volume of the transfer along with 
the latest qualitative assessment of the pipelines are reported to EPA and TDEC in the "Quarterly Highlights for LLLW Tank System Activities." Although a limited evaluation of the untestable pipelines can be made using transfer logs, no transfers occurred during this reporting period.

All of these factors were considered in determining certification of the W-16 Tank System components. Table 13 summarizes the elements of the tank system which were certified and the conditional limits on their certifications.

Table 13. Summary of W-16 Tank System Testing and Certification

\begin{tabular}{|l|c|c|c|c|c|c|}
\hline $\begin{array}{l}\text { System } \\
\text { Component }\end{array}$ & $\begin{array}{c}\text { Length } \\
\text { (ft) }\end{array}$ & $\begin{array}{c}\text { Tested } \\
\text { (Yes/No) }\end{array}$ & $\begin{array}{c}\text { Leak Test } \\
\text { Method }\end{array}$ & $\begin{array}{c}\text { Test } \\
\text { Result }\end{array}$ & $\begin{array}{c}\text { Certification } \\
\text { Certification } \\
\text { Level }\end{array}$ \\
\hline Tank W-16 & & Yes & DP & PASS & Yes & $16 \%$ \\
\hline LS-24 & 55 & Yes & GPD & PASS & Yes & Full Flow \\
\hline LS-25 & 145 & Yes & GPD & PASS & Yes & Full Flow \\
\hline LS-26 & 281 & Yes & GPD & PASS & Yes & Full Flow \\
\hline LS-145* & 200 & No & NT & NT & No & NA \\
\hline LS-163 & 14 & No & NT & NT & No & NT \\
\hline LS-181 & 4 & No & NT & NT & No & NT \\
\hline LS-181A & 4 & Yes & GPD & PASS & Yes & Full Flow \\
\hline LS-181B & 4 & Yes & GPD & PASS & Yes & Full Flow \\
\hline LS-181C & 4 & Yes & GPD & PASS & Yes & Full Flow \\
\hline $\begin{array}{l}\text { DP Differential Pressure } \\
\text { EVB Enhanced volume balancing } \\
\text { GPD Gas pressure decay } \\
\text { INC Inconclusive } \\
\text { LS Line segment } \\
\text { NT Not tested } \\
* \\
\text { Out of service } \\
\text { Not Applicable }\end{array}$ & & & & & \\
\hline
\end{tabular}




\subsubsection{Certification}

Based on the results of the design drawings review, the qualitative corrosion assessment, and the results of the leak testing program, it is my professional opinion that Tank W-16 retains sufficient structural integrity to contain liquids at operating levels up to the maximum level which achieved a PASS during the testing program. Also, based upon the results of pipeline tests, it is my professional opinion that Line Segments 24, 25, 26, 181A, 181B, and $181 \mathrm{C}$ retain sufficient integrity to carry liquids up to the full flow potential of these segments. Table 13 provides a summary description of the certifications for the W-16 Tank System. If future testing is conducted at greater tank levels, then certification levels may also increase.

It is recommended that leak detection and line testing be continued using EPA and TDEC approved methods to support annual certification, until this system has been removed from operation or replaced.

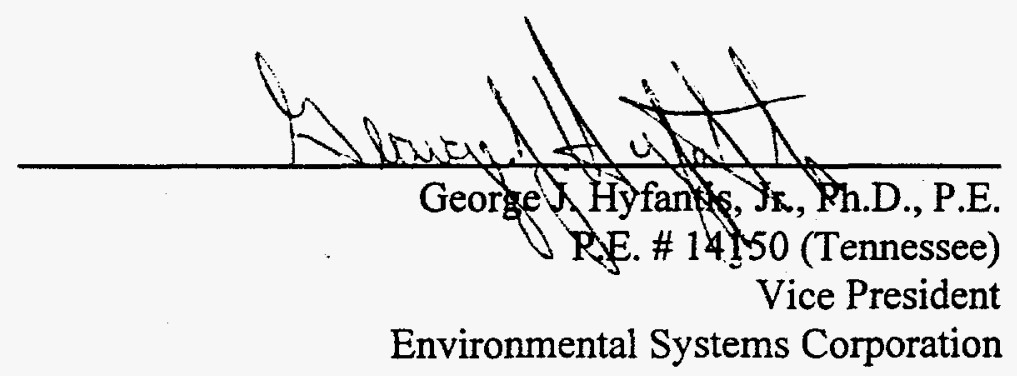




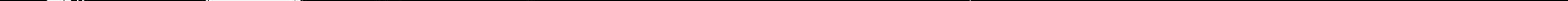




\subsection{WC-2 Tank System}

The WC-2 Tank System is located near the northeast corner of Building 3092, as shown in Figure 1. The WC-2 Tank System collects LLLW from Buildings 3038 and hot off-gas (HOG) duct condensate from a HOG drain trap in Isotope Circle. The tank system consists of Tank WC-2 and nine line segments connected to the system. Because the lines and tank are all singly contained, the tank system has been classified as Category C.

\subsubsection{WC-2 Tank Description}

Tank WC-2 is a 1,000 gallon, buried, singly contained tank. Installed in 1951, WC-2 is mounted vertically to an $8^{\prime}-0^{\prime \prime} \times 8^{\prime}-0^{\prime \prime} \times 0^{\prime}-8^{\prime \prime}$ concrete pad. The tank is constructed of 347 stainless steel and was designed with a $1 / 4$ " wall thickness. All materials welded to the tank are also 347 stainless steel. The tank is constructed with 3/8" thick ASME flanged and dished head on top and 1/4" thick ASME flanged and dished head on the bottom. The outside diameter of the tank is $5^{\prime}-6 "$ ", with a overall height of $77^{\prime} 4-1 / 4^{\prime \prime}$. The design drawing for Tank WC-2 is provided in Figure 13.

The tank is equipped with nine 3 " diameter flanged nozzles, one 8 " diameter flanged nozzle, and one 16" diameter manhole opening. The flanged nozzles are located around a $2^{\prime}-0$ " radius of the tank center, and the manhole is located in the center of the tank. Each of the 3" diameter flanges are fitted to be secured by four 5/8" diameter bolts, and the manhole is fitted to be secured by sixteen $3 / 4$ " diameter bolts. All flanges are slip on welding type. All of the necessary welds on the tank are specified in accordance with code from the ASTM for unfired pressure vessels. At the time of construction, the welds were specified to provide substantially the same composition as adjacent unwelded metal.

The pit containing the tank was constructed with a one and one-half foot deep earthen sump located on the northeast corner of the tank pad. An 8 " diameter vitrified clay pipe, installed 6 " from the bottom of the sump, extended to the surface of the backfilled tank pit and is currently used as a tank pit sample point.

During the tank installation, the tank pit was backfilled with 1-1/2" diameter stone to a minimum depth of one foot above the concrete pad. The remainder of the tank pit was backfilled with earthen materials.

Tank WC-2 was designed to receive material from four sources, which originated in Buildings 3038 and 3028, an isotope off-gas duct condensate drain in Building 3092, and in a pump pit used to contain any spills or leaks that may occur within the vault containing the pump that discharges the liquids from the tank. The tank no longer receives waste from Building 3028. A schematic of the tank system with numbered line segments is provided in Figure 14. 


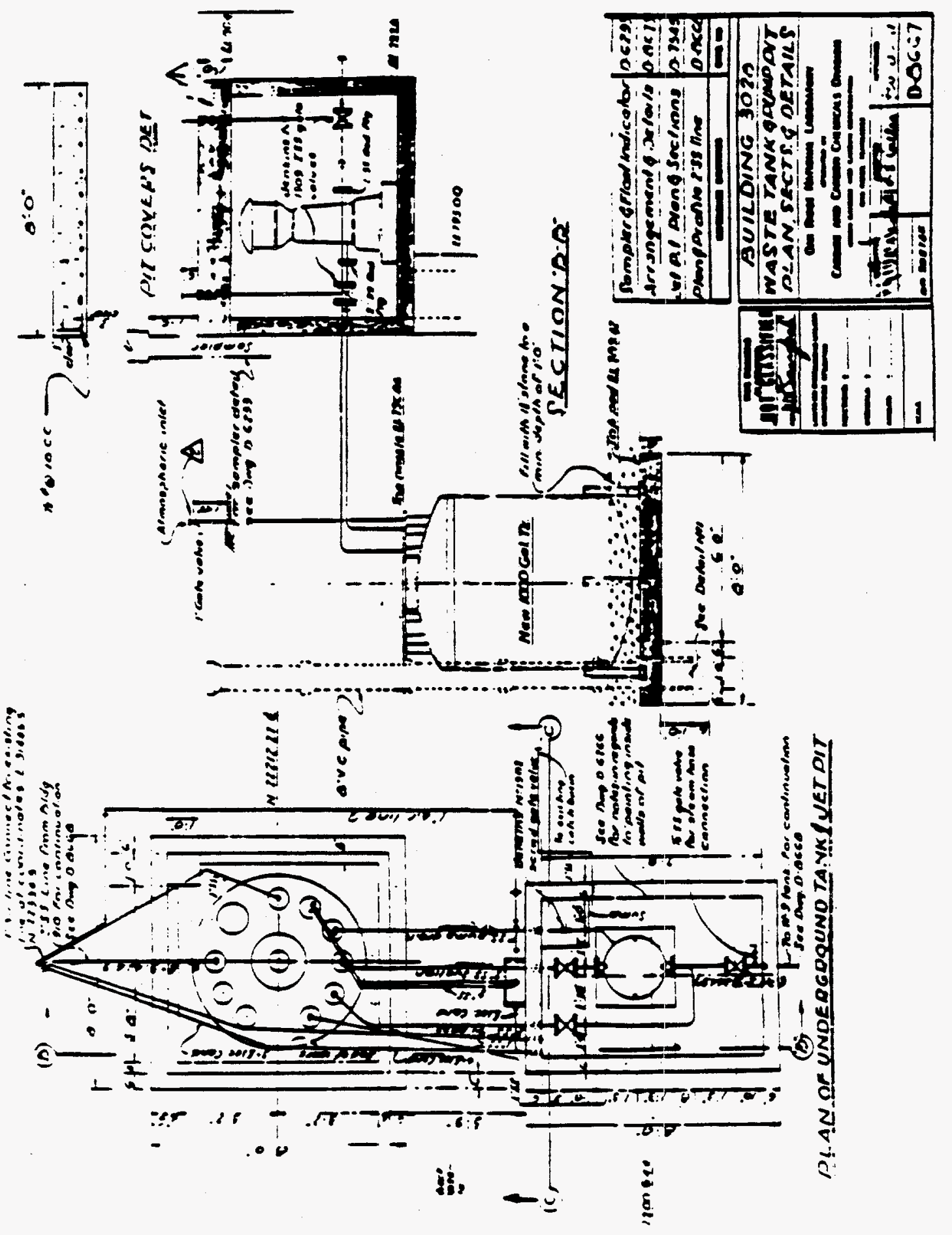

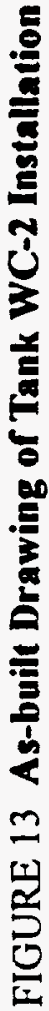




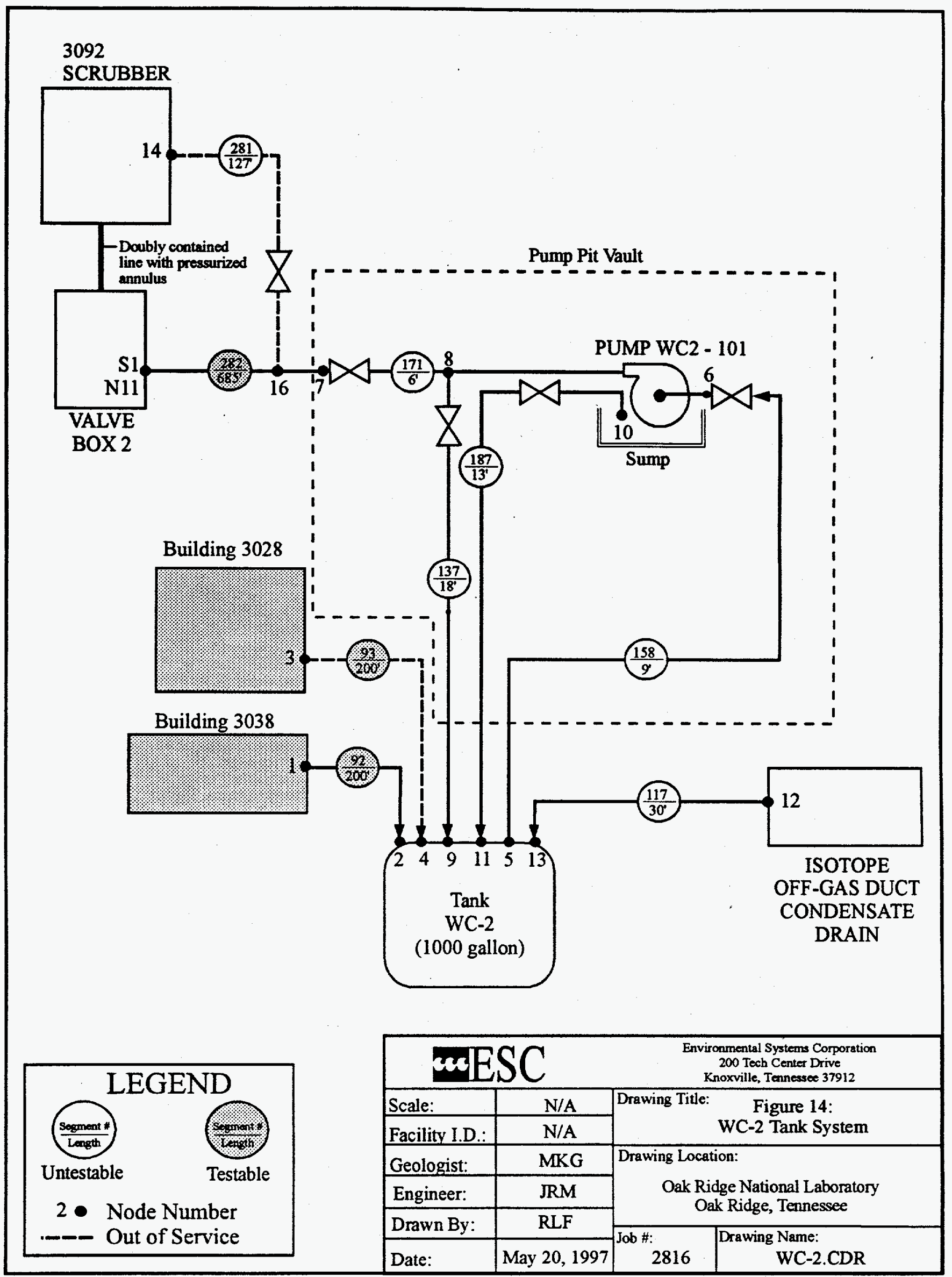




\subsubsection{WC-2 Pipeline Descriptions}

Nine line segments make up the portion of the LLLW pipeline system belonging to Tank WC-2. Characteristics of these nine lines are listed in Table 14, and line segments are shown in Figure 27. All pipelines associated with the WC-2 Tank System are constructed of 347 stainless steel and were installed in 1951.

As shown in Figure 13, WC-2 has five inlet pipelines and one discharge pipeline. The remaining three line segments are not directly connected to Tank WC-2. Two of the gravity drain lines to the tank were originally testable and the main section of the pressurized discharge pipeline is testable.

Line Segments 92 and 93 are inlets for waste coming into Tank WC-2. Line Segment 92 is a $200^{\prime}$ long, $2^{\prime \prime}$ diameter gravity-fed pipeline leading from Building 3038 to Tank WC-2 (node 1 to node 2 in Figure 28). Line Segment 93 is a 200' long, 2" diameter gravity-fed pipeline leading from Building 3028 to Tank WC-2 (node 3 to node 4). This line has been taken out of service and no future use is planned. The remaining inlets into the tank are made up of Line Segments 117, 137, and 187. Line Segments 117 and 137 are 2" diameter inlets and Line Segment 187 is a $1^{\prime \prime}$ diameter inlet. Line Segment 117 is a $30^{\prime}$ long gravityfed element that drains a hot off gas (HOG) duct condensate trap (node 12 to node 13). Line Segment 137 is a $18^{\prime}$ long recirculation line for the WC-2/101 pump back into WC-2 (node 8 to node 9). Line Segment 187 is a 13' long gravity-fed line that drains the WC-2/101 pump pit to WC-2 (node 10 to node 11). Line Segments 117 and 187 are not accessible, therefore leak testing was not possible on these two line segments. Line Segment 137 is untestable due to the lack of an isolation valve at the point where the line enters the tank.

Line Segment 281 is a $127^{\prime}$ long, 2" diameter line comprised of suction and jet discharge transfer piping that jets waste from the Building 3092 scrubber into the WC-2 transfer piping (node 14 to node 16). This line is no longer used due to the construction of a new secondarily contained line from the 3092 scrubber to Valve Box No. 2

Line Segment 158 is part of the primary tank discharge line (node 5 to node 6 ). This segment is a 9' long, 2" diameter section of suction piping that extends from Tank WC-2 to the inlet of centrifugal pump WC2-101. Line Segment 158 lacks a second valve and cannot be isolated or tested. Flow into Line Segment 171 begins at the discharge of pump WC2/101 and extends to a valve known as V-WC-2-104 (node 6 to node 7). Line Segment 171 is 6 ' in length and has a diameter of 2". The pump sits in a concrete vault with a stainless steel gate valve located on either side of the pump. The pump vault, which is not a part of the tested line system, has a $4.5 \mathrm{ft}^{3}{ }^{3}$ collection sump extending two foot below the floor elevation of the vault.

The third testable element, Line Segment 282, is a pressurized 685' long, 2" diameter stainless steel portion of the discharge between Tank WC-2 (at valve V-WC2-104) and Valve Box No. 2 (node 7 to S1 Node 11). 
Line Segment 282 was tested by the gas pressure decay method described in Section 3.2.2. Leak test results are included in Section 7.3.4.

Table 14. Characteristics of Line Segments Evaluated as a Part of Tank System WC-2

\begin{tabular}{|c|c|c|c|c|c|c|c|c|c|}
\hline $\begin{array}{l}\text { Líne } \\
\text { Segment }\end{array}$ & 92 & $93^{*}$ & 117 & 137 & 158 & 171 & 187 & 281* & 282 \\
\hline $\begin{array}{l}\text { Node } \\
\text { Numbers }\end{array}$ & 1 to 2 & 3 to 4 & $\begin{array}{l}12 \text { to } \\
13\end{array}$ & 8 to 9 & 5 to 6 & 8 to 7 & $\begin{array}{c}10 \text { to } \\
11\end{array}$ & 14 to 16 & $\begin{array}{l}16 \text { to } \\
\text { S1-N11 }\end{array}$ \\
\hline $\begin{array}{l}\text { Index } \\
\text { Number }\end{array}$ & G14 & G3 & & & & & & & P16 \\
\hline $\begin{array}{l}\text { Diameter } \\
\text { (in) }\end{array}$ & 2 & 2 & 2 & 2 & 2 & 2 & 1 & 2 & 2 \\
\hline Material & $347 \mathrm{SS}$ & $347 \mathrm{SS}$ & $347 \mathrm{SS}$ & 347 SS & $347 \mathrm{SS}$ & $347 \mathrm{SS}$ & $347 \mathrm{SS}$ & $347 \mathrm{SS}$ & $347 \mathrm{SS}$ \\
\hline Length ( $f t)$ & 200 & 200 & 30 & 18 & 9 & 6 & 13 & 127 & 685 \\
\hline $\begin{array}{l}\text { Volume } \\
\text { (gal) }\end{array}$ & 35 & 35 & 5 & 3 & 2 & 1 & 1 & 22 & 119 \\
\hline $\begin{array}{l}\text { Transfer } \\
\text { Method }\end{array}$ & G & G & G & $\mathrm{CP}$ & $\begin{array}{c}\mathrm{CP} \\
\text { Suct. }\end{array}$ & $\mathrm{CP}$ & G & $\begin{array}{l}\text { SJ \& } \\
\text { Suct. }\end{array}$ & $\mathrm{CP}$ \\
\hline Install Date & 1951 & 1951 & 1951 & 1951 & 1951 & 1951 & 1951 & 1951 & 1951 \\
\hline $\begin{array}{l}{ }^{*} \\
\text { CP } \\
\text { G } \\
\text { SJ } \\
\text { Suct. } \\
\text { SS }\end{array}$ & $\begin{array}{l}\text { f Service } \\
\text { fugal Pum } \\
\text { ty } \\
\text { jet pump } \\
\text { on } \\
\text { ess Steel }\end{array}$ & & & & & & & & \\
\hline
\end{tabular}

\subsubsection{Corrosion Assessment of the WC-2 Tank System}

For the last few years, all waste solutions going into Tank WC-2 were those used to decontaminate the hot cells in Buildings 3028 and 3038 in preparation for decommissioning these buildings. Investigations indicated that surfactants have been used, and the volume added to the tank has only averaged 10 to 20 gallons per week. If acid must be used in the future, based on information obtained from ORNL, only nitric acid would be considered. Type 347 stainless steel is compatible with both of these environments. Furthermore, the solution in the tank is maintained at a highly alkaline level. With the present use, all forms of corrosion on the interior 347 stainless steel walls of the tank and associated piping should be essentially nil. Corrosion damage that may have occurred when the system was used with other environments cannot be assessed.

Some of the stainless steel piping is buried and is subject to corrosion by soil. However, based on information cited in Section 4.0, corrosion of stainless steel by ORNL soil is not believed to be severe. 


\subsubsection{Results of Leak Tests on the WC-2 System}

This section summarizes the results of the leak detection tests conducted on Tank System WC-2 (the tank and its associated pipelines). Each test was completed with a method appropriate for that element. Each method used has been demonstrated to detect a specified leak rate $(0.2 \mathrm{gal} / \mathrm{hr}$ for tank methods; $0.1 \mathrm{gal} / \mathrm{hr}$ for pipeline methods) with a PD no less than $95 \%$ and a PFA no greater than $5 \%$.

\subsubsection{WC-2 Tank}

Leak testing of Tank WC-2 began in January 1996 and continued at monthly intervals through December 1996, with a total of 12 leak test attempts during this reporting period. The results of these tests are summarized in Table 15, which shows the date of each test, the volume of LLLW in the tank at the time of the test, the percent of Tank WC-2's total volume the test represented, ${ }^{6}$ the test result, and comments pertinent to particular tests. The table shows that Tank WC-2 recorded PASS results for all 12 of the monthly leak tests. The maximum volume for which the tank passed the leak testing during this reporting period was $590 \mathrm{gal}$, or $51 \%$ of the total capacity. This is greater than the previously certified level of $519 \mathrm{gal}$ (45\%) for this tank, which was achieved during leak tests in July and August 1994.

Table 15. Summary of Leak Tests Conducted on Tank WC-2

\begin{tabular}{|c|c|c|c|c|}
\hline Date & \# of Gallons & $\%$ Capacity & Test Result & Comment \\
\hline $12 \operatorname{Jan} 96$ & 392 & 34 & PASS & \\
\hline 2 Feb 96 & 398 & 35 & PASS & \\
\hline 1 Mar 96 & 420 & 37 & PASS & \\
\hline 5 Apr 96 & 423 & 37 & PASS & \\
\hline 3 May 96 & 426 & 37 & PASS & \\
\hline 7 Jun 96 & 505 & 44 & PASS & \\
\hline $15 \mathrm{Jul} 96$ & 448 & 39 & PASS & \\
\hline 2 Aug 96 & 537 & 47 & PASS & \\
\hline $6 \operatorname{Sep} 96$ & 537 & 47 & PASS & \\
\hline 11 Oct 96 & 559 & 49 & PASS & \\
\hline 8 Nov 96 & 590 & 51 & PASS & New high level \\
\hline $6 \operatorname{Dec} 96$ & 352 & 31 & PASS & \\
\hline
\end{tabular}

The 12 compensated volume rate (CVR) values from these leak tests were analyzed (1) to verify that the test method was performing properly in this application and (2) to confirm that during this assessment period the use and performance of the leak testing method had not deteriorated. This analysis included a statistical examination of the CVR

${ }^{6}$ WOCC look-up tables show $100 \%$ capacity for WC-2 as 1,148 gal. The percent capacity shown in the table is based on this number. 
data, as well as a comparison of this year's assessment data with prior data. The analysis and the results are described in Section 7.3.4.3.

\subsubsection{WC-2 Pipelines}

The results of the leak detection tests on the testable WC-2 pipelines are summarized in Section 7.3.4.2.1. An assessment of the integrity of the WC-2 pipelines that cannot be tested for leaks with existing approved methods is summarized in Section 7.3.4.2.2.

\subsection{WC-2 Testable Pipelines}

There are three testable pipelines associated with the WC- 2 tank system: two gravity lines and one pressurized discharge line. One gravity line leads from Building 3028 to Tank WC-2 (segment 93) and the second leads from Building 3038 to WC-2 (segment 92). The discharge line connects Tank WC-2 with VB-2 (segment 282). The discharge line was leak tested on December 3, 1996; the line passed that test. The gravity line was tested on January 9, 1997; it too passed the test. Line segment 93 is not used and therefore not scheduled for leak testing. Table 16 shows the results of the leak tests conducted on the WC-2 pipelines.

Table 16. Summary of Leak Test Results for the WC-2 Testable Lines

\begin{tabular}{|c|c|c|c|c|}
\hline Element No. & Line Segment & Test Date & Test Result & Comment \\
\hline \hline G3 & 93 & $\mathrm{n} / \mathrm{t}$ & $\mathrm{n} / \mathrm{a}$ & Out of Service \\
\hline $\mathrm{G} 14$ & 92 & $9 \mathrm{Jan} 97$ & PASS & \\
\hline $\mathrm{P} 16$ & 282 & $3 \mathrm{Dec} 96$ & PASS & \\
\hline
\end{tabular}

\subsection{WC-2 Untestable Pipelines}

The untestable portion of the WC-2 system lines which had transfers, (Line Segments 158 and 171) carries liquids from Tank WC-2 through VB-2 to Tank W-22. WOCC transfer logs show that during the period from January 1996 through December 1996, there was one transfer through these segments, from WC-2 to W-22. For this transfer, the expected error was $141 \mathrm{gal}$. The recorded transfer showed a difference in input/output volume of $58 \mathrm{gal}$, which is less than the maximum expected error. Based upon this, it is concluded that there were no significant transfer differences during this assessment period and therefore that the line is likely tight and free of leaks. Table 17 summarizes the transfer operations. 
Table 17. Summary of Transfers between W-16 and W-22 from January through December 1996

\begin{tabular}{|c|c|c|c|c|c|c|}
\hline 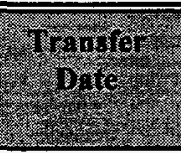 & 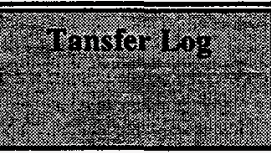 & Whar & 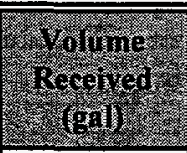 & 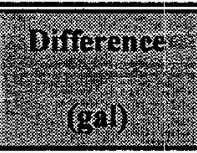 & 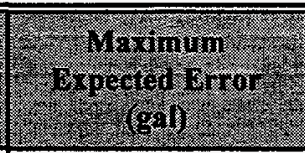 & 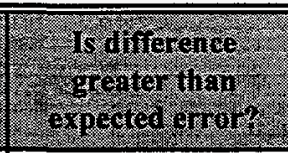 \\
\hline 191 & to WC-22 & 486 & 428 & -58 & 141 & - No \\
\hline
\end{tabular}

\subsubsection{Analysis of Tank WC-2 Leak Test Data}

During this assessment period; a total of 12 leak tests were attempted on Tank WC-2; all 12 of these tests resulted in conclusive decisions. Figure 15 shows a time series plot of the CVR data obtained from each of the usable test results. It can be seen from the plot that all 12 of the CVR values are within the inflow decision and outflow decision thresholds, and are thus consistent with a PASS result.

A comparative analysis of the data shown in Figure 15 was performed. The analysis included using the Student's t-test [Mendenhall, 1992] and the Kolmogorov-Smirnov test (KS) [Benjamin and Cornell, 1970]. The Student's t-test is used to determine the significance of the mean of the CVR data. The KS analysis is used to determine if the population of CVR values from WC-2 is significantly different from a reference set of CVRs. These statistical tests are fully described in Section 5.4.

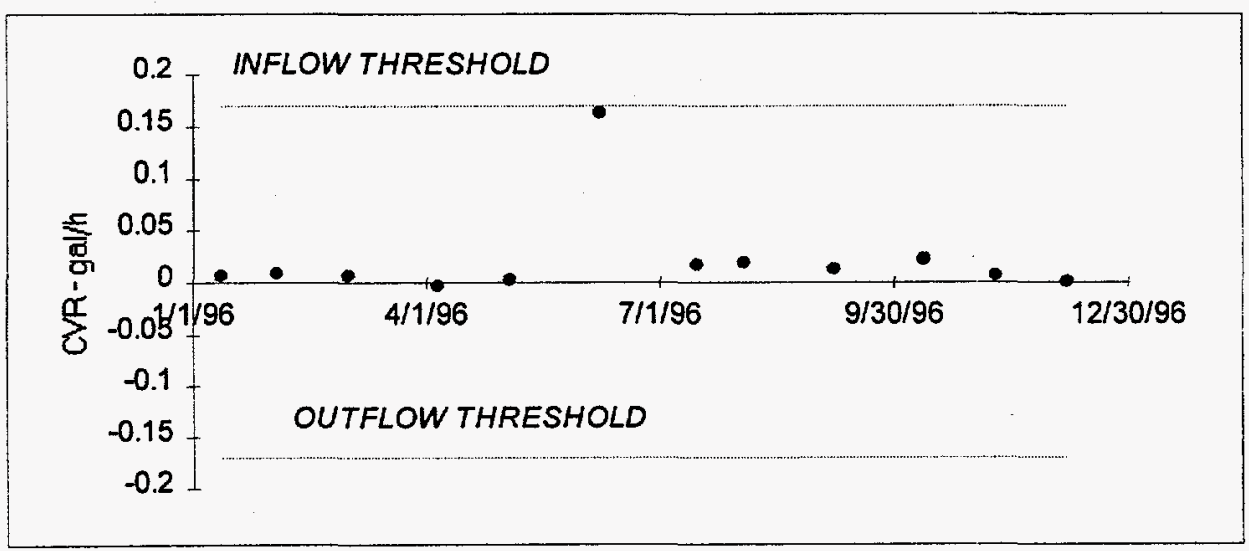

Figure 15. Time series plot of leak test CVRs from Tank WC-2.

Applying the t-test to the 12 data values shown above results in a t-statistic, $t_{\text {stat }}$, of 1.71 , while the critical value, $t_{\text {crit }}$, with a $99 \%$ level of confidence, is 3.11 . Based upon these numbers, we conclude that the mean of the 1996 CVR data from tank WC-2 is equivalent to $0 \mathrm{gal} / \mathrm{h}$.

Figure 16 graphically illustrates the KS test applied to the WC-2 data. The bold line in the figure shows the cumulative distribution function (CDF) obtained from the CVR data 
shown in Figure 15 after the mean has been removed from the data. This CDF shows that the total "spread" about the mean in the CVR data is very small. The light line in the figure shows the CDF obtained from the reference set of CVR values (see Section 5.4). The similarity of the data sets defined by the two lines illustrated in Figure 16 is "tested" with the $\mathrm{KS}$ "goodness-of-fit" test. Here, the test statistic, $\mathrm{KS}_{\text {stat, }}$ is 0.40 , while the critical value, $\mathrm{KS}_{\text {crit }}$ is 0.47 . Since $\mathrm{KS}_{\text {stat }}$, the maximum ordinal difference between the CDF and the test $\mathrm{CDF}$, is less than $\mathrm{KS}_{\text {crit, }}$, the two populations are deemed to be equivalent. Thus, it is concluded from the KS analysis that the CY96 population of Tank WC-2 CVR values is not different from the reference population of CVR values.

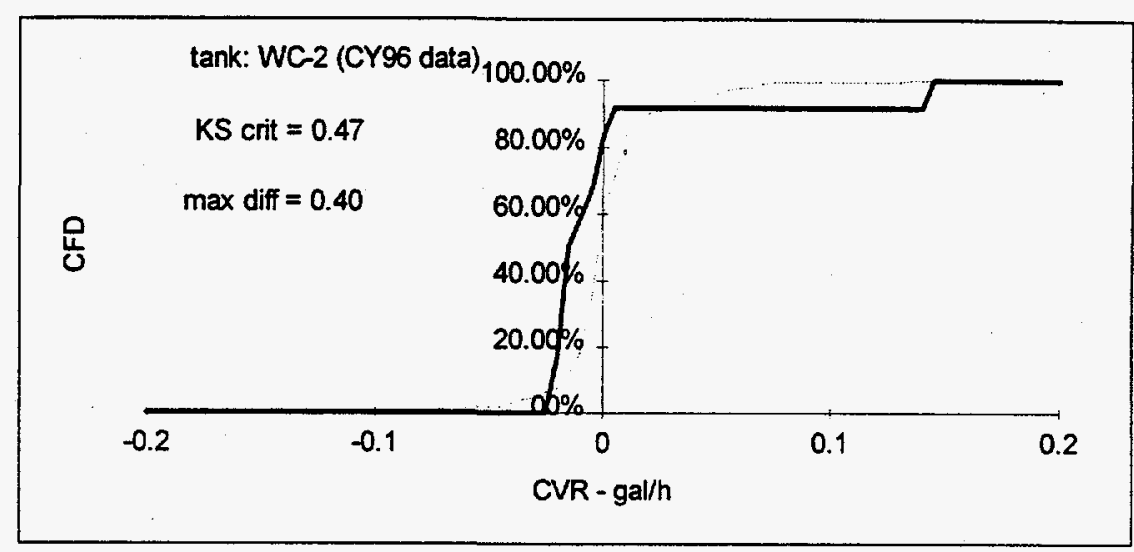

Figure 16. Cumulative frequency distribution from reference CVR data (light line) and WC-2 CY96 CVR data (bold line).

Table 18 summarizes the statistical analyses of the Tank WC-2 CVR data. The table shows that the mean of the CY96 test data is equivalent to $0 \mathrm{gal} / \mathrm{h}$ and that the population of CY96 CVR values is not different from the population of CVR values in the reference (or comparison) data set.

Table 18. Summary of the Statistical Analyses of WC-2 CVR Data (HTV = $14.72 \mathrm{gal} / \mathrm{in}$.)

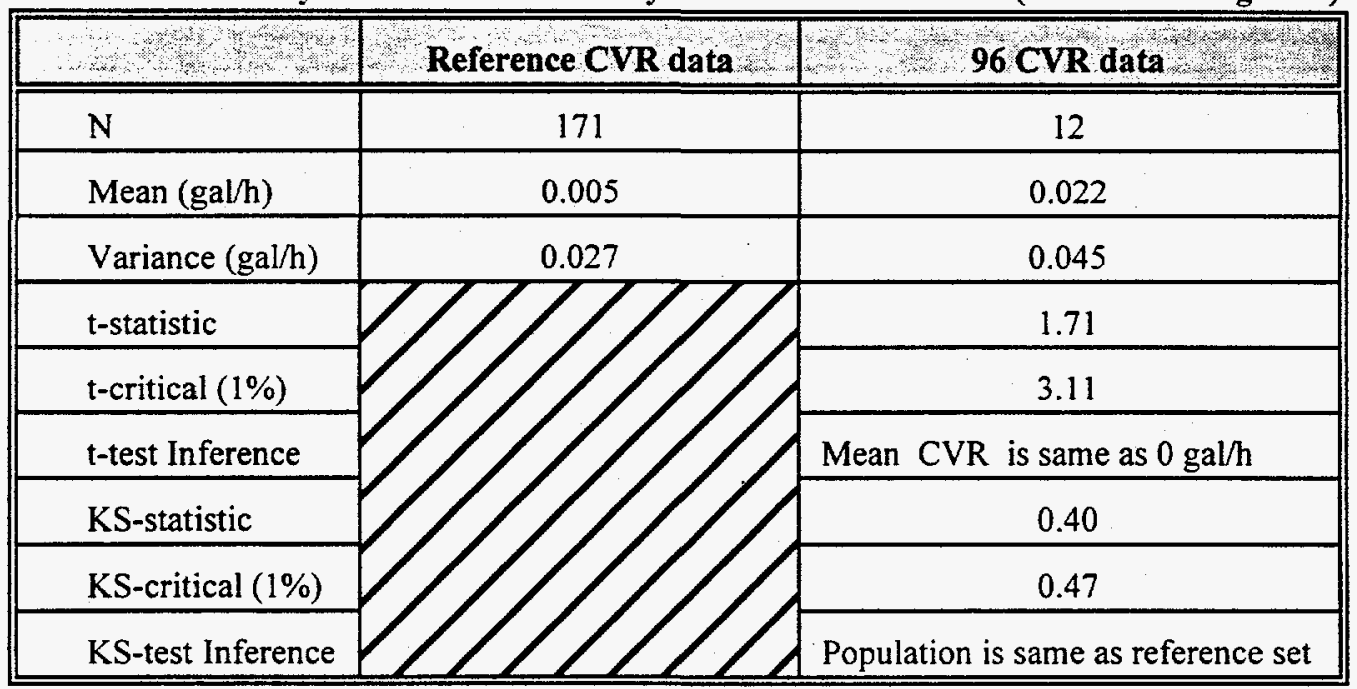




\subsubsection{Findings and Conclusions}

The findings of this report are based on (1) a review of available tank design drawings, (2) a qualitative assessment of corrosion on the tank and pipelines, and (3) leak testing results from the tank and testable pipelines.

Review of the design drawings indicated that the tank was designed in accordance with acceptable practices defined by ASTM and ASME. One concern noted was an abundance of inlets into the tank that were not connected to pipelines. However, because the unused inlets are located on the top of the tank, there is no concern that leakage could occur at those locations as long as the tank is operating at less than full capacity. The design drawings revealed a sound design of the WC- 2 tank.

During the corrosion assessment, it was determined that with the present use of the tank system, all forms of corrosion on the interior walls of the tank and associated piping should be nonexistent. Corrosion damage that may have occurred when the tank was used in past environments cannot be assessed. Furthermore, an analysis of the general aspects of corrosion at ORNL revealed that corrosion of stainless steel by ORNL soil is not believed to be severe.

Leak testing of Tank WC-2 was completed by the DP method in 12 tests. The tank received PASS results for all twelve tests.

Two of three testable line segments passed leak testing by methods discussed previously. The third testable line segment is not used and will not be tested.

Transfer logs were used to qualitatively assess the pipelines which are not testable by currently approved methods. Transfer logs reveal that one transfer was made in November 1996. The difference in the volume sent and the volume received did not exceed the expected error. The volume of the transfer along with the latest qualitative assessment of the pipelines are reported to EPA and TDEC in the "Quarterly Highlights for LLLW Tank System Activities." Although a limited evaluation of the untestable pipelines can be made using transfer logs, this method of assessment is not deemed valid for certification purposes.

All of these factors were considered in determining certification of the WC-2 Tank System components. Table 19 summarizes the elements of the tank system which were certified and the conditional limits on their certifications. 
Table 19. Summary of WC-2 Tank System Testing and Certification

\begin{tabular}{|c|c|c|c|c|c|c|c|}
\hline \multicolumn{2}{|c|}{$\begin{array}{c}\text { System } \\
\text { Component }\end{array}$} & $\begin{array}{l}\text { Length } \\
\text { (ft) }\end{array}$ & $\begin{array}{c}\text { Tested } \\
\text { (Yes/No) }\end{array}$ & $\begin{array}{l}\text { Leak Test } \\
\text { Method }\end{array}$ & $\begin{array}{l}\text { Test } \\
\text { Result }\end{array}$ & Certification & $\begin{array}{c}\text { Certification } \\
\text { Level }\end{array}$ \\
\hline \multicolumn{2}{|c|}{ Tank WC-2 } & & Yes & DP & PASS & Yes & $51 \%$ \\
\hline \multicolumn{2}{|l|}{ LS-92 } & 200 & Yes & EVB & PASS & Yes & $32 \mathrm{gph}$ \\
\hline \multicolumn{2}{|c|}{ LS-93* } & 200 & No & NT & NT & No & NA \\
\hline \multicolumn{2}{|c|}{ LS- 117} & 30 & No & NT & NT & No & NT \\
\hline \multicolumn{2}{|c|}{ LS-137 } & 18 & No & NT & NT & No & NT \\
\hline \multicolumn{2}{|c|}{ LS- 158} & 9 & No & NT & NT & No & NT \\
\hline \multicolumn{2}{|c|}{ LS-171 } & 6 & No & NT & NT & No & NT \\
\hline \multicolumn{2}{|c|}{ LS-187 } & 13 & No & NT & NT & No & NT \\
\hline \multicolumn{2}{|c|}{ LS-281* } & 127 & No & NT & NT & No & NA \\
\hline \multicolumn{2}{|c|}{ LS-282 } & 685 & Yes & GPD & PASS & Yes & Full flow \\
\hline \multicolumn{8}{|c|}{ * Out of Service } \\
\hline DP & \multicolumn{7}{|c|}{ Differential Pressure } \\
\hline EVB & \multicolumn{7}{|c|}{ Enhanced volume balancing } \\
\hline gph & \multicolumn{7}{|c|}{ Gallons per hour } \\
\hline LS & \multicolumn{7}{|c|}{ Line segment } \\
\hline NT & \multicolumn{7}{|c|}{ Not tested } \\
\hline $\mathrm{NA}$ & \multicolumn{7}{|c|}{ Not applicable } \\
\hline
\end{tabular}




\subsubsection{Certification}

Based on the results of the design drawings review, the qualitative corrosion assessment, and the results of the leak testing program, it is my professional opinion that Tank WC-2 retains sufficient structural integrity to contain liquids at operating levels up to the maximum level which achieved a PASS during the testing program. Also, based upon the results of the pipeline tests, it is my professional opinion that Line Segment 282 retains sufficient integrity to contain liquids up to the full flow potential of this line segment and Line Segment 92 retains sufficient integrity to contain liquids up to $32 \mathrm{gph}$ (the rate of leak testing). Table 19 provides a summary description of the certifications for the WC-2 Tank System. If future testing is conducted at greater tank levels, then certification levels may also increase.

It is recommended that leak detection and line testing be continued using EPA and TDEC approved methods, to support annual certification, until this system has been removed from operation or replaced.

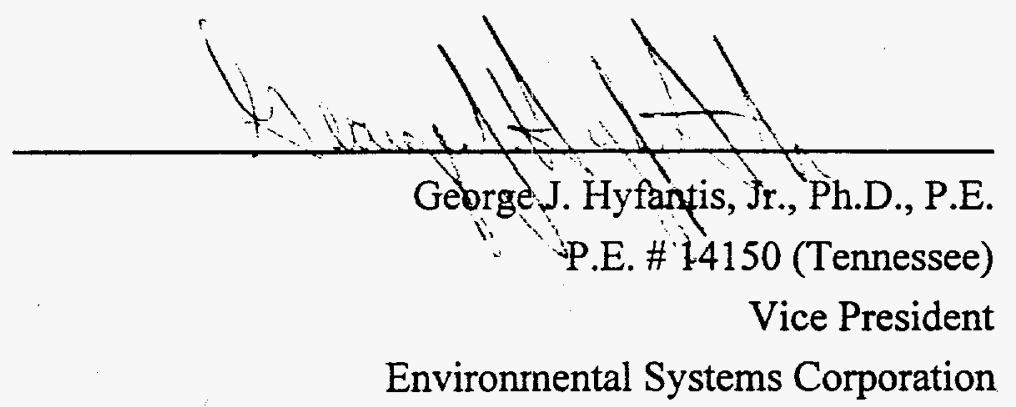




\subsection{WC-3 Tank System}

The WC-3 Tank System is located directly south of Building 3025, as shown in Figure 1. The tank system consists of Tank WC-3 and eight line segments connected to the tank system. The WC-3 Tank System collects waste from the gravity-fed pipeline system in Building 3025. These wastes are transferred by steam-jet from WC-3 to the Evaporator Complex via Valve Pit 3026 (VP-3026) and Valve Box No 1. Because the lines and tank are all singly contained, the tank system has been given the classification of Category $\mathrm{C}$.

\subsubsection{WC-3 Tank Description}

Tank WC-3 is a 1,000 gallon, buried, singly contained tank. Installed in 1951, WC-3 is mounted vertically to a $7^{\prime}-6^{\prime \prime} \times 7^{\prime}-6^{\prime \prime} \times 1^{\prime}-3^{\prime \prime}$ concrete pad. The tank is constructed of 347 stainless steel and was designed with a $1 / 4$ " wall thickness. All materials welded to the tank are also 347 stainless steel. The tank is constructed with a 3/8" thick ASME flanged and dished head on top and a $1 / 4^{\prime \prime}$ thick ASME flanged and dished head on the bottom. The outside diameter of the tank is $5^{\prime}-6$ ", with a overall height of $7^{\prime}-4-1 / 4^{\prime \prime}$. The design drawing for Tank WC-3 is provided as Figure 17.

The tank is equipped with nine 3 " diameter flanged nozzles, one 8" diameter flanged nozzle, and one 16" diameter manhole opening. The flanged nozzles are located around a $2 '-0$ " radius of the tank center, and the manhole is located in the center of the tank. Each of the 3 " diameter flanges are fitted to be secured by four $5 / 8$ " diameter bolts, and the manhole is fitted to be secured by sixteen $3 / 4$ " diameter bolts. All flanges are slip on welding type. All of the necessary welds on the tank are specified in accordance with codes from the ASTM for unfired pressure vessels. At the time of construction, the welds were specified to provide substantially the same composition as adjacent, unwelded metal. The tank is ventilated to the atmosphere through a high efficiency particulate air (HEPA) filter.

The pit containing the tank was constructed with an 8 " diameter vitrified pipe dry well in the southeast corner, extending to just above ground surface. A jet pit which houses an earthen sump is located to the south of the tank pit. The sump is located in the northwest corner of the jet pit.

Building 3025 is the only source of waste which enters Tank WC-3. A schematic of the tank system with numbered line segments is shown in Figure 18. 


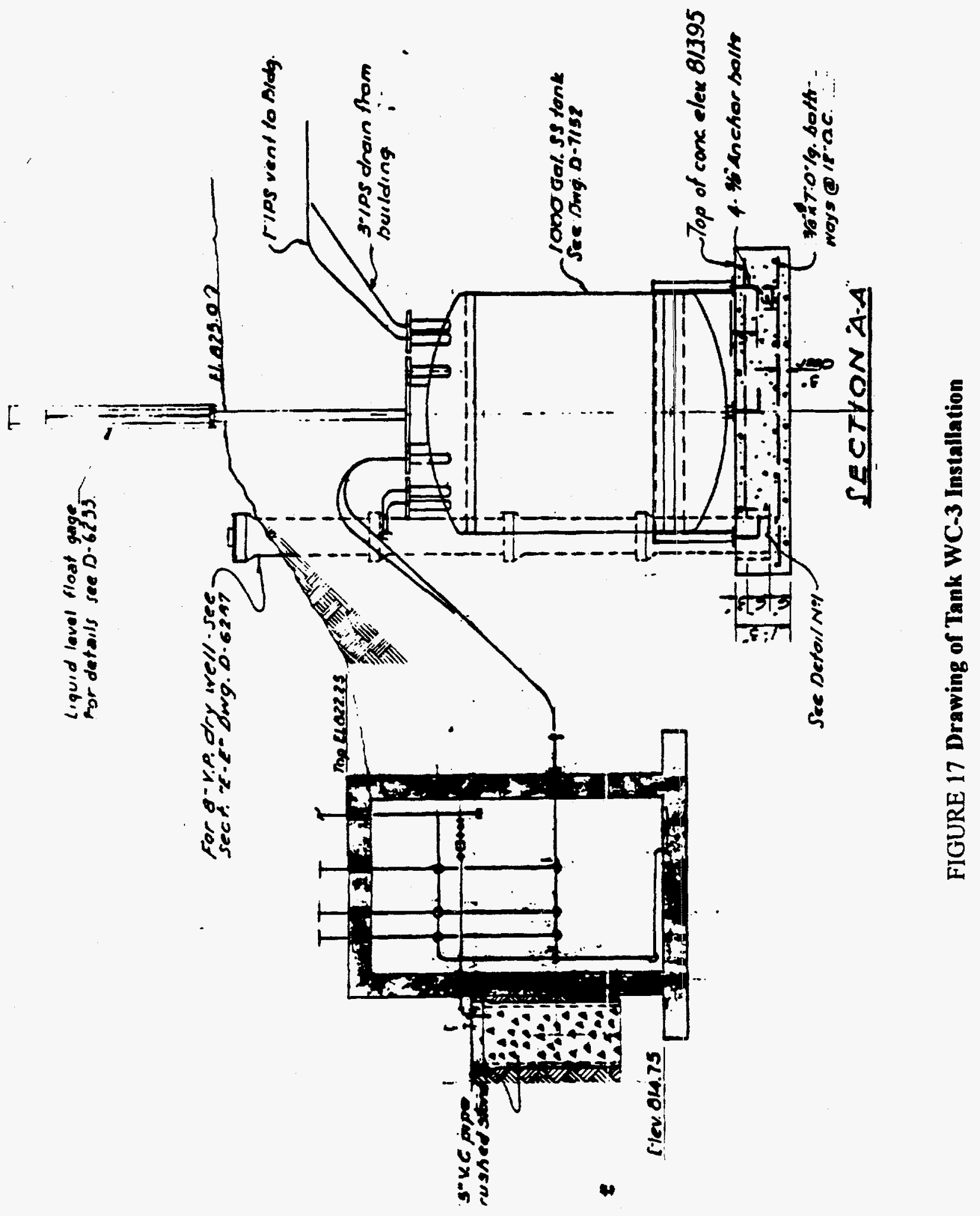




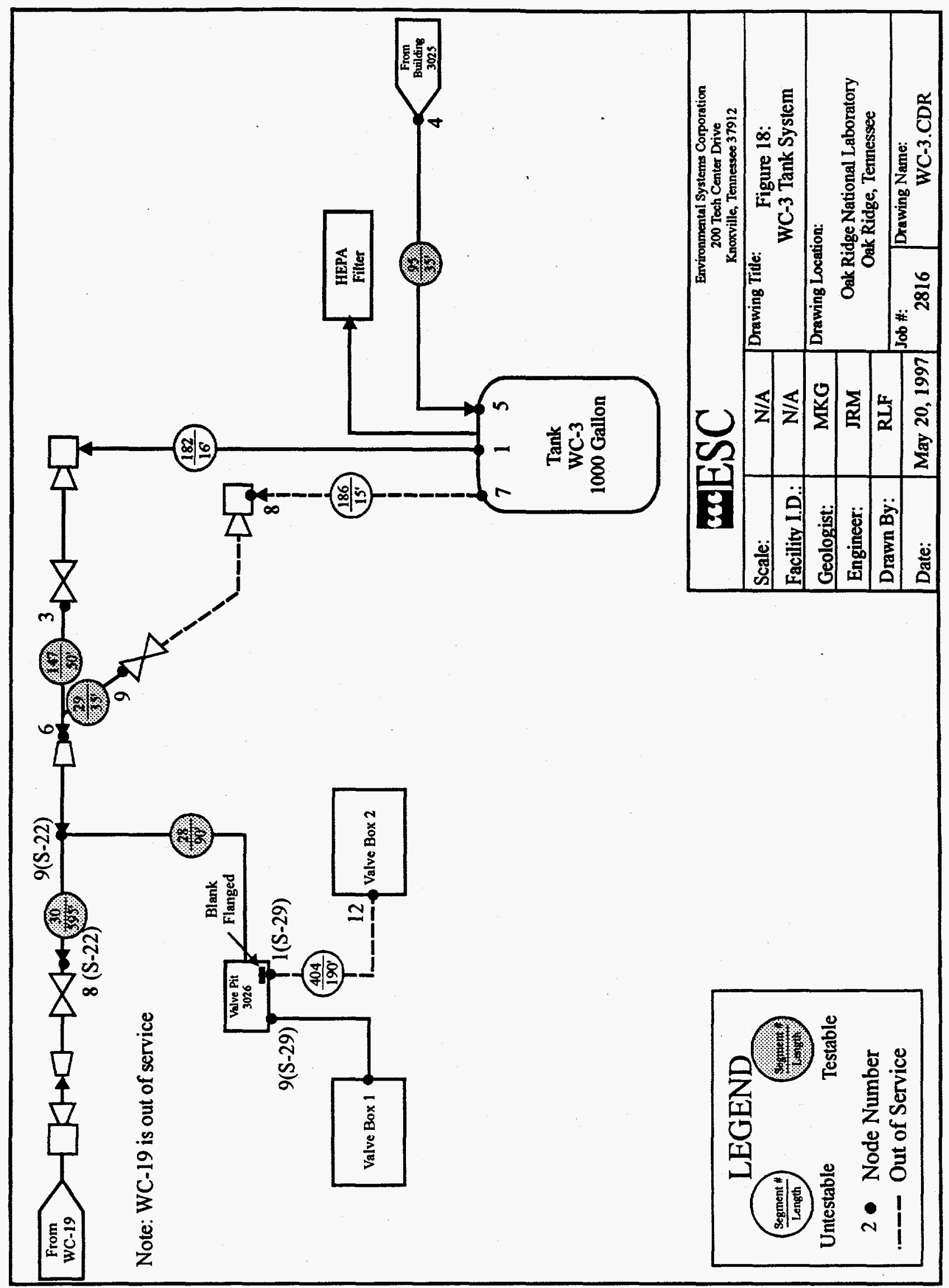




\subsubsection{WC-3 Pipeline Descriptions}

Eight line segments make up the portion of the LLLW pipeline system belonging to Tank WC-3. Details of these lines are listed in Table 20, and line segment numbers are shown in Figure 20. All pipelines associated with the WC-3 Tank System are constructed of 347 stainless steel and were installed in 1951. Materials are transferred through pipelines of WC-3 tank by either a steam jet pump (SJ), or a suction steam jet pump (SJ Suct.). As shown in Figure 20, WC-3 tank has one inlet line and two outlet lines. The remaining five line segments are not directly connected to Tank WC-3.

Of the eight pipelines associated with Tank System WC-3, there are two testable pipeline elements made up of five separate line segments. The first is a gravity-fed line that drains from Building 3025 into Tank WC-3. Line Segment 95 is a 35' long gravity-fed line with a 3" diameter (Building 3025 to node 5 in Figure 20).

A second testable pipeline element, $\mathrm{P} 37$, is a pressurized piping network leading from Tank WC-19 and Tank WC-3 to Valve Box 1 via Valve Pit 3026 and Tank W-16. Element P37 consists of four line segments defined as belonging to WC-3, identified as Line Segments 147, 29, 30, and 28. Line Segments 28, 29, 147, and 30 all intersect at a manifold. Line Segment 28 (nodes 9S-22 to VP-3026) is a 2" diameter line carrying LLLW from lines 29,147 , and 30 to VP-3026. Line Segment 29 (nodes 9 to 6 ) extends $35^{\prime}$ from the isolation valve to the reducer, and intersects with Line Segment 147. Line Segment 30 (nodes 9S-22 to $8 \mathrm{~S}-22$ ) extends $595^{\prime}$ from a reducer connecting to the WC-19 pipeline system.

Line Segment 404 is a pressurized, 2" diameter, 190' long segment leading from VP3026 to Valve Box 2. This element has been disconnected from the discharge system via a blind flange and is therefore no longer used or tested.

The two outlet lines from the tank have index numbers 182 and 186 . These lines are 1 " in diameter and $16^{\prime}$ and $15^{\prime}$ long, respectively. The system has two steam jet inductors that are used to transfer LLLW from WC-3 tank to the VP-302.6. The suction lines from Tank WC-3 to the jets cannot be tested because they cannot be isolated. Line Segment 182 runs from node 1 to node 3 in Figure 20. Line Segment 186 connects Line Segment 29 and Tank WC-3 (node 7 to node 9), however this line is no longer used.

Line Segments 95, 147, 29, 30, and 28 were successfully tested. Each of the line segments were tested by the EVB or GPD testing technique described in Section 5.2. The results of the leak testing are included in Section 7.9.4. The characteristics of each of the eight lines evaluated as part of Tank System WC-3 are given in Table 20. 
Table 20. Characteristics of Line Segments Evaluated as a Part of Tank System WC-3

\begin{tabular}{|c|c|c|c|c|c|c|c|c|}
\hline Line Segment & 28 & 29 & 30 & 95 & 147 & 182 & $186^{*}$ & $404^{*}$ \\
\hline Node Numbers & $\begin{array}{l}\text { S22-N9 to } \\
\text { VP-3026 }\end{array}$ & 9 to 6 & $\begin{array}{l}\text { S22-N9 to } \\
\text { S22-N8 }\end{array}$ & 4 to 5 & 3 to 6 & 1 to 3 & 7 to 8 & $\begin{array}{c}\mathrm{S} 29-\mathrm{N} 1 \\
\text { to } 12\end{array}$ \\
\hline Index Number & P37 & P37 & P37 & G2 & P37 & & & P19 \\
\hline Diameter (in) & 2 & 2 & 2 & 3 & 1 & 1 & 1 & 2 \\
\hline Material & $347 \mathrm{SS}$ & 347 SS & $347 \mathrm{SS}$ & $347 \mathrm{SS}$ & $347 \mathrm{SS}$ & $347 \mathrm{SS}$ & $347 \mathrm{SS}$ & $347 \mathrm{SS}$ \\
\hline Length (ft) & 90 & 35 & 595 & 35 & 50 & 16 & 15 & 190 \\
\hline Volume (gal) & 16 & 6 & 104 & 13 & 2 & 1 & 1 & 33 \\
\hline Transfer Method & SJ & SJ & SJ & G & SJ & $\begin{array}{l}\text { SJ \& } \\
\text { Suct. }\end{array}$ & $\begin{array}{l}\text { SJ \& } \\
\text { Suct. }\end{array}$ & SJ \\
\hline Install Date & 1951 & 1951 & 1951 & 1951 & 1951 & 1951 & 1951 & 1951 \\
\hline $\begin{array}{ll}* & \text { Out of S } \\
\text { G } & \text { Gravity } \\
\text { SJ } & \text { Steam je } \\
\text { Suct. } & \text { Suction } \\
\text { SS } & \text { Stainles }\end{array}$ & $\begin{array}{l}\mathrm{mp} \\
\mathrm{eel}\end{array}$ & & & & & & & \\
\hline
\end{tabular}

\subsubsection{Corrosion Assessment of WC-3 Tank System}

Tank WC-3 presently serves only Building 3025 . The solutions added to the tank are those associated with analytical and metallographic procedures and include etching and electro-polishing solutions (highly acidic), acetone, alcohol, and decontaminating solutions, some of which include salts of citric acid. No chlorine-containing chemicals are used. None of the waste solution is neutralized before addition to the tank, but the lines are flushed with water after each addition. The $\mathrm{pH}$ of the tank solution is maintained at a highly alkaline $\mathrm{pH}$ by occasionally adding a strong alkaline solution to the tank. Under the present conditions, attack on the interior tank walls should not be severe. How much damage may have occurred over the years when tank alkalinity may not have been maintained cannot be assessed.

The tank and associated piping are buried directly in the soil without benefit of coating or cathodic protection. However, based on information cited in Section 4 , corrosion of stainless steel by ORNL soil is not believed to be severe.

\subsubsection{Results of Leak Tests on the WC-3 System}

This section summarizes the results of the leak detection tests conducted on Tank System WC-3 (the tank and its associated pipelines). Each test was completed with a method appropriate for that element. Each method used has been demonstrated to detect a specified leak rate ( $0.2 \mathrm{gal} / \mathrm{hr}$ for tank methods; $0.1 \mathrm{gal} / \mathrm{hr}$ for pipeline methods) with a PD no less than $95 \%$ and a PFA no greater than $5 \%$. 


\subsubsection{WC-3 Tank}

Leak testing of Tank WC-3 began in January 1996 and continued at monthly intervals through December 1996, with a total of 13 leak test attempts during this reporting period. The results of these tests are summarized in Table 21, which shows the date of each test, the volume of LLLW in the tank at the time of the test, the percent of Tank WC-3's total volume the test represented, ${ }^{7}$ the test result, and comments pertinent to particular tests. The table shows that Tank WC- 3 recorded PASS results for 12 of the leak tests. A PASS result was obtained in each of the 12 months in CY96. One INCONCLUSIVE result was obtained as a result of high noise in the data. The maximum volume for which the tank passed the leak testing during this reporting period was $705 \mathrm{gal}$, or $61 \%$ of the total capacity. This is greater than the previously certified level of 490 gal (43\%) for this tank, which was observed in December 1995 and thus represents a new high level for certification purposes.

Table 21. Summary of Leak Tests Conducted on Tank WC-3

\begin{tabular}{|c|c|c|c|c||}
\hline Date & \# of Gallons & \% Capacity & Test Result & Comment \\
\hline \hline 12 Jan 96 & 509 & 44 & PASS & \\
\hline 2 Feb 96 & 506 & 44 & PASS & \\
\hline 1 Mar 96 & 508 & 44 & PASS & \\
\hline 5 Apr 96 & 512 & 45 & PASS & \\
\hline 3 May 96 & 512 & 45 & PASS & \\
\hline 7 Jun 96 & 515 & 45 & PASS & \\
\hline 15 Jul 96 & 680 & $n / a$ & INCONCLUSIVE & High noise \\
\hline 19 Jul 96 & 705 & 61 & PASS & New high level \\
\hline 2 Aug 96 & 307 & 27 & PASS & \\
\hline 6 Sep 96 & 289 & 25 & PASS & \\
\hline 11 Oct 96 & 312 & 27 & PASS & \\
\hline 8 Nov 96 & 520 & 45 & PASS & \\
\hline 6 Dec 96 & 49 & 4 & PASS & \\
\hline
\end{tabular}

The 12 usable compensated volume rate (CVR) data values from these leak tests were analyzed (1) to verify that the test method was performing properly in this application and (2) to confirm that during this assessment period the use and performance of the leak testing method had not deteriorated. This analysis included a statistical examination of the CVR data, as well as a comparison of this year's assessment data with prior data. The analysis and the results are described in Section 7.4.4.3.

${ }^{7}$ WOCC look-up tables show $100 \%$ capacity for WC-3 as 1,148 gal. The percent capacity shown in the table is based on this number. 


\subsubsection{WC-3 Pipelines}

The results of the leak detection tests on the testable WC-3 pipelines are summarized in Section 7.4.4.2.1. An assessment of the integrity of the WC-3 pipelines that cannot be tested for leaks with existing approved methods is summarized in Section 7.4.4.2.2.

\subsection{WC-3 Testable Pipelines}

There are two testable pipelines associated with the WC-3 tank system: one gravity line and one pressurized discharge line. The gravity line (G2) leads from Building 3025 to Tank WC-3 (segment 95). The pressurized line (P37) is comprised of four segments: 28, 29, 30, and 147. The line segments are all part of the WC-3 to VP-3026 discharge system. The gravity line, G2, was tested in October 1996, achieving a PASS result. The discharge line, P37, was leak tested August 8, 1997 and achieved a PASS result. A summary of leak testing results is presented in Table 22.

Table 22. Summary of Leak Test Results for the WC-3 Testable Lines

\begin{tabular}{|c|c|c|c|c|}
\hline Element No. & Line Segment & Test Date & Test Result & Comment \\
\hline \hline G2 & 95 & 29 Oct 96 & PASS & \\
\hline P37 & 28.29 .30 .147 & 8 Aug 97 & PASS & \\
\hline
\end{tabular}

\subsection{WC-3 Untestable Pipelines}

The untestable portion of the WC-3 System consists of two suction lines (Line Segments 182 and 186) between Tank WC-3 and the jet pumps that are used to transfer LLLW from Tank WC-3 to Valve Box 1 and on to Tank W-22. Line 186 (node 7 to node 9) is not used. Transfer logs show that during the period from January 1996 through December 1996 there were four transfers made from WC-3 through Line 182 to W-22. These transfers are summarized in the first four columns of Table 23. The differences between the volumes sent (column 3) and the volumes received (column 4) are shown in column 5 .

Table 23. Summary of Transfers between W-16 and W-22 from January through December 1996

\begin{tabular}{|c|c|c|c|c|c|c|}
\hline $\begin{array}{l}\text { Transter } \\
\text { Datef }\end{array}$ & Iransrer log & 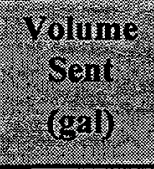 & $\begin{array}{l}\text { Wolnine } \\
\text { Received } \\
\text { (gal) }\end{array}$ & $\frac{\text { Difrerence }}{(\text { gai) }}$ & 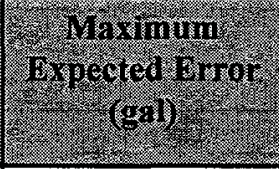 & 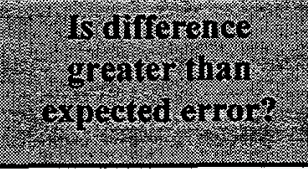 \\
\hline 29 Jul 96 & WC-3 to W-22 & 435 & 410 & -25 & 141 & No \\
\hline 5 Sep 96 & $W C-3$ to $W-22$ & 89 & 89 & 0 & 141 & No \\
\hline 21 Nov 96 & WC-3 to W-22 & 433 & 436 & 3 & 141 & No \\
\hline 30 Nov 96 & $W C-3$ to $W-22$ & 227 & 227 & 0 & 141 & No \\
\hline
\end{tabular}


For the WC-3 to W-22 transfers, the maximum expected error was $141 \mathrm{gal}$. The recorded transfers show volume differences less than the maximum expected error; therefore, it is concluded that there were no significant differences during this assessment period, and that the pipelines are likely tight.

\subsubsection{Analysis of Tank WC-3 Leak Test Data}

During this assessment period, a total of 13 leak tests were attempted on Tank WC-3; of these, 12 tests resulted in conclusive decisions. Figure 19 shows a time series plot of the CVR data obtained from each of the usable test results. It can be seen from the plot that all 12 of the conclusive CVR values are within the inflow decision and outflow decision thresholds, and are thus consistent with a PASS result.

A comparative analysis of the data shown in Figure 19 was performed. The analysis included using the Student's t-test [Mendenhall, 1992] and the Kolmogorov-Smirnov test (KS) [Benjamin and Cornell, 1970] statistical tests. The Student's t-test is used to determine the significance of the mean of the CVR data. The KS analysis is used to determine if the population of CVR values from WC-3 is significantly different from a reference set of CVRs. These statistical tests are fully described in Section 5.4.

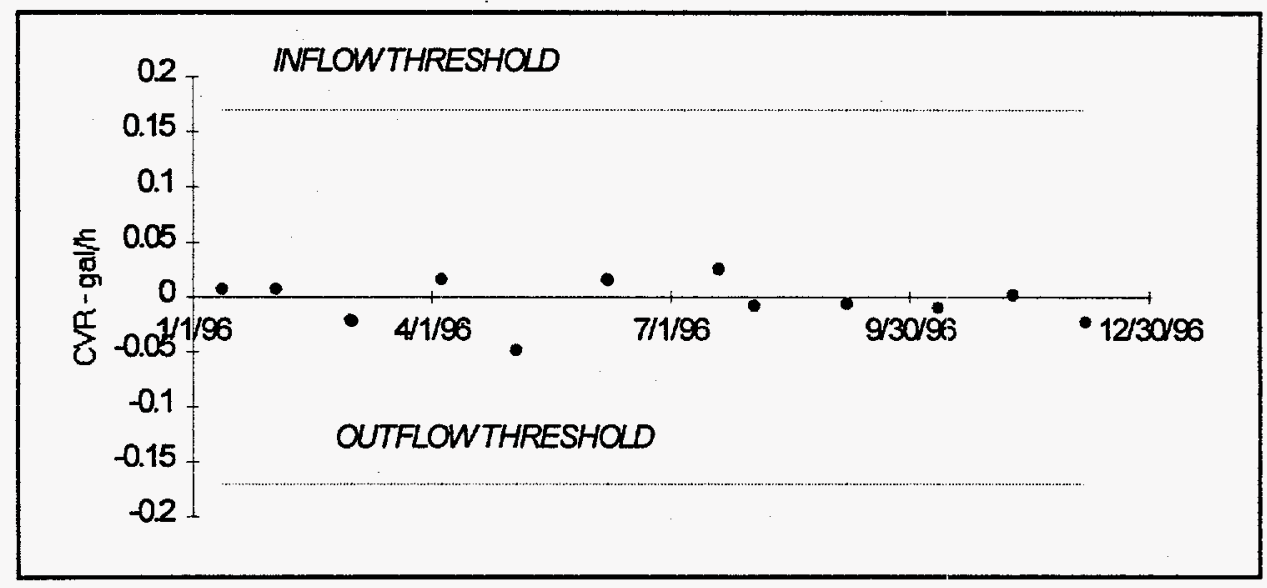

Figure 19. Time series plot of leak test CVRs from Tank WC-3.

Applying the t-test to the 12 data values shown above results in an absolute value of the $t$-statistic, $t_{\text {stat }}$ of 0.51 , while the critical value, $t_{\text {crit }}$, with a $99 \%$ level of confidence is 3.11. Based upon these numbers, we conclude that the mean of the 1996 CVR data from Tank WC-3 is equivalent to $0 \mathrm{gal} / \mathrm{h}$.

Figure 20 graphically illustrates the KS test applied to the WC-3 data. The bold line in the figure shows the CDF obtained from the CVR data shown in Figure 19, after the mean has been removed from the data. This CDF shows that the total "spread" about the mean in the CVR data is very small. The lighter line in the figure shows the CDF obtained from the 
reference set of CVR values (see Section 5.4) after the mean has been removed from the data. The similarity of the data sets defined by the two lines illustrated in Figure 23 is "tested" with the KS "goodness-of-fit" test. Here, the test statistic, $\mathrm{KS}_{\text {stat }}$, is 0.25 , while the critical value, $\mathrm{KS}_{\text {crit }}$ is 0.47 . Since $\mathrm{KS}_{\text {stat }}$ the maximum ordinal difference between the $\mathrm{CDF}$ and the test $\mathrm{CDF}$, is less than $\mathrm{KS}_{\text {crit }}$, the two populations are deemed to be equivalent.

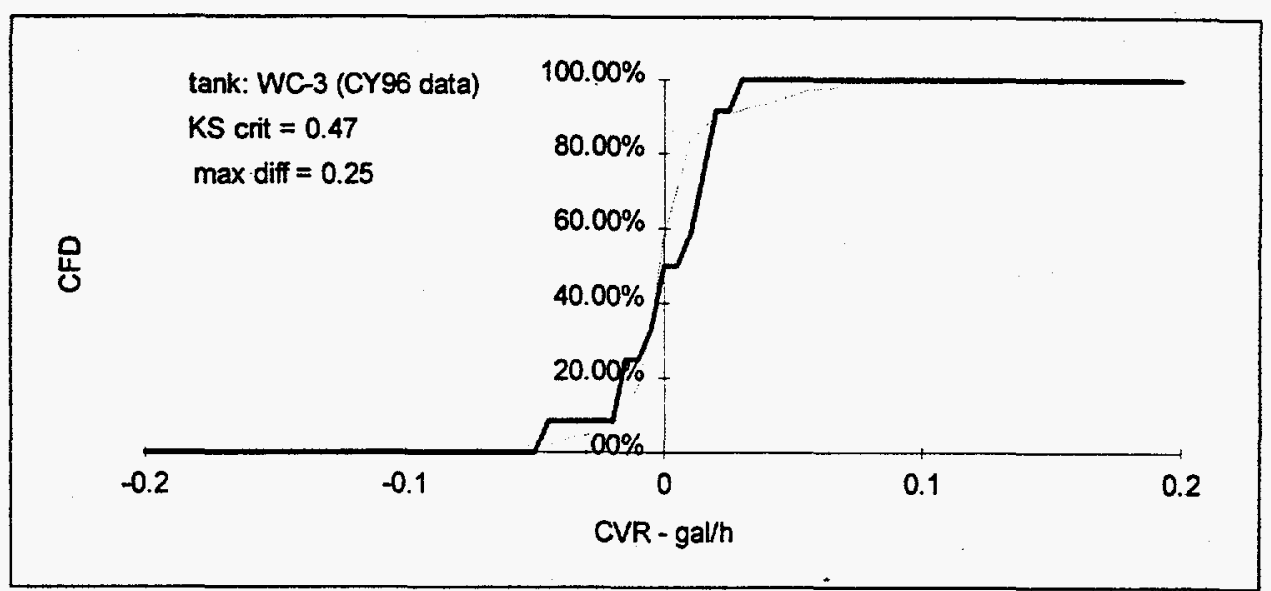

Figure 20. Cumulative frequency distribution from reference CVR data (light line) and WC-3 CY96 data (bold line).

Table 24 summarizes the statistical analyses of the Tank WC-3 CVR data. The table shows that the mean of the CY96 test data is equivalent to $0 \mathrm{gal} / \mathrm{h}$, and that the population of CY96 CVR values is not different from the population of CVR values in the reference (or comparison) data set.

Table 24. Summary of the Statistical Analyses of WC-3 CVR Data (HTV = 14.72 gal/in.)

\begin{tabular}{|l|c|c|}
\hline & Reference CVR Data & 96 CVR Data \\
\hline $\mathrm{N}$ & 171 & 12 \\
\hline Mean (gal/h) & 0.005 & 0.003 \\
\hline Variance (gal/h) & 0.02 \\
\hline t-statistic & 0.027 \\
\hline t-critical (1\%) & \\
\hline t-test Inference & \\
\hline KS-statistic & \\
\hline KS-critical $(1 \%)$ & \\
\hline KS-test Inference & \\
\hline
\end{tabular}




\subsubsection{Findings and Conclusions}

The findings of this report are based on (1) a review of available tank design drawings, (2) a qualitative assessment of corrosion on the tank and pipelines, and (3) leak testing results from the tank and testable pipelines.

Review of the design drawings indicated that the tank was designed in accordance with acceptable practices defined by ASTM and ASME. One concern noted was an abundance of nozzles into the tank that were not connected to pipelines. However, because the unused nozzles are located on the top of the tank, there is no concern that leakage could occur at those locations as long as the tank is operating at less than full capacity. The design drawings revealed a sound design of the tank.

During the corrosion assessment, it was determined that with the present use of the tank system, all forms of corrosion on the interior walls of the tank and associated piping should be nonexistent. Corrosion damage that may have occurred when the tank was used in past environments cannot be assessed. Furthermore, an analysis of the general aspects of corrosion at ORNL revealed that corrosion of stainless steel by ORNL soil is not believed to be severe.

Leak testing of Tank WC-3 was completed by the DP method in 13 tests. The tank had PASS results for 12 of the leak tests, and an INCONCLUSIVE result during one test.

The five testable line segments passed leak testing by methods discussed previously. Line Segments 186 and 404 are no longer in use and were not leak tested.

Transfer logs were used to qualitatively assess the pipelines which are untestable by currently approved methods. These transfer logs reveal that four transfers were made, during the period from July 1996 through November 1996. The difference between the measured volume sent from Tank WC-3 and the measured volume received in Tank W-22 was less than the maximum expected error. The successful transfer, coupled with the untestable line being a suction line, are a positive indication of the lines integrity. The volume of the transfer, along with the latest qualitative assessment of the pipelines, are reported to EPA and TDEC in the "Quarterly Highlights for LLLW Tank System Activities." Although a limited evaluation of the untestable pipelines can be made using transfer logs, this method of assessment, due to its limited accuracy, is not deemed valid for certification purposes.

All of these factors were considered in determining certification of the WC-3 Tank System components. Table 25 summarizes the elements of the tank system that were certified and the conditional limits on their certifications. 
Table 25. Summary of Tank System Certification for Tank WC-3

\begin{tabular}{|c|c|c|c|c|c|c|c|}
\hline \multicolumn{2}{|c|}{$\begin{array}{l}\text { System } \\
\text { Component }\end{array}$} & $\begin{array}{c}\text { Length } \\
\text { (ft) }\end{array}$ & $\begin{array}{l}\text { Tested } \\
\text { (Yes/No) }\end{array}$ & $\begin{array}{l}\text { Leak } \\
\text { Test } \\
\text { Method }\end{array}$ & $\begin{array}{l}\text { Test } \\
\text { Result }\end{array}$ & Certification & $\begin{array}{c}\text { Certification } \\
\text { Level }\end{array}$ \\
\hline \multicolumn{2}{|c|}{ Tank WC-3 } & & Yes & DP & PASS & Yes & $61 \%$ \\
\hline \multicolumn{2}{|l|}{ LS-95 } & 35 & Yes & EVB & PASS & Yes & $32 \mathrm{gph}$ \\
\hline \multicolumn{2}{|l|}{ LS-28 } & 90 & Yes & GPD & PASS & Yes & Full Flow \\
\hline \multicolumn{2}{|l|}{ LS-29 } & 35 & Yes & GPD & PASS & Yes & Full Flow \\
\hline \multicolumn{2}{|l|}{ LS-30 } & 595 & Yes & GPD & PASS & Yes & Full Flow \\
\hline \multicolumn{2}{|c|}{ LS-147 } & 50 & Yes & GPD & PASS & Yes & Full Flow \\
\hline \multicolumn{2}{|c|}{ LS-182 } & 16 & No & NT & NT & No & NA \\
\hline \multicolumn{2}{|c|}{ LS-186* } & 15 & No & NT & NT & No & NA \\
\hline \multicolumn{2}{|c|}{ LS-404* } & 190 & No & NT & NT & No & NA \\
\hline \multicolumn{8}{|c|}{ * $\quad$ Out of Service } \\
\hline DP & \multicolumn{7}{|c|}{ Differential Pressure } \\
\hline EVB & \multicolumn{7}{|c|}{ Enhanced volume balancing } \\
\hline GPD & \multicolumn{7}{|c|}{ Gas pressure decay } \\
\hline gph & \multicolumn{7}{|c|}{ Gallons per hour } \\
\hline LS & \multicolumn{7}{|c|}{ Line segment } \\
\hline NT & \multicolumn{7}{|c|}{ Not tested } \\
\hline NA & \multicolumn{7}{|c|}{ Not applicable } \\
\hline
\end{tabular}




\subsubsection{Certification}

Based on the results of the design drawings review, the qualitative corrosion assessment, and the results of the leak testing program, it is my professional opinion that Tank WC-3 retains sufficient structural integrity to contain liquids at operating levels up to the maximum level which achieved a PASS result during the testing program. Also, based upon the results of the pipeline tests, it is my professional opinion that Line Segments 28, 29,30 , and 147 retains sufficient integrity to contain liquids up to the full flow potential of these line segments and Line Segment 95 retains sufficient integrity to contain liquids up to a flow rate of $32 \mathrm{gph}$. Table 25 provides a summary description of the certifications for the WC-3 Tank System. If future testing is conducted at larger pipeline flows and greater tank levels, then certification levels may also increase.

It is recommended that leak detection and line testing using the EPA and TDEC approved methods be continued to support annual certification, until this system has been removed from operation or replaced.

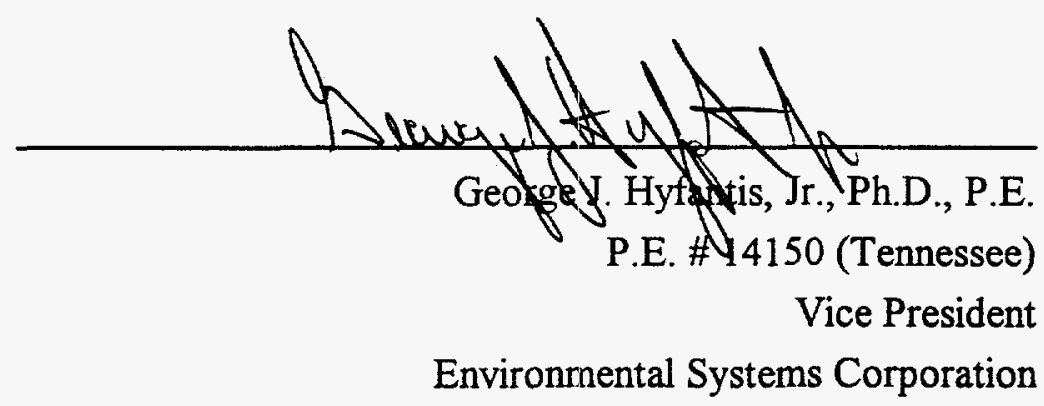




\subsection{WC-9 Tank System}

The WC-9 Tank System is located in the Bethel Valley area south of Building 3503, as shown in Figure 1. The tank system is an active system, and collects rainwater from the WC-9 Pump Pit. It was also used to drain LLLW from Building 3503. The tank system is singly contained and is classified as Category $\mathrm{C}$.

\subsubsection{WC-9 Tank Description}

Tank WC-9 is a 2,150 gallon, buried, singly contained tank, and was installed in 1962. The tank is mounted vertically on four legs anchored to a concrete pad. The tank is constructed of 347 stainless steel with an outside diameter of 7'-0" and a length of 10'-9". The bottom of the tank is concave on an $84^{\prime \prime}$ radius and the top of the tank has a flanged and dished head profile on an $84^{\prime \prime}$ radius with a $1 / 8^{\prime \prime}$ minimum wall thickness. The top of the tank has four 2" diameter flanged nozzles, three 2-1/2" diameter flanged nozzles, one 4" diameter-flanged nozzle, and one $18^{\prime \prime}$ diameter flanged manhole located at the top center of the tank. All of the flanged nozzles are located around a $3^{\prime}-0^{\prime \prime}$ radius from the center of the tank. The manhole is fitted with a $16^{\prime \prime} 1$. D. extension constructed with $3 / 16^{\prime \prime}$ stainless steel walls. The manhole is capped with a $30^{\prime \prime}$ diameter-flanged inlet. The height of the extension is unknown. Two lifting lugs are provided located on opposite sides of the top of the tank. The operating volume of the tank is 1,500 gallons. The design drawing for Tank WC-9 is given in Figure 21. The tank is located in an earthen pit backfilled with crushed stone. The burial depth is $6^{\prime}-6^{\prime \prime}$ to the top of the tank.

Tank WC-9 is capable of receiving material from three sources. The sources originate in Building 3503, an off-gas condensate drain trap located south of Building 3503, and a pump pit sump pump. A schematic of the tank system with numbered line segments is provided in Figure 22.

\subsubsection{WC-9 Pipeline Descriptions}

Nine separate line segments make up the portion of the LLLW pipeline system belonging to the WC-9 Tank System. Characteristics of the lines are listed in Table 26, and line segments numbers are shown in Figure 22.

The testable portion of the WC-9 pipeline system consists of two elements: the gravity-fed inlet line from Building 3503 to Tank WC-9 and a portion of the pressurized discharge line between Tank WC-9 and Valve Box 2. The testable gravity-fed inlet line, Line Segment 97 (node 1 to node 2 in Figure 24), is 95' long, has a diameter of 3", and is made of 347 stainless steel. This line is out of service. The testable pressurized line, index number P2 consists of two Line Segments: 301 and 27 (node 41 to node 10). Line Segment 301 (note 41 to node 42 ) is a section of stainless steel doubly contained pipeline which 


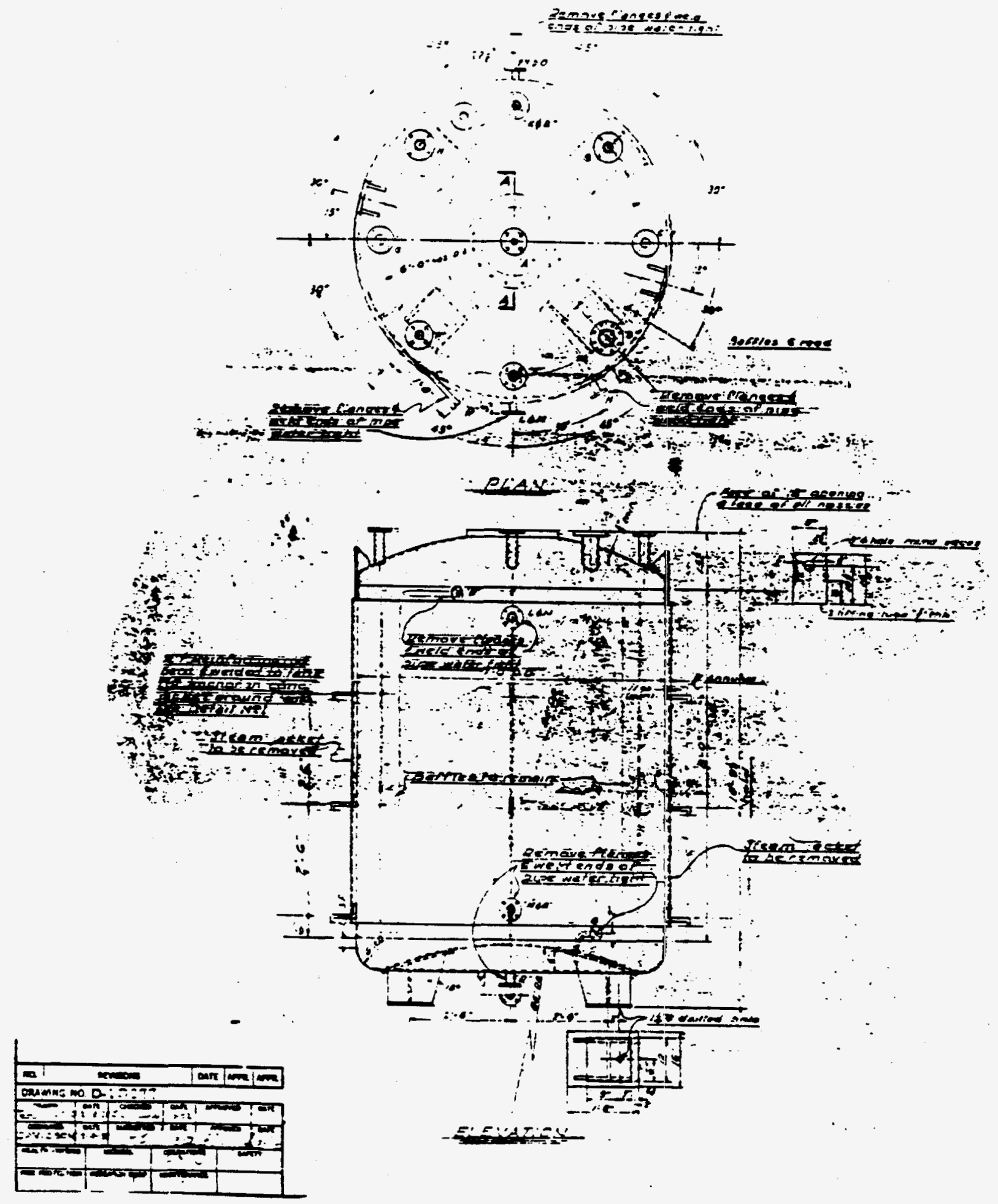

FIGURE 21 WC-9 Tank Design Drawing 


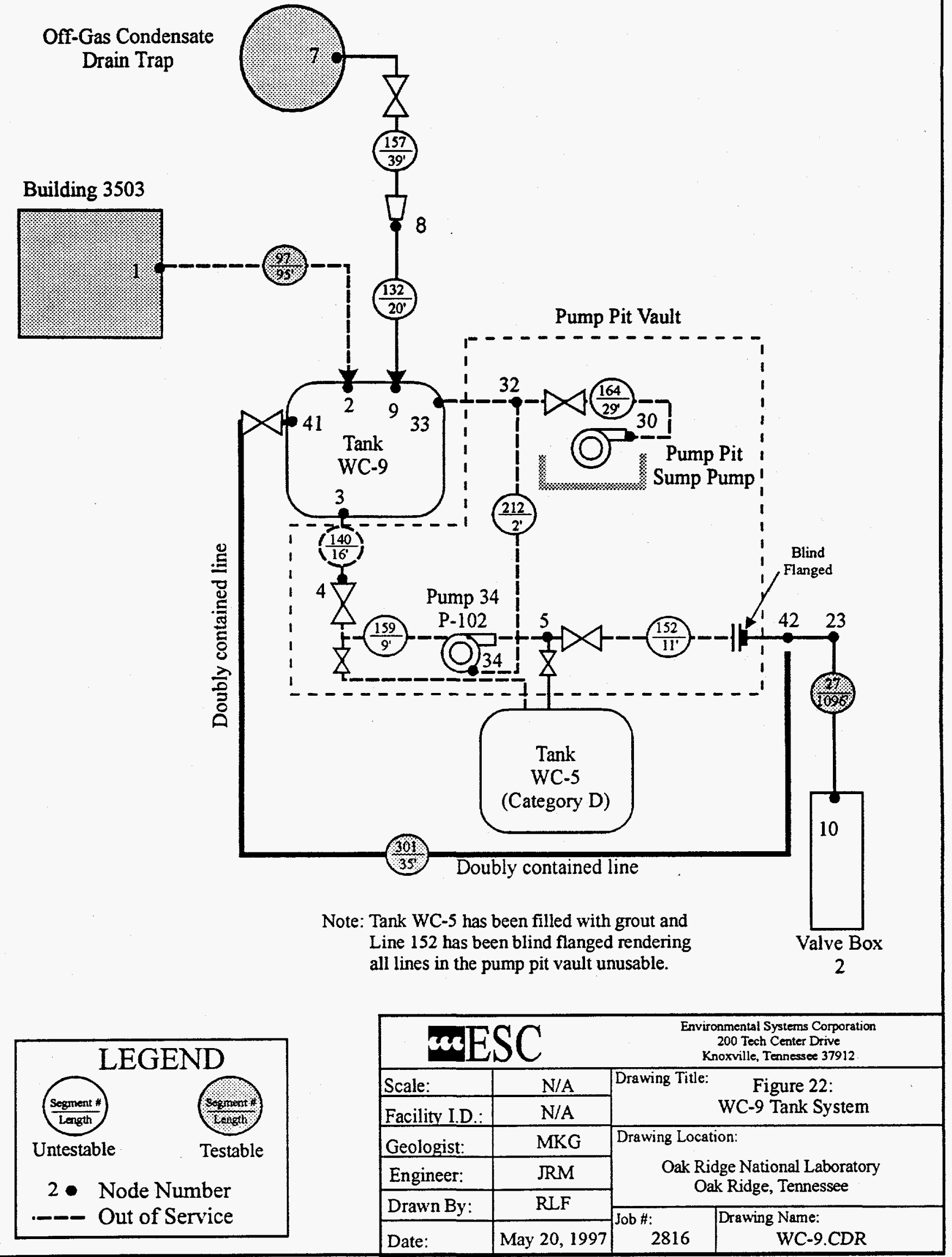


connects Tank WC-9 with the discharge line to Valve Box 2. This line is $35^{\prime}$ long and has an inner pipe diameter of 2" and an outer pipe diameter of 3". Line Segment 27 (node 23 to node 10 ) is 1096' long and has a diameter of 2". Nodes 6, 23, and 42 are all in one location and are only included for clarity of line identification.

There are four untestable pipeline elements associated with the WC-9 system. The first untestable pipeline element is the gravity-fed inlet line connecting an off-gas condensate drain trap to Tank WC-9. This pipeline element (node 7 to node 9) is comprised of two segments, Line Segments 132 and 157. The pipeline element is 59' long, is comprised of 1" and $2 "$ diameter sections, and is made of 347 stainless steel.

The second untestable pipeline element is the discharge line from a pump pit sump pump that empties the sump into WC-9 Tank. This element is made up of one stainless steel segment: Line Segment 164 (node 30 to node 33), which is $29^{\prime}$ long, with a $1^{\prime \prime}$ diameter. The two remaining untestable elements are no longer used. It should be noted that the only discharge line from the pump vault, Line Segment 152, has been cut and capped, rendering all lines in the pump pit vault unusable. This is a result of two projects: 1) an upgrade program that installed a submersible pump in WC-9, and connected the submersible pump discharge to the WC-9 transfer piping via a section of doubly contained pipeline (Line Segment 301); 2) filling the other three tanks served by the pump pit (tanks WC-5, WC-6, and WC-8) with grout. One of the untestable elements is the (now-unused) suction piping between Tank WC-9 and Pump P-102 and a short section of P-102 discharge piping. This line (node 3 to node 5) is comprised of two segments, Line Segments 140 and 159, and is 25' long, with a 2 " diameter. The other untestable element is the (now-unused), Line Segment 212, (node 34 to node 32) which served to drain Pump P-102 back into Tank WC-9. This pipeline is 2 ' long, with a 1 " diameter.

Table 26. Characteristics of Line Segments Evaluated as a Part of Tank System WC-9

\begin{tabular}{|c|c|c|c|c|c|c|c|c|c|c|}
\hline Line Segment & 27 & $97 *$ & 132 & $140^{*}$ & $152^{*}$ & 157 & $159 *$ & $164^{*}$ & $212^{*}$ & 301 \\
\hline Node Numbers & 23 to 10 & 1 to 2 & 8 to 9 & 3 to 4 & 5 to 6 & 7 to 8 & 4 to 5 & 30 to 32 & 32 to 34 & 41 to 42 \\
\hline Index Number & $\mathrm{P} 2$ & Gl & & & & & & & & $\mathrm{P} 2$ \\
\hline Diameter (in) & 2 & 3 & 2 & 2 & 2 & 1 & 2 & 1 & 1 & \\
\hline Material & $347 \mathrm{SS}$ & 347 SS & $347 \mathrm{SS}$ & $347 \mathrm{SS}$ & 347 SS & $347 \mathrm{SS}$ & 347 SS & $347 \mathrm{SS}$ & $347 \mathrm{SS}$ & \\
\hline Length $(f t)$ & 1096 & 200 & 20 & 16 & 11 & 39 & 9 & 29 & 2 & 35 \\
\hline Volume (gal) & 250421 & 95 & 4 & 3 & 2 & 2 & 2 & 2 & $<1$ & \\
\hline Transfer Method & $\mathrm{CP}$ & G & G & $\mathrm{CP}$ & $\mathrm{CP}$ & G & $\mathrm{CP}$ & $\mathrm{CP}$ & $\mathrm{CP}$ & $\mathrm{CP}$ \\
\hline Install Date & 1952 & 1952 & 1952 & 1952 & 1952 & 1952 & 1952 & 1952 & 1952 & 1994 \\
\hline $\begin{array}{ll}\text { CP } & \text { Centrif } \\
\text { G } & \text { Gravity } \\
\text { SS } & \text { Stainle } \\
* & \text { Out of } \\
\end{array}$ & $\begin{array}{l}\text { gal pump } \\
\text { steel } \\
\text { ervice }\end{array}$ & & & & & & & & & \\
\hline
\end{tabular}




\subsubsection{Corrosion Assessment of the WC-9 Tank System}

Tank WC-9 collects condensate from the hot off-gas system in Building 3503 and from the pump pit sump (rain water). The waste solution has not been characterized, but the $\mathrm{pH}$ in the tank solution is presently maintained as highly alkaline which should minimize corrosion. Corrosion damage that may have occurred during periods when the $\mathrm{pH}$ of the solution was not maintained at a high value cannot be assessed.

Based on information cited in Section 4, soil-side corrosion of the underground tank and associated piping is probably not severe, even though the tank and piping are neither coated nor cathodically protected.

\subsubsection{Results of Leak Tests on the WC-9 System}

This section summarizes the results of the leak detection tests conducted on Tank System WC-9 (the tank and its associated pipelines). Each test was completed with a method appropriate for that element. Each method used has been demonstrated to detect a specified leak rate $(0.2 \mathrm{gal} / \mathrm{hr}$ for tank methods; $0.1 \mathrm{gal} / \mathrm{hr}$ for pipeline methods) with a probability of detection $(\mathrm{PD})$ no less than $95 \%$ and a probability of false alarm ( $\mathrm{PFA}$ ) no greater than $5 \%$.

\subsubsection{WC-9 Tank}

Leak testing of Tank WC-9 began in January 1996 and continued at frequent intervals through December 1996. During this period, there were 32 leak tests processed using the automated software; 11 of these were PASS results, and the remaining 21 test results were INCONCLUSIVE due to necessary transfers of the hot-off gas condensate (HOG) pot to Tank WC-9 which coincided with testing periods. The frequency of the HOG pot transfers increased at the beginning of CY96 primarily due to a ventilation system operating condition in Building 3517 that caused the HOG pot to fill up faster, (which is unrelated to Tank WC9). In order to obtain conclusive tests for January, February and March; archived data from the WOCC for Tank WC-9 was inspected for periods during which the HOG pot was not transferred. One period for each of January, February and March was selected and processed using the leak test software. The test decisions for these three periods were each PASS and these results are shown in Table 27. This resulted in a total of 35 leak test attempts during this reporting period. The results of these tests are summarized in Table 27, which shows the date of each test, the volume of LLLW in the tank at the time of the test, the percent of Tank WC-9's total volume the test represented, ${ }^{8}$ the test result, and comments pertinent to particular tests. The table shows that Tank WC-9 recorded PASS results for 14 of the leak tests, with INCONCLUSIVE results for the other 21 tests attempted.

${ }^{8}$ WOCC look-up tables show $100 \%$ capacity for WC-9 as 2,400 gal. The percent capacity shown in the table is based on this number. 
The maximum volume for which WC-9 passed the leak testing during this reporting period was 1,280 gal, or $53 \%$ of the total capacity of the tank. This is less than the previously certified level of $1,407 \mathrm{gal}(59 \%)$ for this tank, which was achieved during a leak test on February 24, 1995.

Table 27. Summary of Leak Tests Conducted on Tank WC-9

\begin{tabular}{|c|c|c|c|c|}
\hline 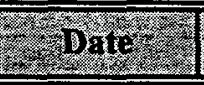 & 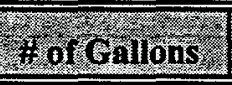 & 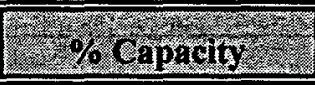 & 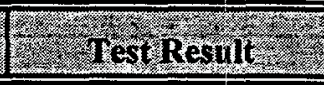 & Writs \\
\hline $12 \operatorname{Jan} 96$ & 9522 & $\mathbf{n} / \mathbf{a}$ & INCONCLUSIVE & HOG transfer during test \\
\hline $19 \operatorname{Jan} 96$ & 8344 & $\mathbf{n} / \mathbf{a}$ & INCONCLUSIVE & HOG transfer during test \\
\hline $20 \operatorname{Jan} 96$ & 8244 & 34 & PASS & Additional data set \\
\hline 26 Jan 96 & 8788 & $\mathrm{n} / \mathrm{a}$ & INCONCLUSIVE & HOG transfer during test \\
\hline 2 Feb 96 & 111919 & $\mathrm{n} / \mathrm{a}$ & INCONCLUSIVE & HOG transfer during test \\
\hline 9 Feb 96 & 110404 & $\mathbf{n} / \mathbf{a}$ & INCONCLUSIVE & HOG transfer during test \\
\hline 16 Feb 96 & 7488 & $\mathrm{n} / \mathrm{a}$ & INCONCLUSIVE & HOG transfer during test \\
\hline 16 Feb 96 & 136868 & 57 & PASS & Additional data set \\
\hline $23 \mathrm{Feb} 96$ & 139797 & $\mathrm{n} / \mathrm{a}$ & INCONCLUSIVE & HOG transfer during test \\
\hline 1 Mar 96 & 109595 & $\mathrm{n} / \mathrm{a}$ & INCONCLUSIVE & HOG transfer during test \\
\hline $22 \operatorname{Mar} 96$ & 7455 & $\mathrm{n} / \mathrm{a}$ & INCONCLUSIVE & HOG transfer during test \\
\hline 23 Mar 96 & 7422 & 31 & PASS & Additional data set \\
\hline $29 \operatorname{Mar} 96$ & 121111 & $\mathbf{n} / \mathbf{a}$ & INCONCLUS॥VE & HOG transfer during test \\
\hline 5 Apr 96 & 8388 & $\mathrm{n} / \mathrm{a}$ & INCONCLUSIVE & HOG transfer during test \\
\hline 12 Apr 96 & 125959 & $\mathrm{n} / \mathbf{a}$ & INCONCLUSIVE & HOG transfer during test \\
\hline 19 Apr 96 & 122929 & $\mathrm{n} / \mathrm{a}$ & INCONCLUSIVE & HOG transfer during test \\
\hline 26 Apr 96 & 7499 & 31 & PASS & \\
\hline 3 May 96 & 103434 & $\mathbf{n} / \mathbf{a}$ & INCONCLUSIVE & HOG transfer during test \\
\hline 10 May 96 & 110909 & 46 & PASS & \\
\hline 7 Jun 96 & 110303 & $\mathrm{n} / \mathrm{a}$ & INCONCLUSIVE & HOG transfer during test \\
\hline 26 Jul 96 & 8900 & 37 & PASS & \\
\hline 2 Aug 96 & 119797 & $\mathrm{n} / \mathrm{a}$ & INCONCLUSIVE & HOG transfer during test \\
\hline 9 Aug 96 & 8722 & $\mathrm{n} / \mathrm{a}$ & INCONCLUSIVE & HOG transfer during test \\
\hline 16 Aug 96 & 110808 & 46 & PASS & \\
\hline 23 Aug 96 & 128080 & 53 & PASS & \\
\hline 30 Aug 96 & 127979 & 53 & PASS & \\
\hline $6 \operatorname{Sep} 96$ & 126464 & 53 & PASS & \\
\hline $13 \operatorname{Sep} 96$ & 8155 & $\mathrm{n} / \mathrm{a}$ & INCONCLUSIVE & HOG transfer during test \\
\hline 11 Oct 96 & 7066 & $\mathrm{n} / \mathrm{a}$ & INCONCLUSIVE & HOG transfer during test \\
\hline 18 Oct 96 & 9566 & 40 & PASS & \\
\hline
\end{tabular}




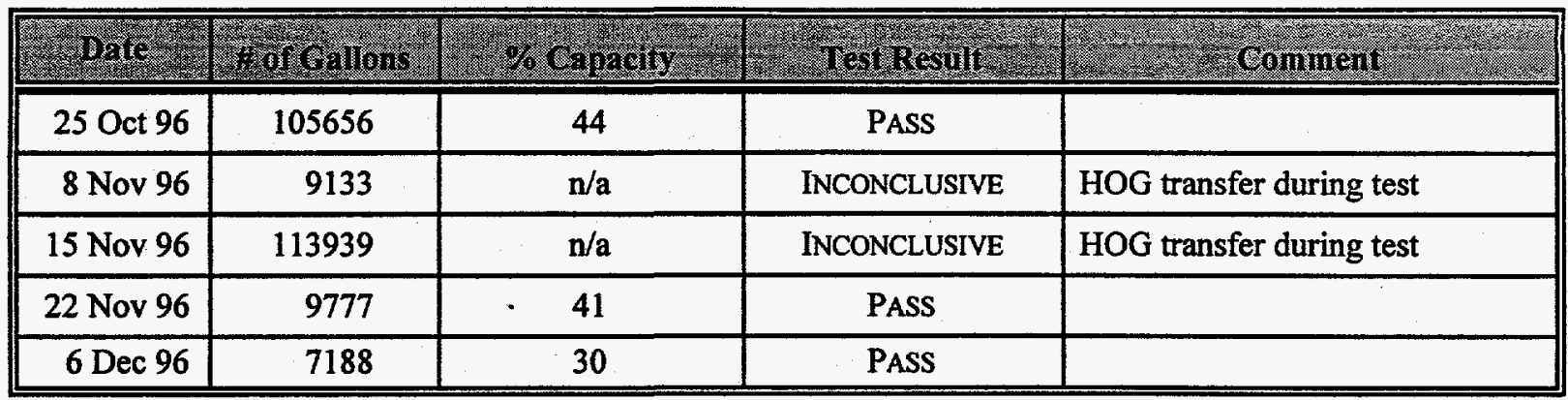

The 14 usable compensated volume rate (CVR) values from these leak tests were analyzed (1) to verify that the test method was performing properly in this application and (2) to confirm that during this assessment period the use and performance of the leak testing method had not deteriorated. This analysis included a statistical examination of the CVR data, as well as a comparison of this year's assessment data with prior data. The analysis and the results are described in Section 7.5.4.3.

\subsubsection{WC-9 Pipelines}

The results of the leak detection tests on the testable WC-9 pipelines are summarized in Section 7.5.4.2.1. An assessment of the integrity of the WC-9 pipelines that cannot be tested for leaks with existing approved methods is summarized in Section 7.5.4.2.2.

\subsection{WC-9 Testable Pipelines}

There are two testable pipeline elements associated with the WC-9 system-a gravity-fed inlet line leading to WC-9 from Building 3503 (G1, segment 97), and a portion of the pressurized discharge line between the tank and VB-2. The gravity line from Building 3503 is no longer in service and therefore not tested. The discharge line, P2, is comprised of segments 27 and 301. This line was tested in January 1997; the test yielded a PASS result. Table 28 shows the results of the leak tests conducted on the WC-9 pipelines.

Table 28. Summary of the Leak Test Results for the WC-9 Testable Lines

\begin{tabular}{|c|c|c|c|c|}
\hline Nongin 10 . & 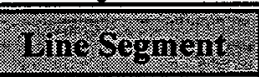 & Plon & 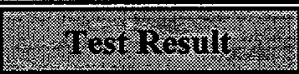 & W(1) \\
\hline P2 & 27,301 & $31 \operatorname{Jan} 97$ & PASS & \\
\hline
\end{tabular}

\subsection{WC-9 Untestable Pipelines}

There are six untestable line segments associated with the WC-9 tank system. Three of these segments, $140,152,159,164$, and 212, are no longer in service. Segments 157 and 132 make up the transfer line connecting the HOG pot to the WC-9 tank. This transfer line is in use but transfer data are not available due to lack of accurate level instrumentation on the HOG pot. 


\subsubsection{Analysis of Tank WC-9 Leak Test Data}

During this assessment period, a total of 35 leak tests were attempted on Tank WC-9; of these, 14 tests resulted in conclusive decisions. Figure 23 shows a time series plot of the CVR data obtained from each of the usable test results. It can be seen from the plot that all 14 of the CVR values are within the inflow decision and outflow decision thresholds, and are thus consistent with a PASS result.

A comparative analysis of the data shown in Figure 23 was performed. The analysis included using the Student's t-test [Mendenhall, 1992] and the Kolmogorov-Smirnov test (KS) [Benjamin and Cornell, 1970]. The Student's t-test is used to determine the significance of the mean of the CVR data. The KS analysis is used to determine if the population of CVR values from WC-9 is significantly different from a reference set of CVRs. These statistical tests are fully described in Section 5.4.

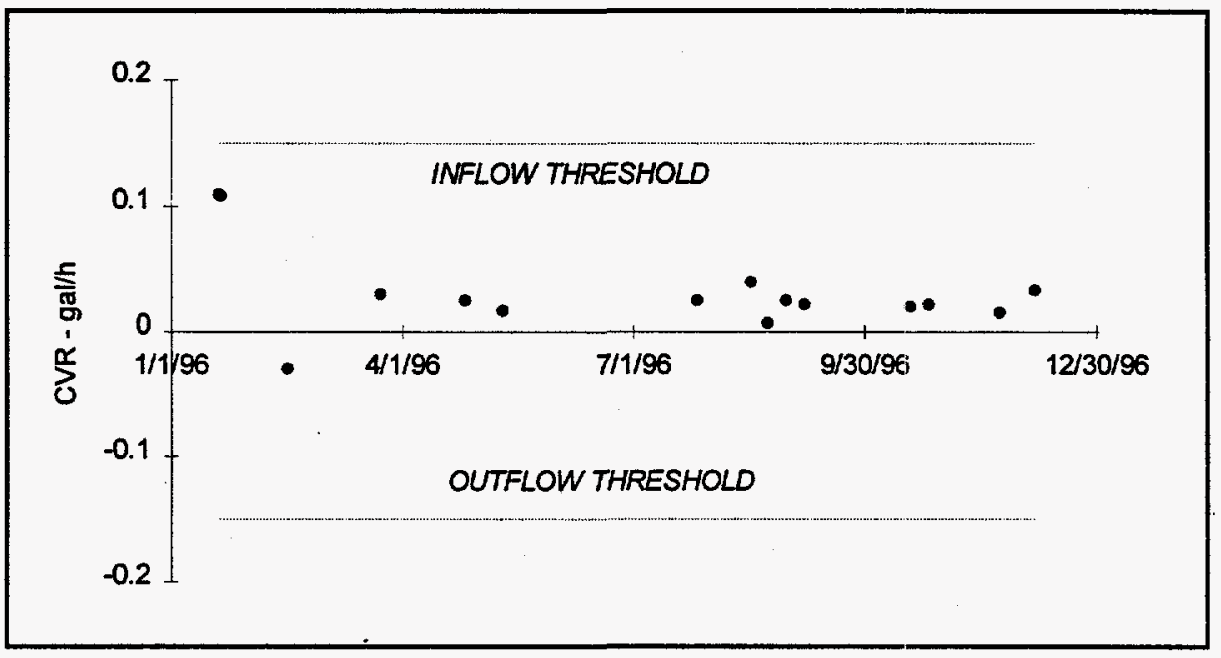

Figure 23. Time series plot of leak test CVRs from Tank WC-9.

Applying the $t$-test to the 14 data values shown above results in a $t$-statistic, $t_{\text {stat }}$ of 3.25 , while the critical value, $t_{\text {crit }}$, with a $99 \%$ level of confidence is 3.01 . Based upon these numbers, we conclude that the mean of the 1996 CVR data from Tank WC-9 is not equivalent to $0 \mathrm{gal} / \mathrm{h}$. This indicates that there might be an instrument calibration problem, additional drainage from the frequent HOG pot transfers, or other sources of small inleakage to the tank.

Figure 24 graphically illustrates the KS test applied to the WC-9 data. The bold line in the figure shows the CDF obtained from the CVR data shown in Figure 23, after the mean has been removed from the data. This CDF shows that the total "spread" about the mean in the CVR data is very small. The light line in the figure shows the CDF obtained from the reference set of CVR values (see Section 5.4) after the mean has been removed from the data. The similarity of the data sets defined by the two lines illustrated in Figure 27 is "tested" with the KS "goodness-of-fit" test. Here, the test statistic, $\mathrm{KS}_{\text {stat }}$ is 0.12 , while the critical 
value, $\mathrm{KS}_{\text {crit }}$ is 0.42 . Since $\mathrm{KS}_{\text {stat }}$ the maximum ordinal difference between the $\mathrm{CDF}$ and the test $\mathrm{CDF}$, is less than $\mathrm{KS}_{\text {crit }}$ the two populations are deemed to be equivalent.

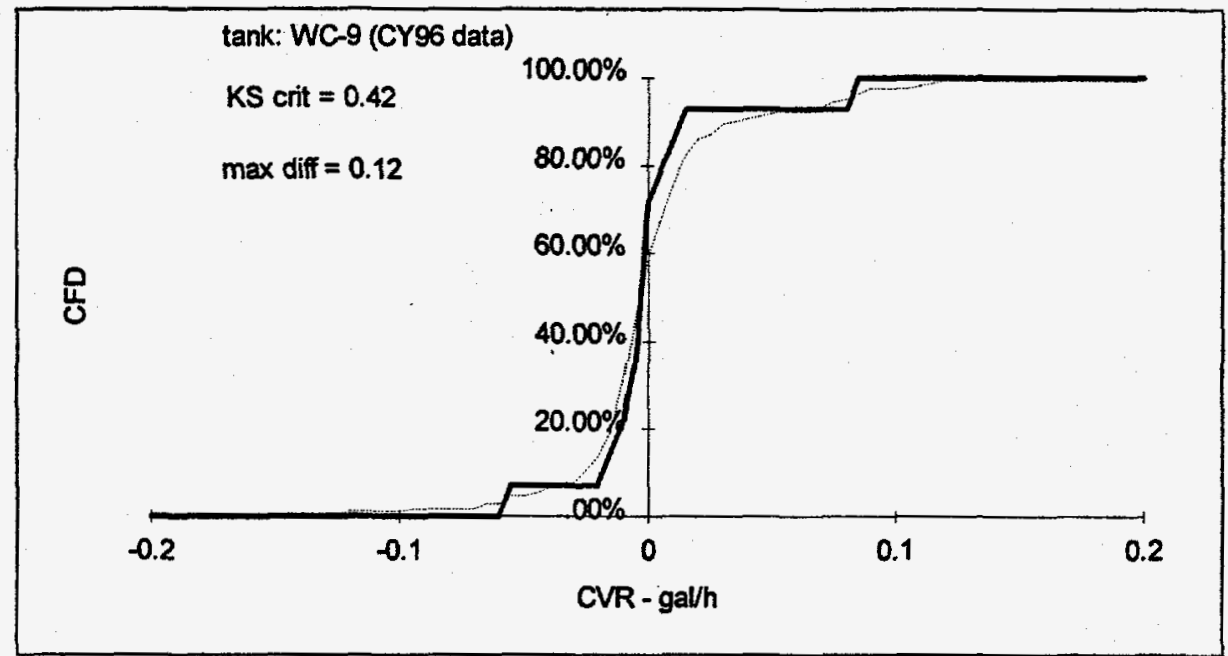

Figure 24. Cumulative frequency distribution from reference CVR data (light line) and WC-9 CY96 CVR data (bold line).

Table 29 summarizes the statistical analyses of the Tank WC-9 CVR data. The table shows that while the population of CY96 CVR values is equivalent to the population of CVR values in the reference (or comparison) data set, the mean of the CY96 test data is not equivalent to $0 \mathrm{gal} / \mathrm{h}$. Based upon these data it is recommended that the dp cell attached to WC-9, as well as other WC-9-related leak test hardware, be re-calibrated to minimize instrument error in the interpretation of the CVR data.

Table 29. Summary of the Statistical Analyses of WC-9 CVR Data $(H / \mathrm{V}=23.88 \mathrm{gal} / \mathrm{in}$.)

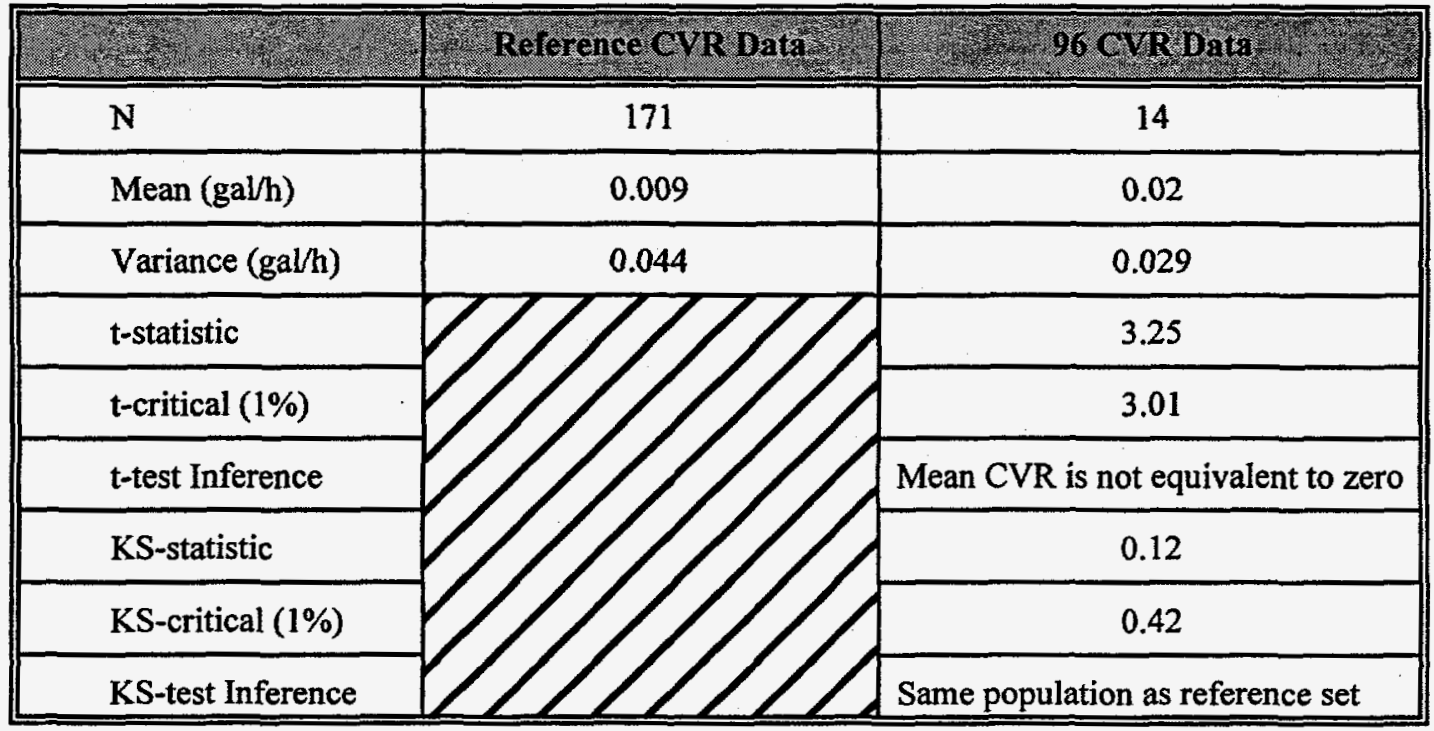




\subsubsection{Findings and Conclusions}

The findings of this report are based on (1) a review of available tank design drawings, (2) a qualitative assessment of corrosion on the tank and pipelines, and (3) leak testing results from the tank and testable pipelines.

Review of the design drawings indicated that the tank was designed with an abundance of inlets into the tank which were not connected to pipelines. However, because the unused inlets are located on the top of the tank, the concern of leakage from the ports is nonexistent when operating at less than full tank capacity. The design drawings revealed a sound design of the WC-9 tank.

During the corrosion assessment, it was determined that with the present use of the tank system, all forms of corrosion on the interior walls of the tank and associated piping should be nonexistent. Corrosion damage that may have occurred when the tank was used in past environments cannot be assessed. Furthermore, an analysis of the general aspects of corrosion at ORNL revealed that corrosion of stainless steel by ORNL soil is not believed to be severe.

Leak testing of Tank WC-9 was completed by the Volumetric DP method in 35 tests. The tank passed 14 of the tests and had INCONCLUSIVE results in 21 tests.

Two of the three testable line segments passed leak testing by the GPD method. The third testable line segment was not tested because it has been removed from service.

No transfer logs are available for the untestable line segments currently in use.

All of these factors were considered in determining certification of the WC-9 system components. Table 30 summarizes the elements of the tank systems which were certified and the conditional limits on their certifications. 
Table 30. Summary of WC-9 Tank System Testing and Certification

\begin{tabular}{|c|c|c|c|c|c|c|}
\hline $\begin{array}{l}\text { System } \\
\text { Component }\end{array}$ & $\begin{array}{l}\text { Length } \\
\text { (ft) }\end{array}$ & $\begin{array}{l}\text { Tested } \\
\text { (Yes/No) }\end{array}$ & $\begin{array}{l}\text { Leak } \\
\text { Test } \\
\text { Method }\end{array}$ & Test Result & $\begin{array}{c}\text { Certificatio } \\
\text { n }\end{array}$ & $\begin{array}{l}\text { Certification } \\
\text { Level }\end{array}$ \\
\hline Tank WC-9 & $\mathrm{NA}$ & Yes & DP & PASS & Yes & $57 \%$ \\
\hline LS-27 & 1096 & Yes & GPD & PASS & Yes & Full Flow \\
\hline LS-97* & 200 & No & NT & NT & No & NA \\
\hline LS-132 & 20 & No & NT & NT & No & NA \\
\hline LS-140* & 16 & No & NT & NT & No & NA \\
\hline LS-152* & 11 & No & NT & NT & No & NA \\
\hline LS- 157 & 39 & No & NT & NT & No & NA \\
\hline LS-159* & 9 & No & NT & NT & No & NA \\
\hline LS-164* & 29 & No & NT & NT & No & $\mathrm{NA}$ \\
\hline LS-212* & 2 & No & NT & NT & No & NA \\
\hline LS-301 & 35 & Yes & GPD & PASS & Yes & Full Flow \\
\hline $\begin{array}{ll}* & \text { Out } \\
\text { GPD } & \text { Gas } \\
\text { DP } & \text { Diff } \\
\text { LS } & \text { Lin } \\
\text { NT } & \text { Not } \\
\text { NA } & \text { Not } \\
\end{array}$ & $\begin{array}{l}\text { f Service } \\
\text { ressure De } \\
\text { ential pres } \\
\text { egment } \\
\text { sted } \\
\text { oplicable } \\
\end{array}$ & & & & & \\
\hline
\end{tabular}




\subsubsection{Certification}

Based on the results of the design drawings review, the qualitative corrosion assessment, and the results of the leak testing program, it is my professional opinion that Tank WC-9 retains sufficient structural integrity to contain liquids at operating levels up to the maximum level which achieved a PASS during the testing program. Also, based upon the results of the pipeline tests, it is my professional opinion that Line Segments 27 and 301 retain sufficient structural integrity to contain liquids at operating levels up to full flow conditions. Table 30 provides a summary description of the certifications for the WC-9 Tank System. If future testing is conducted at greater tank levels, then the certification level may also increase.

It is recommended that leak detection and line testing using the EPA and TDEC approved methods be continued to support annual certification, until this system has been removed from operation or replaced.

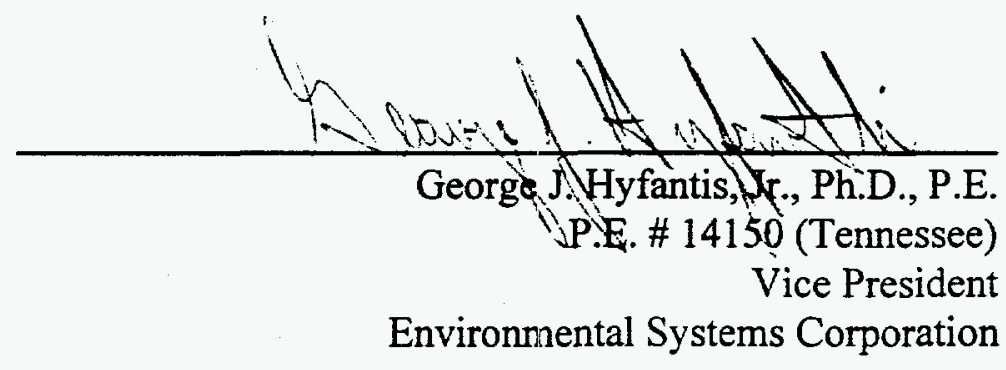




\subsection{WC-10 Tank System}

The WC-10 Tank System is located south of Building 3587, as shown in Figure 1. The WC-10 Tank System collects LLLW and rainwater from the Isotope Circle area. The tank system is made up of Tank WC-10 and seven line segments connected to the system. Because the lines and tank are all singly contained, the tank system has been classified as Category $\mathrm{C}$, according to the FFA.

\subsubsection{WC-10 Tank Description}

Tank WC-10 is a 2,300 gallon, buried, singly contained tank, installed in 1951. Tank WC-10 is mounted horizontally on two reinforced concrete pillars. The tank is constructed of stainless steel and has an unknown wall thickness. The outside diameter of the tank is $76^{\prime \prime}$ with a length of 124". The working volume of the tank is 1,650 gallons. The design drawing for Tank WC-10 is given in Figures 25 and 25A.

The tank is equipped with three 2 " diameter nozzles, one 3 " diameter nozzle, two $1 / 2 "$ diameter sample nozzles, three unused nozzles, and one manhole. All of the nozzles, including the manhole, are located on top of the tank aligned with the tank centerline.

The tank is anchored to the support pillars which are anchored to a 34'-0" x 16'-9" reinforced concrete pad. The pad also supports six other tanks, one horizontally mounted, five vertically mounted. The tank pad and all of the tanks are placed in an earthen pit which has been backfilled with gravel to the top of the tanks. The gravel was then covered with earth. The top of tank WC-10 is 10'-2" below the surface elevation. The tank is equipped with a precision level sensor and can be tested for leaks.

\subsubsection{WC-10 Pipeline Descriptions}

Seven separate line segments make up the portion of the LLLW pipeline system belonging to Tank WC-10. Characteristics of the lines are listed in Table 45. A schematic of the tank system with numbered line segments is shown in Figure 26. All pipelines associated with the WC-10 Tank System are constructed of stainless steel and were installed in 1951. 


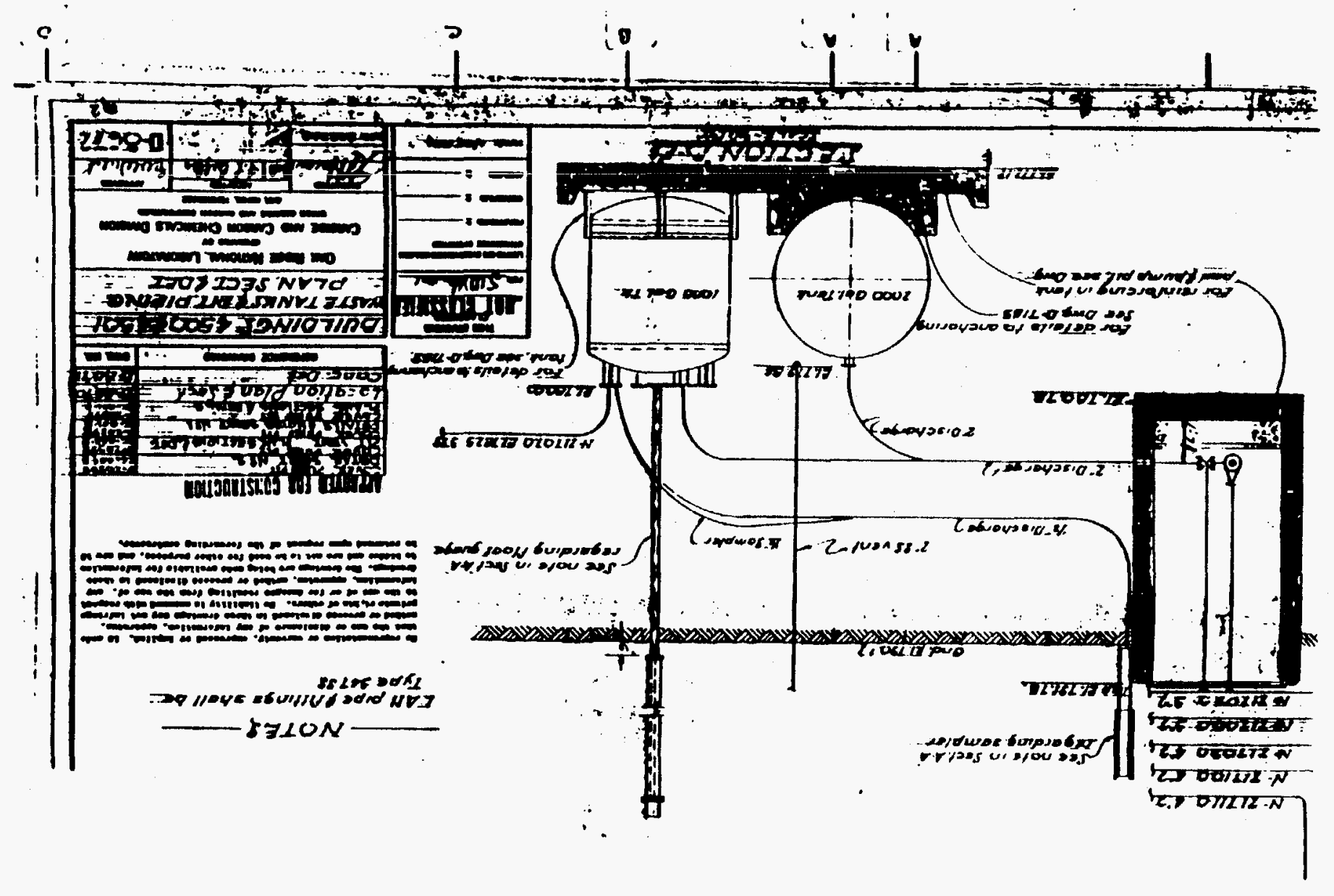




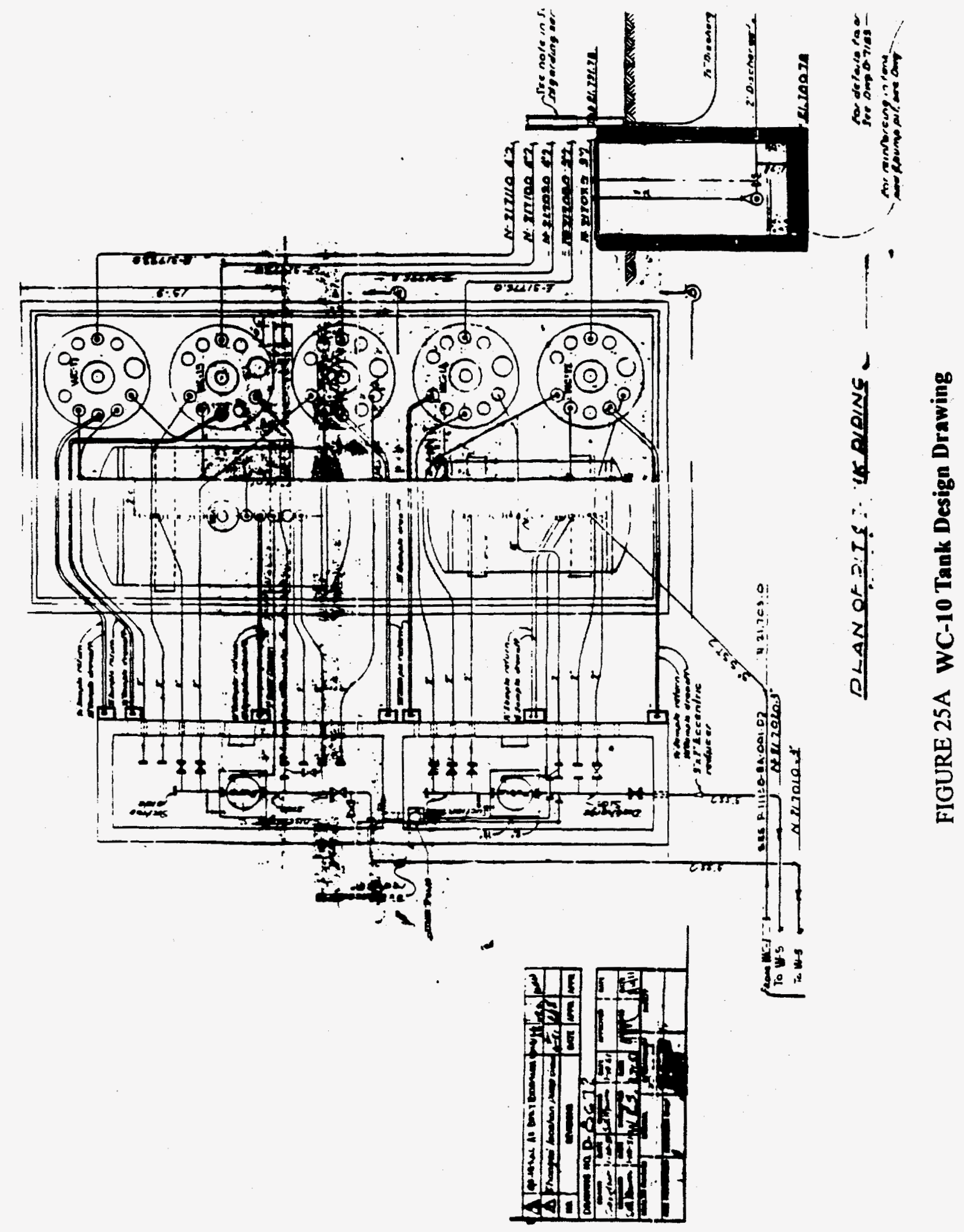




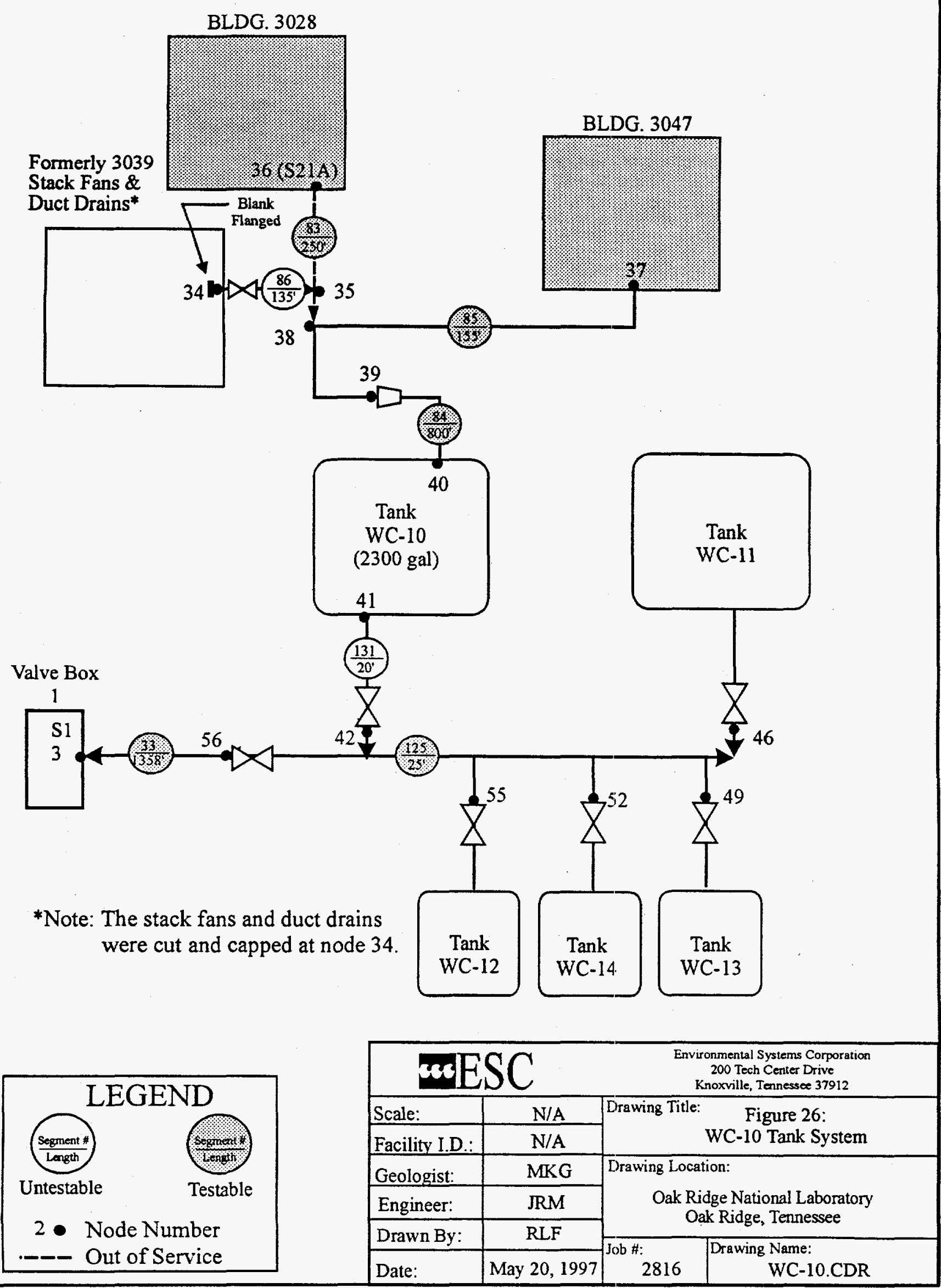


Table 31. Characteristics of Line Segments Evaluated as a Part of Tank System WC-10

\begin{tabular}{|c|c|c|c|c|c|c|c|}
\hline Gine Segment & 33 & $83^{*}$ & 84 & 85 & $86^{*}$ & 125 & 131 \\
\hline Node Numbers & $\begin{array}{l}56 \text { to } \\
\text { S1-N3 }\end{array}$ & $\begin{array}{c}\mathrm{S} 21-\mathrm{N} 36 \\
\text { to } 35\end{array}$ & 39 to 40 & 37 to 39 & 34 to 35 & 46 to 42 & 41 to 42 \\
\hline Index Number & P6 & G29 & G32 & G32 & & P6 & \\
\hline Diameter (in) & 3 & 6 & 3 & 6 & 6 & 2 & 2 \\
\hline Material & SS & SS & SS & SS & SS & SS & SS \\
\hline Length (ft) & 1358 & 250 & 800 & 155 & 135 & 25 & 20 \\
\hline Volume (gal) & 522 & 375 & 307 & 233 & 203 & 6 & 4 \\
\hline $\begin{array}{l}\text { Transfer } \\
\text { Method }\end{array}$ & $\mathbf{P}$ & SJ\&G & G & G & G & $\mathbf{P}$ & $\mathbf{P}$ \\
\hline Install Date & 1951 & 1951 & 1951 & 1951 & 1951 & 1951 & 1951 \\
\hline $\begin{array}{ll}* & \text { Out of } \\
\text { G } & \text { Gravity } \\
\text { P } & \text { Pressur } \\
\text { SJ } & \text { Steam } \\
\text { SS } & \text { Stainle }\end{array}$ & $\begin{array}{l}\text { rvice } \\
\text { pump } \\
\text { Steel }\end{array}$ & & & & & & \\
\hline
\end{tabular}

As shown in Figure 26, Tank WC-10 has one gravity-fed inlet line and one pressure discharge pipeline. The remaining five line segments are not directly connected to Tank WC-10. There are three testable stainless steel pipeline elements associated with Tank System WC-10. The first testable element, element No. G32, is made up of two line segments. Line Segment 85 is a testable gravity-fed line that runs 155' from Building 3047 to a reducing bushing located in the inlet line (node 37 to node 39). Line Segment 84 runs $800^{\prime}$ from the reducing bushing (which converts Line Segment 85 from 6" diameter to 3" diameter), into Tank WC-10 (node 39 to node 40 ).

The second testable line of the WC-10 Tank System is identified as Element G29. The element is made up of Line Segments 83 and 84, and runs from Building 3028 to Tank WC-10. Line Segment 83 is a 6 " diameter gravity-fed line that runs $250^{\prime}$ from node 36 (S21A on Figure 29) at Building 3028 to node 38. Line Segment 84, also a part of the first testable element of WC-10, is described above. Line Segment 83 is no longer in service.

The third testable element of the WC-10 Tank System is Element P6, and consists of Line Segments 33 and 125. This element is a pressurized portion of the discharge line leading from Tanks WC-10 and WC-11 to Valve Box 1. This element runs from nodes 46, $49,52,55$, and 42 , to node $3(\mathrm{~S} 1)$. This element has a total length of $1383^{\prime}$, and has sections with diameters of $2 "$ and $3 "$.

The pipeline identified as Line Segment 86 originates as a drain for stack fans and duct drains in Building 3039 and connects to the 6" diameter line, Line Segment 83, at node 35. The duct drains have been cut and capped. Line Segment 86 is $135^{\prime}$ in length and has a 6" diameter. Line Segment 86 is not used and therefore was not leak tested. The second 
untestable line segment is a 20'-2" section of discharge line identified as Line Segment 131 (node 41 to 42). This segment cannot be tested because it cannot be isolated at the tank end of the line.

\subsubsection{Corrosion Assessment of the WC-10 Tank System}

Tank WC-10 collects waste from hot cells in Buildings 3028 through 3033, 3047, and 3118. For the past several years, most of the liquid materials added to the tank were decontaminating solutions including nitric acid, oxalic acid, potassium permanganate, and commercial cleansers such as Ajax and Mr. Clean. Only diluted solutions have been used, and these have been further diluted with large volumes of rinse water. After additions to the tank, drain lines are always flushed with water. As with the solutions in most waste tanks, the $\mathrm{pH}$ is maintained at a high value by adding a strong caustic to the tank after each emptying.

Under the present mode of operation, the interior surfaces of the tank should experience only slight corrosion. It is probable, however, that for some periods during the greater than 40 year life of the tank, the $\mathrm{pH}$ was neither neutral nor acid, and corrosion may have been appreciable.

In November 1993, an attempt was made to determine the cumulative damage to the interior tank walls during its life. A small video camera was inserted into the tank and a video cassette was made. Examination of the video indicated no evidence of gross corrosion damage. Most of the wetted surfaces were covered with a scale that in some areas appeared to contain iron (red) and in other areas seemed much lighter in color. It is possible that heavy scale may have obscured heavy attack beneath it. In some scaled areas, there appeared to be many pits, but these may be small areas where some of the scale had spalled. The resolution of the video was not sufficient to determine the thickness of the scale, the depth of the apparent pits, or the morphology of the surface.

Based on information cited in Section 4.0, corrosion damage to the exterior surfaces of the buried 347 stainless steel tank and pipelines associated with it are probably not extensive.

\subsubsection{Results of Leak Tests on the WC-10 System}

This section summarizes the results of the leak detection tests conducted on Tank System WC-10 (the tank and its associated pipelines). Each test was completed with a method appropriate for that element. Each method used has been demonstrated to detect a specified leak rate $(0.2 \mathrm{gal} / \mathrm{hr}$ for the monthly tank testing; $0.1 \mathrm{gal} / \mathrm{hr}$ for the annual pipeline testing) with a probability of detection $(\mathrm{PD})$ no less than $95 \%$ and a probability of false alarm $\left(\mathrm{PFA}_{\mathrm{FA}}\right.$ no greater than $5 \%$. 


\subsubsection{WC-10 Tank}

Leak testing of Tank WC-10 began in January 1996 and continued at frequent intervals through December 1996, with a total of 33 leak test attempts during this reporting period. The results of these tests are summarized in Table 32, which shows the date of each test, the volume of LLLW in the tank at the time of the test, the percent of Tank WC-10's total volume the test represented, ${ }^{9}$ the test result, and comments pertinent to particular tests. The table shows that there were 10 PASS results achieved this period, 15 INFLOW results, and 8 INCONCLUSIVE results. The PASS results were obtained as a direct result of two repairs to a pipeline leading to the tank that was allowing ground water to enter. These repairs were accomplished in April and May of 1996.

The 25 usable CVR values from these leak tests were analyzed (1) to verify that the test method was performing properly in this application and (2) to confirm that during this assessment period the use and performance of the leak testing method had not deteriorated. This analysis included a statistical examination of the CVR data, as well as a comparison of this year's assessment data with prior data. The analysis and the results are described in Section 7.6.4.3.

\subsubsection{WC-10 Pipelines}

The results of the leak detection test on the testable WC-10 pipelines are summarized in Section 7.6.4.2.1. An assessment of the integrity of the WC-10 pipelines that cannot be tested for leaks with existing approved methods is summarized in Section 7.6.4.2.2.

\subsection{WC-10 Testable Pipelines}

There are three testable lines in the WC-10 system. One is a gravity-fed inlet line from Building 3047 to tank WC-10 (G32, segments 84 and 85); this line was tested on June 9,1997 and received an INCONCLUSIVE result due to variable inflows into the tank. However, a comparison of the volume of liquid received in the tank to the volume of liquid pumped into the pipeline drain, shows that there is no reason to conclude that the line is not tight. Another testable line is a portion of the discharge piping leading from the tank to VB-1 (P6, segments 33 and 125); this line was tested in March 1997, achieving a PASS result. A third testable line is a gravity-fed inlet line from Building 3028 to Tank WC-10 (G29, segment 83 ); this line is not used and therefore will not be tested. Table 32 summarizes the results of the leak tests conducted on the WC-10 pipelines.

${ }^{9}$ WOCC look-up tables show $100 \%$ capacity for WC-10 as 2,300 gal. The percent capacity shown in the table is based on this number. 
Table 32. Summary of Leak Tests Conducted on Tank WC-10

\begin{tabular}{|c|c|c|c|c|}
\hline Pretre Dare & \# of Gallons & $\% \%$ Capacity & Test Result & W Comment \\
\hline $12 \operatorname{Jan} 96$ & 433 & 19 & INFLOW & \\
\hline $26 \operatorname{Jan} 96$ & 627 & 27 & INFLOW & \\
\hline 2 Feb 96 & 805 & $\mathbf{n} / \mathbf{a}$ & INCONCLUSIVE & \\
\hline 9 Feb 96 & 975 & 42 & INFLOW & \\
\hline 16 Feb 96 & 474 & 21 & INFLOW & \\
\hline 23 Feb 96 & 1039 & 45 & INFLOW & \\
\hline 1 Mar 96 & 543 & 24 & INFLOW & \\
\hline 22 Mar 96 & 1248 & 54 & INFLOW & \\
\hline 29 Mar 96 & 779 & 34 & INFLOW & \\
\hline 5 Apr 96 & 747 & $\mathrm{n} / \mathrm{a}$ & INCONCLUSIVE & \\
\hline 12 Apr 96 & 886 & 39 & INFLOW & \\
\hline 19 Apr 96 & 386 & 17 & INFLOW & \\
\hline 26 Apr 96 & 932 & 41 & INFLOW & \\
\hline 3 May 96 & 349 & 15 & INFLOW & \\
\hline 10 May 96 & 1180 & 51 & INFLOW & \\
\hline 17 May 96 & 541 & 24 & PASS & \\
\hline 24 May 96 & 928 & $\mathrm{n} / \mathrm{a}$ & INCONCLUSIVE & \\
\hline 7 Jun 96 & 507 & $\mathrm{n} / \mathrm{a}$ & INCONCLUSIVE & \\
\hline 5 Jul 96 & 403 & 18 & PASS & \\
\hline 26 Jul 96 & 1192 & 52 & PASS & \\
\hline 2 Aug 96 & 410 & 18 & PASS & \\
\hline 9 Aug 96 & 443 & $\mathrm{n} / \mathrm{a}$ & INCONCLUSIVE & \\
\hline 16 Aug 96 & 452 & 20 & PASS & \\
\hline 23 Aug 96 & 480 & $n / a$ & INCONCLUSIVE & \\
\hline 30 Aug 96 & 1072 & 47 & INFLOW & \\
\hline $6 \operatorname{Sep} 96$ & 876 & $\mathrm{n} / \mathrm{a}$ & INCONCLUSIVE & \\
\hline 13 Sep 96 & 1028 & 45 & INFLOW & \\
\hline 20 Sep 96 & 1071 & 47 & PASS & \\
\hline 11 Oct 96 & 475 & $\mathrm{n} / \mathrm{a}$ & INCONCLUSIVE & \\
\hline 18 Oct 96 & 617 & 27 & PASS & \\
\hline 25 Oct 96 & 655 & 28 & PASS & \\
\hline 8 Nov 96 & 775 & 34 & PASS & \\
\hline $6 \operatorname{Dec} 96$ & 1292 & 56 & PASS & New high level \\
\hline
\end{tabular}


Table 33. Summary of Leak Test Results for the WC-10 Testable Lines

\begin{tabular}{|c|c|c|c|c|}
\hline Element No. & Cine Segment & Test Date & Test Result & Comment \\
\hline G32 & 84,85 & June 9, 1997 & INCONCLUSIVE & Variable inflow into tank \\
\hline P6 & 33,125 & April 2, 1997 & PASS & \\
\hline
\end{tabular}

\subsection{WC-10 Untestable Pipelines}

The untestable portion of the WC-10 system (Line Segments 86 and 131) consists of the gravity-fed line between the Building 3039 stack, fans and duct drain and Tank WC-10, and a portion of the discharge line leading from Tank WC-10 to Valve Box 1. The drains to the gravity drain line (Line Segment 86) have been cut and capped in the 3039 stack area and therefore, this line segment is not in use. However, the discharge line carries transfers from Tank WC-10 through Valve Box 1 to Tank W-22, and the volume in both of these tanks is measured and recorded by WOCC. Transfer logs show that during the period from January 1996 through December 1996, 19 transfers were made through the line. These transfers are summarized in the first four columns of Table 34. The difference between the volume sent (column 3 ) and the volume received (column 4) is shown in column 5.

For the WC-10-to-W-22 transfers, the expected error was 141 gal. Three of the 19 recorded transfers showed input-output volume differences greater than the maximum expected error. Two of these three transfer differences were positive, however, indicating that more liquid was measured going into Tank W-22 than was measured leaving Tank WC10. This result suggests numerical errors in the volume balance, or unrecorded flush or prime water that was added to the system. One transfer, conducted on May 4, recorded a significant negative difference. However, comments in the transfer logs indicated that this line was empty prior to the transfer. Since part of the volume transferred out of Tank WC-10 would be used to re-fill the previously empty pipeline, it is expected that the volume received at W-22 would be less than was sent. Thus, no further investigation is warranted at this time.

Table 34. Summary of Transfers between WC-10 and W-22 from January through December 1996

\begin{tabular}{|c|c|c|c|c|c|c|}
\hline $\begin{array}{c}\text { Transfer } \\
\text { Date }\end{array}$ & Transfer Log & $\begin{array}{c}\text { Volume } \\
\text { Sent } \\
\text { (gal) }\end{array}$ & $\begin{array}{c}\text { Volume } \\
\text { Received } \\
\text { (gal) }\end{array}$ & Difference & $\begin{array}{c}\text { Maximum } \\
\text { (gal) }\end{array}$ & $\begin{array}{c}\text { Is difference } \\
\text { greater than } \\
\text { (gal) }\end{array}$ \\
\hline \hline expected error? \\
\hline 13 Jan 96 & WC-10 to W-22 & 1023 & 1080 & 57 & 141 & No \\
\hline 24 Jan 96 & WC-10 to W-22 & 990 & 990 & 0 & 141 & No \\
\hline 4 Feb 96 & WC-10 to W-22 & 750 & 980 & 230 & 141 & Yes \\
\hline 15 Feb 96 & WC-10 to W-22 & 1039 & 1039 & 0 & 141 & No \\
\hline 29 Feb 96 & WC-10 to W-22 & 1030 & 1030 & 0 & 141 & No \\
\hline 11 Mar 96 & WC-10 to W-22 & 1043 & 1243 & 200 & 141 & No \\
\hline 26 Mar 96 & WC-10 to W-22 & 312 & 312 & 0 & 141 & Yes \\
\hline
\end{tabular}




\begin{tabular}{|r|c|c|c|c|c|c||}
\hline $\begin{array}{c}\text { Transfer } \\
\text { Date }\end{array}$ & Transfer Log & $\begin{array}{c}\text { Volume } \\
\text { Sent } \\
\text { (gal) }\end{array}$ & $\begin{array}{c}\text { Volume } \\
\text { Received } \\
\text { (gal) }\end{array}$ & $\begin{array}{c}\text { Difference } \\
\text { (gal) }\end{array}$ & $\begin{array}{c}\text { Maximum } \\
\text { Expected Error } \\
\text { (gal) }\end{array}$ & $\begin{array}{c}\text { Is difference } \\
\text { greater than } \\
\text { expected error? }\end{array}$ \\
\hline 19 Apr 96 & WC-10 to W-22 & 1070 & 1070 & 0 & 141 & No \\
\hline 30 Apr 96 & WC-10 to W-22 & 1232 & 1232 & 0 & 141 & No \\
\hline 4 May 96 & WC-10 to W-22 & 1040 & 690 & -350 & 141 & Yes \\
\hline 14 May 96 & WC-10 to W-22 & 1082 & 1040 & -42 & 141 & No \\
\hline 24 May 96 & WC-10 to W-22 & 1064 & 1050 & -14 & 141 & No \\
\hline 9 Jun 96 & WC-10 to W-22 & 1056 & 1056 & 0 & 141 & No \\
\hline 26 Jun 96 & WC-10 to W-22 & 950 & 960 & 10 & 141 & No \\
\hline 4 Sep 96 & WC-10 to W-22 & 1100 & 1100 & 0 & 141 & No \\
\hline 28 Sep 96 & WC-10 to W-22 & 951 & 951 & 0 & 141 & No \\
\hline 12 Oct 96 & WC-10 to W-22 & 825 & 825 & 0 & 141 & No \\
\hline 9 Dec 96 & WC-10 to W-22 & 935 & 935 & 0 & 141 & No \\
\hline
\end{tabular}

${ }^{1}$ The line had been emptied to conduct FFA-required GPD test.

\subsubsection{Analysis of Tank WC-10 Leak Test Data}

During this assessment period, a total of 33 leak tests were attempted on Tank WC10; of these, eight tests resulted in inconclusive decisions and 25 in conclusive decisions. From the 25 conclusive results, there were 15 INFLOW results and 10 PASS results. Figure 27 shows a time series plot of the CVR data obtained from each of the 25 conclusive results. Figure 27 shows that the CVR values from the leak tests from January through mid-May were clearly consistent with the INFLOW results obtained during the time. The CVR data abruptly changes in May, however, as a result of the repairs to the inlet pipeline. After the repairs, it is seen that the CVR data indicates mostly PASS results. The analysis of the CVR data (below) was performed for the entire year so as to be consistent with the analysis of other tank systems reported in this assessment reports, and it was concluded that the tank has an inflow. However, has the analysis been limited to just the last six months of data and the first months of CY97, it would probably show that Tank WC-10 is likely tight and free of leaks.

A comparative analysis of the data shown in Figure 27 was performed. The analysis included using the Student's t-test [Mendenhall, 1992] and the Kolmogorov-Smirnov test (KS) [Benjamin and Cornell, 1970]. The Student's t-test is used to determine the significance of the mean of the CVR data. The KS analysis is used to determine if the population of CVR values from WC-10 is significantly different from a reference set of CVRs. These statistical tests are fully described in Section 5.4. 


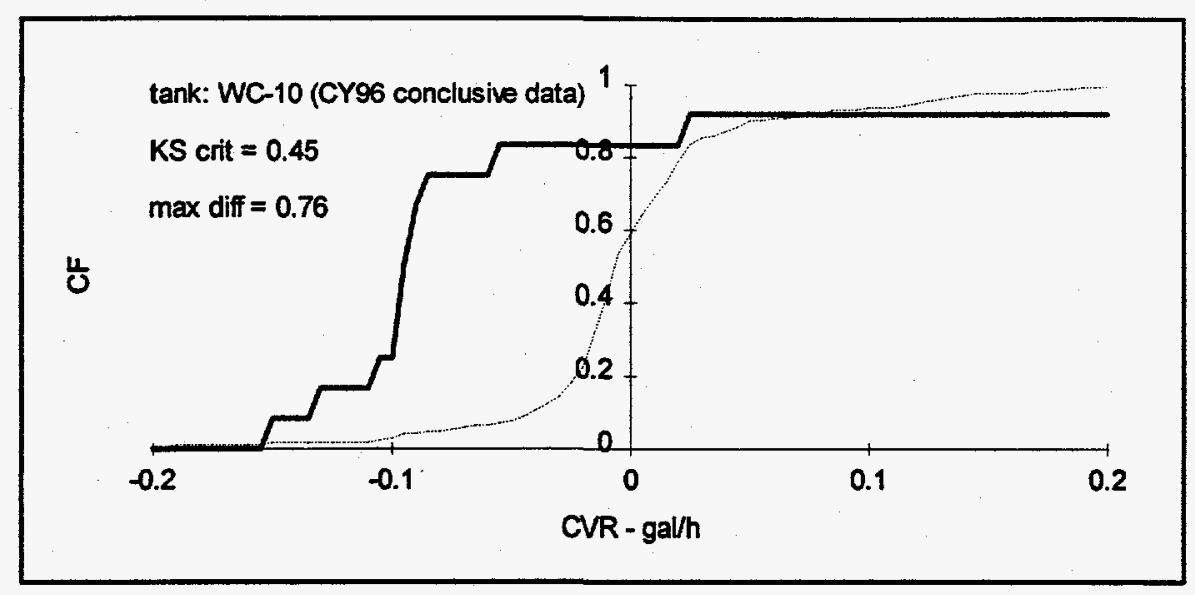

Figure 27. Time series plot of leak test CVRs from Tank WC-10.

Applying the $t$-test to the 25 data values shown above results in a t-statistic, $t_{\text {stat }}$ of 41.8 , while the critical value, $t_{\text {crit }}$, with a $99 \%$ level of confidence is 2.71 . Based upon these numbers, we conclude, obviously, that the mean of the 1996 CVR data from Tank WC-10 is not equivalent to $0 \mathrm{gal} / \mathrm{h}$.

Figure 28 graphically illustrates the KS test applied to the WC-10 data. The light line in the figure shows the CDF obtained from the reference set of CVR values (see Section 5.4), after the mean has been removed from those data and after those values have been scaled by the H/V coefficient of WC-10 (38 gal/in.), divided by the H/V of the (meanremoved) reference set $(14.72 \mathrm{gal} / \mathrm{in}$.). The bold line in the figure shows the CDF obtained from the CVR data shown in Figure 29, after the mean has been removed from the data. The similarity of the data sets defined by the two lines illustrated in Figure 28 is "tested" with the KS "goodness-of-fit" test. Here, the test statistic, $\mathrm{KS}_{\text {stat }}$, is 0.36 , while the critical value, $\mathrm{KS}_{\text {crit }}$, is 0.26 . Since $\mathrm{KS}_{\text {stat }}$, the maximum ordinal difference between the CDF and the test $\mathrm{CDF}$, is greater than $\mathrm{KS}_{\text {crit }}$, the two populations are deemed to be different.

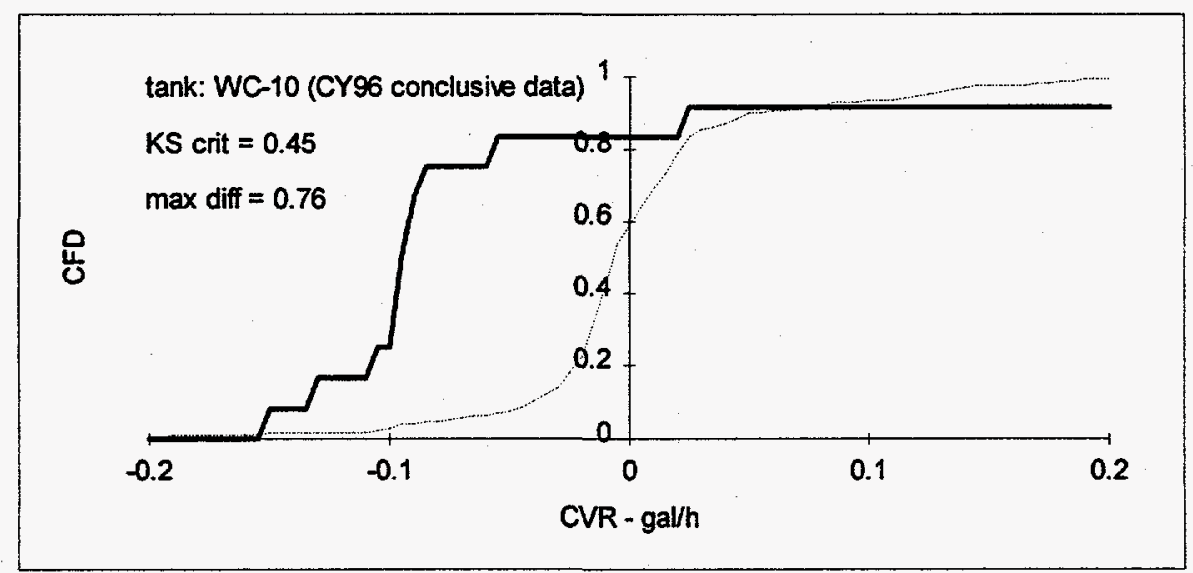

Figure 28. Cumulative frequency distributions from the reference CVR data (light line) and WC-10 CY96 CVR data (bold line). 
Table 35 summarizes the statistical analyses of the Tank WC-10 CVR data. The table shows that the mean of the CY96 test data is not equivalent to $0 \mathrm{gal} / \mathrm{h}$, and that the population of CY96 CVR values is different than the population of CVR values in the reference, or comparison data set.

Table 35. Summary of Statistical Analyses of WC-10 CVR Data (H/V =38 gal/in.)

\begin{tabular}{|l|c|c|}
\hline & Rererence CVR data & 96 CVRdata \\
\hline $\mathrm{N}$ & 118 & 25 \\
\hline Mean (gal/h) & 0.012 & 3.42 \\
\hline Variance (gal/h) & 0.080 & 0.505 \\
\hline $\mathrm{t}$-statistic \\
\hline $\mathrm{t}$-critical (1\%) \\
\hline $\mathrm{t}$-test Inference \\
\hline KS-statistic \\
\hline KS-critical (1\%) \\
\hline KS-test Inference
\end{tabular}

\subsubsection{Findings and Conclusions}

The findings of this report are based on (1) a review of available tank design drawings, (2) a qualitative assessment of corrosion on the tank and pipelines, and (3) leak testing results from the tank and testable pipelines.

Review of the design drawings indicated that the tank was designed in accordance with acceptable practices defined by ASTM and ASME. One concern noted was an abundance of inlets into the tank which were not connected to pipelines. However, because the unused inlets are located on the top of the tank, the concern of leakage out of the tank through the ports is nonexistent at operation levels of less than full tank capacity. The design drawings revealed a sound design of the WC-10 Tank.

During the corrosion assessment, it was determined that with the present use of the tank system, all forms of corrosion on the interior walls of the tank and associated piping should be nonexistent. However, corrosion damage that may have occurred when the tank was used in past environments cannot be assessed. An attempt to determine cumulative damage to the interior tank wells during its entire life revealed substantial iron containing scale on some areas of the tank. Heavy attack corrosion may be obscured beneath the scaled areas. An analysis of the general aspects of corrosion at ORNNL revealed that corrosion of stainless steel by ORNL soil is not believed to be severe.

Leak testing of Tank WC-10 was completed by the Volumetric DP method in 33 tests. The tank had INCONCLUSIVE results in eight tests, INFLOW results for 15 tests and PASS results for 10 tests. 
Two of five testable line segments passed leak testing by the Gas Pressure Decay Method. Two other segments were tested by the EVB method with INCONCLUSIVE results. The remaining testable line segment is not used and was not tested.

Transfer records were used to qualitatively assess the pipelines which are untestable by currently approved methods. Transfer logs reveal that 19 transfers were made during the period from January 1996 through December 1996. Although the difference in the volume sent and the volume received exceeded the expected error in three transfers, none of these suggest a leak in the line. The volume of each of the transfer along with the latest qualitative assessment of the pipelines are reported to EPA and TDEC in the "Quarterly Highlights for LLLW Tank System Activities." Although a limited evaluation of the untestable pipelines can be made using transfer logs, this method of assessment is not deemed valid for certification purposes.

All of these factors were considered in determining certification of the WC-10 system components. Table 36 summarizes the elements of the tank system which were certified and the conditional limits on their certifications.

Table 36. Summary of Tank System Certification for Tank WC-10

\begin{tabular}{|c|c|c|c|c|c|c|}
\hline $\begin{array}{l}\text { System } \\
\text { Component }\end{array}$ & $\begin{array}{l}\text { Length } \\
\text { (ft) }\end{array}$ & $\begin{array}{c}\text { Tested } \\
\text { (YesiNo) }\end{array}$ & $\begin{array}{l}\text { Leak Test } \\
\text { Method }\end{array}$ & Test Result & Certification & $\begin{array}{c}\text { Certification } \\
\text { Level }\end{array}$ \\
\hline Tank WC-10 & & Yes & DP & INCONCLUSIVE & NA & NA \\
\hline LS-33 & 1358 & Yes & GPD & PASS & Yes & Full flow \\
\hline LS-83* & 250 & No & NT & NT & No & NT \\
\hline LS-84 & 800 & Yes & EVB & INC & No & NA \\
\hline LS-85 & 155 & Yes & EVB & INC & No & NA \\
\hline LS-86* & 135 & No & NT & NT & No & NA \\
\hline LS- 125 & 25 & Yes & GPD & PASS & Yes & Full flow \\
\hline LS-131 & 20 & No & NT & NT & No & NT \\
\hline $\begin{array}{ll}\text { * } & \mathrm{O} \\
\text { DP } & \mathrm{Di} \\
\text { EVB } & \mathrm{En} \\
\text { LS } & \mathrm{Li} \\
\mathrm{NT} & \mathrm{Nc} \\
\text { GPD } & \mathrm{Ga} \\
\mathrm{NA} & \mathrm{Nc}\end{array}$ & $\begin{array}{l}\text { ice } \\
1 \text { pressure } \\
\text { volume bal } \\
\text { ent } \\
\text { re decay } \\
\text { able }\end{array}$ & & & & & \\
\hline
\end{tabular}




\subsubsection{Certification}

Based on the results of the design drawings review, the qualitative corrosion assessment, and the results of the leak testing program, it is my professional opinion that Tank WC-10 cannot be certified at this time. Based upon the results of the pipeline tests, it is my professional opinion that Line Segments 33 and 125 retain sufficient integrity to contain liquids up to the full flow potential of this line segment. Table 36 provides a summary description of the certifications for the WC-10 Tank System.

It is recommended that leak detection and line testing using the EPA and TDEC approved methods be continued, until this system has been removed from operation or replaced.

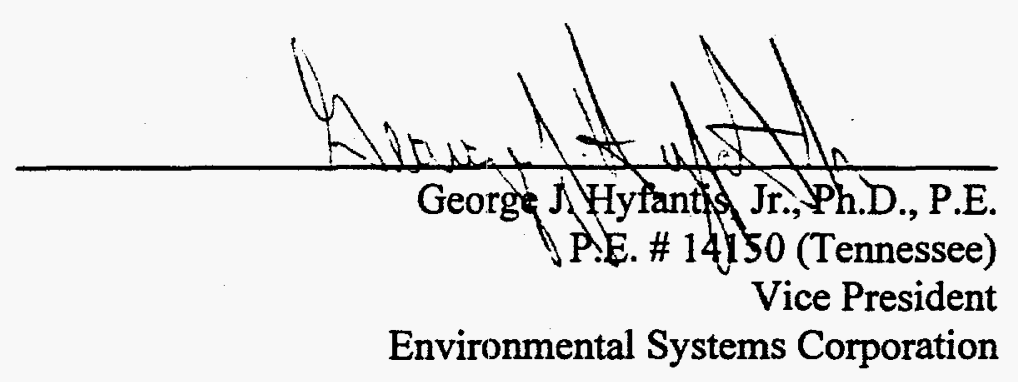




\section{REFERENCES}

Douglas, D. G., J. W. Starr, T. M. Juliano, J. W. Maresca, Jr., and R. A. Bennahmias, "Detailed Leak Detection Test Plan and Schedule for the Oak Ridge National Laboratory LLLW Active Pipelines," Report No. DOE/OR/01-1167\&D2, prepared for U.S. DOE, Office of Environmental Restoration and Waste Management, Oak Ridge National Laboratory, Oak Ridge, Tennessee, prepared by Vista Research, Inc., Mountain View, California (August 1994).

U.S. Environmental Protection Agency, "40 CFR 280 - Technical Standards and Corrective Action Requirements for Owners and Operators of Underground Storage Tanks," Federal Register, Vol. 53, No. 185 (September 23, 1988).

Bucholz, C. S., Trans. AM. Inst. of Electr. Eng., Vol. 78, Part 2, No. 46, pp. 394-399 (1960)

Gerhold, W. F., E. Esclante and B. T. Sanderson, "The Corrosion Behavior of Selected Stainless Steels in Soil Environments," NBSIR 81-2228 (Feb. 1981).

Lechkie, H. P. and H. H. Uhlig, J. of Electrochem. Soc., Vol 113, No. 12, pp. 1262-1267 (1966).

Ondrejcin, R., Savannah River Plant, telephone conversation with author, (1991).

Romanoff, M. "Underground Corrosion," National Bureau of Standards Circular 579 (1957).

Shreir, L. L., R. A. Jarman and G. T. Brunson eds., Corrosion, Vol. 1, 3rd ed., ButterworthHeinemann, Oxford, (1994).

Douglas, D. G., R. F. Wise, J. W. Starr, and J. W. Maresca, Jr., "Leak Testing Plan for the Oak Ridge National Laboratory Liquid Low-Level-Waste System (Active Tanks)," Volumes I, II and III, Report No. ORNL/ER/Sub/92-SK263/1, prepared for Martin Marietta Energy Systems, Inc., Oak Ridge, Tennessee (June 1992).

Summers, G., W. Peters, and C. Armstrong, Basic Statistics in Business and Economics, 2nd ed.,Belmont, California: Wadsworth Publishing Company, Inc. (1977).

Mendenhall, W. and T. Sinchick, Statistics for Engineering and the Sciences, 3rd ed., San Francisco: Dellen Publishing Company (1992).

Benjamin, Jack R. and C. Allin Cornell, "Probability, Statistics, and Decision for Civil Engineers", McGraw-Hill Book Company (1970).

"Structural Integrity Assessments for the Category C Liquid Low-Level Waste Tank Systems at the Oak Ridge National Laboratory", DOE/OR/01-1385\&D2, prepared by International Waste Management Systems, Knoxville, Tennessee, prepared for US Department of Energy, Oak Ridge National Laboratory, September 1995. 


\section{DISTRIBUTION}

1. L. V. Asplund

2. W. R. Clark

3. C. E. Devore

4-6. J. T. Ethridge

7. T. M. Koepp

8. M. W. Kohring

9. T. W. Morris

10. P. T. Owen

11. B. D. Patton

12-13. M. R. Peet

14-16. L. B. Raulston

17. S. T. Rudell

18. C. B. Scott

19. R. C. Stewart

20. L. J. Turner

21. Central Research Library

22. Engineering Document Management Center

23. File-EMEF DMC-RC

24. G. Hyfantis, International Waste Management Systems, 200 Tech Center Dr., Knoxville, TN 37912

25. B. A. Skokan, Remediation Project Engineer, U.S. Department of Energy, Cloverleaf Building, Room 2165, 19901 Germantown Road, Germantown MD 20874

26-27. R. C. Sleeman, Director, Remediation Management, DOE Oak Ridge Operations Office of Environmental Management, P.O. Box 2001, Oak Ridge, TN 37831-8541

28. Vista Research, 100 View Street, P.O. Box 998, Mountain View, CA 94042

29. J. W. Wagoner II, Supervisory Remediation Project Engineer, U.S. Department of Energy, Cloverleaf Building, Room 2163, 19901 Germantown Road, Germantown, MD 20874 